\title{
Dynamics of mood and cortisol in depression : a study in daily life
}

Citation for published version (APA):

Peeters, F. P. M. L. (2002). Dynamics of mood and cortisol in depression : a study in daily life. [Doctoral Thesis, Maastricht University]. Universiteit Maastricht. https://doi.org/10.26481/dis.20030124fp

Document status and date:

Published: 01/01/2002

DOI:

10.26481/dis.20030124fp

Document Version:

Publisher's PDF, also known as Version of record

\section{Please check the document version of this publication:}

- A submitted manuscript is the version of the article upon submission and before peer-review. There can be important differences between the submitted version and the official published version of record.

People interested in the research are advised to contact the author for the final version of the publication, or visit the DOI to the publisher's website.

- The final author version and the galley proof are versions of the publication after peer review.

- The final published version features the final layout of the paper including the volume, issue and page numbers.

Link to publication

\footnotetext{
General rights rights.

- You may freely distribute the URL identifying the publication in the public portal. please follow below link for the End User Agreement:

www.umlib.nl/taverne-license

Take down policy

If you believe that this document breaches copyright please contact us at:

repository@maastrichtuniversity.nl

providing details and we will investigate your claim.
}

Copyright and moral rights for the publications made accessible in the public portal are retained by the authors and/or other copyright owners and it is a condition of accessing publications that users recognise and abide by the legal requirements associated with these

- Users may download and print one copy of any publication from the public portal for the purpose of private study or research.

- You may not further distribute the material or use it for any profit-making activity or commercial gain

If the publication is distributed under the terms of Article $25 \mathrm{fa}$ of the Dutch Copyright Act, indicated by the "Taverne" license above, 
DYNAMICS OF MOOD AND CORTISOL IN DEPRESSION 
$1 S B N 90-9016497-9$

(P) FML Peeters, Maastricht 2002

Production: Danawyse / Uniwersitaire Pers Maastricht 


\section{DYNAMICS OF MOOD AND CORTISOL IN DEPRESSION \\ A Study in Daily Life}

\section{PROEFSCHRIFT}

ter verkrijging van de graad van doctor aan de Universiteit Maastricht,

op gezag van de Rector Magnificus,

Prol. dr. A.C. Nieuwenhuijzen Kruseman, volgens het besluit van het College van Decanen, in het openbaar te verdedigen op vrijdag 24 januari 2003 om 16.00 uur

door

FRANCISCUS PETRUS MARIA LUDOVICUS PEETERS 


\section{PROMOTOR}

Prof.dr. M.W. deVries

CO-PROMOTOR

Dr. N.A. Nicolson

\section{BEOORDELINGSCOMMISSIE}

Prof.dr. J. van Os (voorzitter)

Prof.dr. J. Herbert (University of Cambridge)

Prof.dr. H.F. Kraan (Universiteit Twente)

Prof.dr. M. Maes

Prof.dr. H. Merckelbach 


\title{
CONTENTS
}

\author{
CHAPTER 1 \\ Dynamics of mood and cortisol in depression: introduction $\quad 7$
}

CHAPTER 2

Daily patterns of mood states in major depressive disorder $\quad 23$

CHAPTER 3

Levels and variability of daily life cortisol secretion in major depression $\quad 41$

CHAPTER 4

Effects of daily events on mood states in major depressive disorder 57

CHAPTER 5

Corrisol responses to daily events in major depressive disorder

CHAPTER 6

Cortisol responses to a speech task in major depression and their relarionship to corrisol responses to negative events in daily life

\section{CHAPTER 7}

Dynamics of mood and cortisol in depression: conclusions, general discussion, future directions, and final remarks $\quad 107$

\author{
SUMMARY 121 \\ SAMENVATTING 125 \\ DANKWOORD $\quad 129$ \\ CURRICULUM VITAE 137 \\ PUBLICATIES 133
}





\section{CHAPTER 1}

\section{Dynamics of mood and cortisol in depression: Introduction}


During the last year of my training as a resident in psychiatry, $\mathbb{L}$ was involved in treating outparients with the same kind of severe psychiatric disorders that I had met in clinical facilities during my first years as a resident. What struck me most, was that the stories of the patients were so different. Where inpatients told about their symptoms and complaints without much referral to a context, the outpatients provided vivid stories about their symptoms in reciprocal relationship to their surroundings. These were stories of people living in a house with partners and children, stories of people interacting with family and friends, stories of people who were doing ordinary and sometimes extraordinary things; just stories from people who, sometimes successfully and sometimes unsuccessfully, tried to make the best of their lives. To me, it was a clear and illustrative lesson that symptoms like feeling depressed are dynamic and, at least to some extent, a result of the interaction between individual and environment.

Carrying out this research project brought back some of the astonishment that I experienced as a resident; despite the enormous amount of research in the field of mood disorders, only few studies appeared to have been carried out while subjects were in their natural environment. This dissertation presents results from a study into the dynamics of mood and cortisol in the daily life of depressed individuals. The introduction provides a short description of major depressive disorder, which is followed by a general theoretical background, a description of aims and methods of the study, and an outline of the dissertarion.

\section{MAJOR DEPRESSIVE DISORDER}

Fluctuations in mood are a normal phenomenon in individual daily experience. Many individuals also experience more pervasive episodes in which mood is low and life seems less worthwhile. Such episodes can often be ascribed ro particular circumstances, and may be understood as adaptive and meaningful reactions of the individual in interaction with the environment (Nesse, 2000). Although people often refer to such experiences as "feeling depressed," these episodes do not fulfill criteria for what, in clinical psychology and psychiatry, is classified as major depressive disorder (MDD). The diagnostic criteria for MDD in the DSM-IV (APA, 1994), nowadays the most influential psychiatric classification system, include depressed mood and/or the loss of interest and pleasure in nearly all activities. In addition to these essential features, alterations in appetite, sleep disturbances, psychomotor changes, farigue and decreased energy, feelings of worthlessness, impaired ability ro think, and thoughts of death are considered to be characteristic symptoms. For a diagnosis of an episode of MDD, one of the essential features together with at least four additional symptoms have to be present most of the day, nearly every day, for at 
least two weeks. The episode must be accompanied by significant distress or impairment in important areas of funcrioning. An episode of MDD has mothing to do with "having a bad time" and should not be considered as something one just has to pulj through. It is a serious psychiatric disorder with a great burden on the patient, the immediate social network, and society (Wells et al., 1992). Driven by personal experience, several authors have published outstanding portrayals of MDD in recent years (Styron, 1990; Karp, 1996; Solomon, 2001), which illustrate the severity of the disorder, its impact on daily life, and complexities involving its treatment.

MDD is a common psychiatric disorder, with a 12 -month prevalence of $5.8 \%$ in the Netherlands (Bijl, 1997). Epidemiological studies have shown that the prevalence of MDD in women is between 1.5 and 3 times higher than in men; the causes of this difference are still not well understood (Cyranowski et al., 2000; Kessler, 2000). MDD was traditionally considered to be a disorder that manifests itself primarily in single episodes, but recent epidemiological studies have shown that recurrences are a very common phenomenon (Judd, 1997; Solomon et al., 2000), and that substantial numbers of patients experience extended periods with subsyndromal symptoms, in which daily functioning is still impaired (Keller, 1994; Judd et al., 2000).

\section{MAJOR DEPRESSIVE DISORDER, THE ENVIRONMENT AND THE HYPOTHALAMIC-PITUITARY-ADRENAL AXIS}

MDD is currently considered to be a heterogenous mood disorder, with a wide range of biological, psychological, and environmental factors that are known to be of etiological importance. In daily clinical practice, the role of stressful environmental factors in the etiology of MDD has long been acknowledged. Epidemiological studies in the last decades have firmly established this role of the environment; severe life events and chronic difficulties contribute to development and course of MDD (Brown \& Harris, 1978; Brown \& Harris, 1989; Jeneway \& Paykel, 1997). These environmental factors may interact with pre-existing generic and developmental vulnerabilities, leading to episodes of MDD (Kendler et al., 1993; Meyer er al., 2001). Etiological models have become increasingly complex, as (1) processes that modify and mediate these interactions are not well understood (Bolger \& Zuckerman, 1995; Kessler, 1997; Kaufman et al., 2000; Meyer et al., 2001), and (2) vulnerability to develop episodes of MDD appears to be dynamic in time (Kendler et al., 2000, 2001; Ormel et al., 2001).

In addition to epidemiological studies of stress-disorder relarionships, animal models (Sapolsky, 1996; Willner, 1997) and biological challenge paradigms (Thase \& Howland, 1995) have been developed to investigate possible (patho) physiological mechanisms involved in responses of the organism to the environment. The hypotha- 


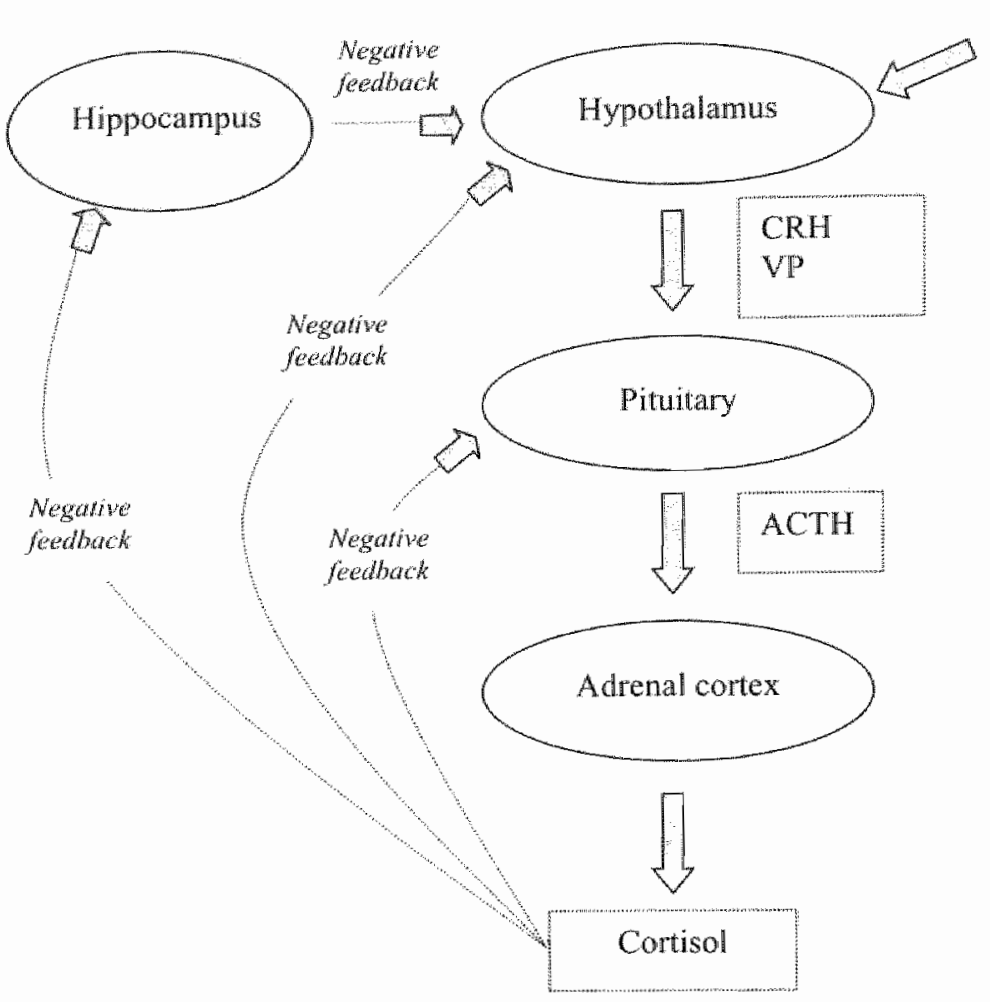

Stress

Figure 1. Main elements, regularion and feedback mechanisms of rhe hypothalamic-pituitary-adrenal axis (actapted from McQuade \& Youg, 2000)

lamic-picuitary-adrenal (HPA) axis is the most important neuroendocrine system involved in responses to stress; it is activated by major life events and traumatic experiences (Rahe et al., 1990; Cruess et al., 1995; Yehuda, 1997). Recently, it has been shown that minor daily stressors are also capable of activating this system (M. van Eck et al., 1996; Smyth et al., 1998).

The HPA axis consists of elements of the hypothalamus, pituitary, and adrenal correx and includes many feedback loops at various levels (see Figure 1). Neurons in the paraventricular nucleus of the hypothalamus release corticotropin-releasing hormone (CRH) and vasopressin (VP) in response to stress, which migrate to the pituitary portal system. In the pituitary, CRH and VP stimulate both synthesis and release of adrenocorticotropin ( $\mathrm{ACTH}$ ) into the systemic circulation.

ACTH promotes the release of cortisol from the adrenal cortex. Cortisol, in some sense the final product of the HPA axis, has numerous actions which are important for adaption to an acute challenge. Complex feedback loops are involved in maintaining homeostasis in the HPA axis. Negative feedback derives mainly from the release of 
cortisol, which inhibits CRH release. Because corrisol can be secreted within a wide concentration range and inappropriate secretory activity may have deleterious effects on all target organs (including the brain), fine-tuned homeostatis is critical. Excessive levels of CRH and corrisol result in anxiety, changes in apperite and sleep, psychomotor disturbances, cognitive disturbances, and lowered mood (Van Londen et al., 1998; Holsboer, 2001).

Currently, dysfunction of the HPA axis is thought to play a role in both etiology and pathophysiology of MDD (Arborelius et al., 1999; Holsboer, 2000). Abnormalities at all levels of the axis have been described, including abnormalinies in cortisol levels and patterns of cortisol secretion over time (Sachar et al., 1973; Halbreich et al., 1985; Linkowski er al., 1985; Pfohl er al., 1985; Mortola et al., 1987; APA task force, 1987; Yehuda et al., 1993; Trestman et al., 1995; Deuschle et al., 1997; Rybakowski \& Twardowska, 1999). Diminished corticosteroid receptor sensitivity, becoming functionally apparent in circumstances where the HPA axis is highly activated for a longer period of time, is thought to underlie these abnormalities (Holsboer, 2000, 2001), although clinical evidence is equivocal (Harris et al., 2000; Strickland et al., 2002).

Beyond its theoretical importance, HPA dysregulation has significant clinical implications in MDD. There is growing support for the hypothesis that contemporary antidepressants exert their primary influence via the HPA axis (Holsboer \& Barden, 1996; Holsboer, 2000). Moreover, drugs that specifically target HPA function, for example by inhibiting cortisol biosynthesis or antagonizing CRH receptors, show clear antidepressant efficacy (Wolkowirz et al., 1999; McQuade \& Young, 2000; Zobel et al., 2000). There is also some evidence that depressed patients with elevated HPA acrivity, compared to those with normal HPA activity, are more likely to benefit from pharmaceutical interventions than from cognitive behavioral therapy (Thase et al., 1996). Most HPA abnormalities appear to be state features of current depression, which disappear following successful treatment (Linkowski et al., 1987; Holsboer, 1995). However, the persistence of HPA abnormalities in treated patients, even those who show clinical improvement, is associated with a higher risk of relapse (Greden et al., 1983; Zobel et al., 1999).

It is important to note that most research into secretory patterns of cortisol in MDD has been done in inpatient-dominated samples, which raises questions about the generalizability of findings to the outpatient majority of patients with MDD. In fact, studies in adult or adolescent outpatient or community populations have provided little evidence of hypercortisolism (Dahl et al., 1991; Maes et al., 1994; Goodyer et al., 1996; Yehuda et al., 1996; Strickland et al., 1998; Scott et al., 1999; Michael et al., 2000; Posener et al., 2000; Strickland et al., 2002). Other aspects of cortisol secretion in the daily life of outpatients have not been studied. 
As already indicated, altered responsiwity of the HPA axis ro siress is thought to be an important element of the link berween environment and biological abnormalities in MDD. To date, normal or blunted cortisol responses to experimental stress in MDD have been reported (Breier et al., 1988; Trestman et a.., 1991; Croes er al., 1993; Gotthard et al. 1995; Heim et al., 2000; Kudoh et al., 2000; Young et al., 2000 . However, it is not clear wherher responses to experimental stressors provide a valid representation of the affective and neuroendocrine processes that occur in individuals reacting to stressors in their daily lives. Studies that have addressed this issue in healthy subjects reported non-significant correlations between cortisol responses to laboratory tasks and cortisol responses to stressful events in the field (Houtman $\&$ Bakker, 1987; Lundberg et al., 1990; van Eck er al., 1996). If abnormal HPA axis responses to stress are indeed involved in the pathophysiology of MDD, they should also manifest themselves in everyday life. Therefore, the most direct cest for the existence of abnormal HPA axis responsivity in $\mathrm{MDD}$ is the study of stress responses in the everyday environment.

\section{MOOD, DAILYEVENTS AND THE HPA AXIS}

In contrast to commonly used unidimensional measures of mood (e.g. from "very depressed" to "very happy"), investigations of the dimensionality of mood have provided evidence for the existence of relatively independent negative and positive affective states (Diener \& Emmons, 1984; Watson et al., 1999). The dimension of negative affect (NA) represents the extent to which individuals experience feelings. such as nervousness, tension, irritation, and guilt. Positive affect (PA) reflects the level of pleasurable engagement with one's environment, characterized by feelings such as enthusiasm, interest, and satisfaction. Previous studies have shown that the symptomatic phase of an episode of major depressive disorder (MDD) is characterized by high levels of NA and, more specifically, low levels of PA (Clark et al., 1990; Jolly er al., 1994: Warson et al., 1995).

Negative daily events are followed by increases in negative affect (NA) and decreases in positive affect (PA) (van Eck et al., 1998; Marco et al., 1999; Gable et al., 2000). In particular, increases in $\mathrm{NA}$ in response to daily minor events are known to lead to higher cortisol levels (van Ecket al., 1996; Smyth et al., 1998; Buchanan et al., 1999). Positive daily events are associated with lower NA and higher PA (Clark \& Watson, 1988; David et al., 1997; Gable er al., 2000). Evidence for effects of positive events on cortisol secretion is equivocal. Previous research reported decreases (Berk et al., 1989; Hubert \& de Jong-Meyer, 1989), increases (Brown et al., 1993) or no changes (Hubert \& de Jong-Meyer, 1991a, 1991 b; Clark er al., 2001) in cortisol levels following experimental inducrion of positive mood. Effects of positive daily events 
on cortisol have never been studied. Such knowledge is clinically porentially relevan, given suggestions that positive events and subsequent mood changes may act as a buffer against the damaging effects of HPA axis abnormalities that result from chronic stress and MDD (Sapolsky, 1996; McEwen, 1998).

Previous studies in depressed subjects have shown a strong positive association between depressed mood and frequency of negarive daily events (Lewinsohn, 1975; Lewinsohn \& Amenson, 1978; Grosscup \& Lewinsohn, 1980; Ravindran et al., 1995). However, these srudies relied on retrospective methods such as end-of-day diaries, which are vulnerable to several sources of bias (Tourangeau, 2000). Mulriple measurements of mood and events in the flow of daily life reduce these sources of bias and additionally allow the investigation of changes in mood states following daily negative and positive events. Given the mediating role of mood in cortisol responses to daily stressors, such a research approach, combined with cortisol measurements, may also contribute to our knowledge of how interactions between depressed individuals and daily environmental demands contribute to neuroendocrine abnormalities of MDD.

Multiple mood measurements may also provide a better knowledge of daily patterns of mood states in MDD. To date, two aspects of basal mood patterns in MDD have been studied. Firstly, diumal variation in mood (e.g., morning worse) is thought to be a common and clinically relevant phenomenon in depressed subjects, especially evident in those meeting criteria for melancholic subtype (Haug \& Wirz-Justice, 1993; APA, 1994). Knowledge abour diurnal variation in daily life is scarce because all studies were carried out in inpatient facilities (Haug \& Fahndrich, 1990; Cowdry et al., 1991; Gordijn et al., 1994; Wefelmeyer \& Kuhs, 1996). Secondly, previous work has produced conflicting evidence on the variability of mood during and between days in depressed subjects (Eastwood et al., 1985; Cowdry et al., 1991; Hall et al., 1991; Wefelmeyer \& Kuhs, 1996; Golier et al., 2001). However, these studies were also carried out in inparient facilities and based on either frequent measurements during one day or a few measurements on each of several days. Mood variability in daily life has never been studied in MDD. A major drawback shared by these previous studies was their reliance on unidimensional mood scales, typically asking the subjects to rate their current mood ranging from "worst ever felt" to "best ever felt." Such ratings do not capture the different aspects of NA and PA that may blend together in some fashion to produce unidimensional judgements of mood. Moreover, PA is known to have a clear diurnal rhythm in healthy individuals; $N A$, in contrast, is fairly constant throughout the day. The diurnal rhythm of and variability in NA and PA in MDD have never been studied. 
Briefly summarized, not much is known about patterns of mood states and cortisol secretion, and the relationship berween daily events, mood, and determinants of neuroendocrine dysregulation in depressed patients in their natural environment. By addressing these topics in currently depressed and healthy individuals, the present: study was designed to fill some gaps in the theoretical models linking stress to MDD, wirth the use of methods suired for studying individuals in rheir daily lives. Additionally, a laboratory stress test (a speech task) was included, to examine the association between stress responses in the laborarory and in daily life.

The study addressed five main topics; (1) patterns of mood states, (2) cortisol secretory parterns, (3) reactivity of mood states to daily events, (4) cortisol responses to daily events, and (5) a comparison of cortisol responses to experimental stress with cortisol responses following daily life stress.

The Experience Sampling Methodology (ESM; Csikszenrmihalyi \& Larson, 1987; deVries, 1992) was used to assess clinically depressed outpatients and a comparison group of healthy individuals in their daily environment. ESM has been shown to be a valid and reliable technique for the simultaneous assessment of mood, behaviors, cognition and various health outcomes in people's natural environment (Delespaul, 1995; van Eck et al., 1996; van Eck et al., 1998; Marco er al., 1999; Affleck et al., 2000; Swendsen et al., 2000; Myin-Germeys et al., 2001; Barge-Schaapveld \& Nicolson, 2002). All participants received auditory signals (beeps) from a wristwatch programmed to emit 10 beeps between 7:30 a.m. and $10: 30$ p.m. each day, at semi-random intervals of approximately 90 minutes. After receiving a beep, participants completed self-report forms concerning current activities and mood states, and were asked to describe and appraise briefly any positive and/or negative event that may have taken place since the last ESM report. Participants completed ESM reports for 6 consecutive days, including a weekend. While completing rhe self report forms, parricipants collected saliva samples for cortisol determination. Salivary cortisol is a reliable indicator of the free cortisol in plasma, which is considered to be the biologically active hormone (Kirschbaum \& Hellhammer, 1994). In addition to information on differences between subjects (e.g., magnirude of mood responses following minor daily events), the repeated multiple measurements also provide the opportunity to study temporally unfolding abnormaliries in regulatory systems within subjects (e.g., diurnal patterns in mood). Statisrical analysis relied heavily on hierarchical linear analysis, which is a variant of the multiple regression model (Snijders \& Bosker, 1999). This type of analysis is highly appropriate for datasers with a multilevel structure. In ESM data, three different levels (beep, day, and person) can be distinguished. 


\section{OUTLINE OF THIS DISSERTATION}

Chapter 2 addresses daily patterns and inter-and intraindividual variability in NA and PA in the depressed and healthy subjects. Furthermore, associations between duration and quality of sleep, clinical characteristics, and mood states are examined.

Chapter 3 examines differences between depressed and healthy subjects in basal cortisol levels and cortisol secretory patterns over time, while controlling for extraneous influences. Associations berween cortisol secretion and clinical characteristics in the depressed group are also tested.

Chapter 4 describes changes in mood states following negative and positive daily events. First, differences in frequency of events in daily life are examined, followed by differences in mood reactivity between the groups. Event appraisals are investigated for their possible differential effects on mood states. Finally, associations between clinical characteristics and mood reactivity in depressed subjects are examined.

Chapter 5 examines differences in cortisol responses following negative and positive events for depressed and healthy subjects. Furthermore, we assess whether cortisol responses are mediated by mood responses. Finally, we examine the influence of clinical characteristics in the depressed group on patterns of cortisol reactiviry.

Chapter 6 describes the cortisol responses to the laboratory stress test in the same groups. The main objective of this chapter is to examine the correlations berween laborarory and daily life cortisol measures, in particular the generalizability of responses to stress in the laboratory to those occurring in daily life.

Chapter 7 summarizes and discusses the main research findings, and attempts to integrate the results into a general framework. Finally, directions for future studies are outlined. 


\section{REFERENCES}

Affeck, G., Apter, A., Tennen, H., Reisine, S., Barrows, E., Willard, A., Unger, J., \& ZuWallack, R. (2000). Mood states associated with transirory changes in asthma symptoms and peak expiratory flow. Psychosom Med, 62(1), $61-68$.

APA. (1994). Diagnowic and Statistical Mantal of Mestal Divorders (Fourth Edition). Washington, DC: American 'sychiatric Association.

APA Task Force on Labotatory Test in Psychiatry (1987). The dexamethasone suppression rest: an overview of its current status in psychiatry. Am J Psychiatry, 144, 1253-1262.

Arborelius, L., Owens, M. J., Plotsky, P. M.* \& Nemeroff, C. B. (1999). The role of oorricotropin-releasing factor in depression and anxiery disorders. J Endocrinol, $160(1), 1-12$.

Barge-Schapvidd, D. Q. C. M., \& Nicolson, N. A. (2002). Effecrs of antidepressant treatment on the quality of daily life an experience sampling study. J Clin Psychatry, 63(6), 477-485.

Berk, L. S., Tan, S. A., Fry, W. F., Napier, B. J., Lee, J. W., Hubbard, R. W., Lewis, ]. E., \& Eby, W. C. (1989). Neuroendocrine and stress hormone changes during mirthful laughter. Aw J Med Sri, $298(6), 390-396$.

Bijl, v. R., Zessen, van G. Ravelli, A. (1997). Psychiatrische morbiditeit onder wolwassenen in Nederland: het NEMESIS-onderzoek. II. Prevalentie van psychiatrische stoornissen. Ned. Tijdschrift Geneckinde. 141(50), 2453-2460.

Bolger, N. \& Zuckerman, A. (1995). A framework for studying personaliry in the stress process. J Pers Soc Psychol, 69(5), 890-902.

Breier, A., Wolkowicz, O. M., Doran, A. R., Bellar, S., \& Pickar, D. (1988\%. Neurobiological effects of lumbar pancture stress in psychiatric patients and heallhy volunteers. Psychatry Res, 25, 187-194.

Brown, G., \& Harris, T. (1978). Soczal origins of depression. London: Free Press.

Brown, G. W. \& Harris, T. O. (1989). Life events and illwess. London: Unwin Hyman.

Brown, W. A., Sirota, A. D. Niaura, R. \& Engebretson, T. O. (1993). Enclocrine correlates of sadness and clation. Psychosw Med. 55(5), 458-467.

Buchanan, T. W., al'Albsi, M., \& Lowallo, W. R. (1999). Cortisol fluctuates with increases and decreases on negarive affect. Psychoneusoendocinology, 24, 227-241.

Clark, D., Beck, A., \& Stewart, B. (1900). Cognitive specificity and positive-negative affectivity: complementary or contradictory views on anxiery and depression? I Abn Psychol, 99(2), 148-155.

Chark. L., Iversen, S. D. B. Goodwin, G. M. (2001). The influence of positive and negarve mood states on risk raking, verbal fluency, and salivary cortisol. J Affer Diserd, $63(1-3), 179-187$.

Clark, L. A. \& Watson, D. (1988). Mood and the mundane: relations between daily life events and self-reporred mood. J Pow Sor Pychol, 54(2), 296-308.

Cowdry, W. W., Gardner, D. L., O'Leary, K.M., Leibenluft, E, \& Rubinow, D. R. (1991). Mood variability: a sudy of four groups. Am / Psyobiany, /48(11), 1505-15.11.

Crocs. S. Merz, P. \& Neter, P. (1993). Cortisol reaction in stecess and fälure condition in endogenous depressed patients and controls. Psychoweteroendocinolog, 18(1), 23-35.

Crucss, D., Ironson, G., Kumar, M., Wynings, C., Benight, C., Greenwood, D., Steffen, P., Baum, A., 8. Schncideman, N. (1995). Intrusive and awoidant thoughts and cortisol at two time points afrer Hurricane Andrew. Psothosom Med, 57,72.

Csilkzentmilatyi, M. \& Larson. R. (1987). Validiry and reliabiliry of the Experience-Sampling Merthod. INow Ment Dis, $175(9), 526-536$.

Cyranowski, I. M., Frank, E. Young, E., Sr Shear, K. (2000). Adolescent onser of the gender difference in liferime rates of major depression. Anch Gen Pachiamy, 57, $21-27$.

Dalul, R. E., Ryan, N. D., Puig-Antich, J., Nguyen, N. A. al-Shabbout, M., Meyer, V. A., \& Perel, J. (1991). 24-hour cortisol measures in adolescents with major depression: a controlled study. Biol Psychiday, 30(1), 25-36. 
David, J. P., Green, P. J., Martin, R. \& Suls. J. (1997). Differential roles of neuroticism, extaversion, and event desirability for mood in dally life: an integrative model of cop-down and bortom-up inthences. J Pers Soc Psychol, 73(1), 149-159.

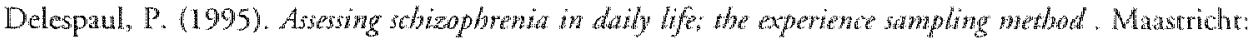
University Press Mastricht.

Deuschle, M., Schweiger, U., Weber, B., Gothard, U., Korner, A., Schmider, J., Standhard, H., Lammers, C. H., \& Heuser, I. (1997). Diurnal acrivity and pulsatility of the hyporhalamus-pinitary-adrenal system in male depressed patients and healthy conerols. J Clin Endocrinol Metab. 82(1), $234-238$.

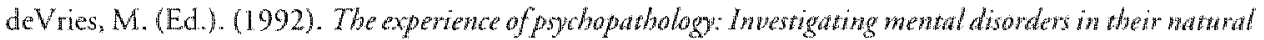
setrings. Cambridge: Cambridge University Press.

Diener, F, \& Emmons, R. A. (1984). The independence of positive and negative affecr. J Pers Sor Psychol, 47(5), $1105-1117$.

Eastwood, M. R., Whitron, J. L., Kramer, P. M., \& Peter, A. M. (1985). Infradian rhyrthms. A comparison of affective disorders and normal persons. Ard Gen Psyclswtry, 42(3), 295-299.

Gable, S. L., Reis, H. T., \& Ellior, A. J. (2000). Behavioral acrivation and inhibition in everyday life. J Pers Soc Psychal, 78(6), 1135-1149.

Golier, I. A., Yehuda, R., Schmeidler, J., \& Siever, L. J. (2001). Variability and severity of depression and anxiety in post traumatic stress disonder and major depressive disorder. Depress Anxiety, 13(2), $97-100$.

Goodyer, I., Herbert, J., Alham, P., Pearson, J., Secher, S., \& Shiers, H. (1996). Adrenal secretion during major depression in 8- ro 16-years-olds, 1. Alered diumal rlyrthms in sallivary cortisol and dehydroepiandrosterone (DHEA) ar presentarion. Pychol Med, 26,245-256.

Gordijn, M. C., Beersma, D. G., Bouhuys, A. L., Reinink, E, \& Van den Hoofdakker, R. H. (1994). A longitudinal sudy of diumal mood variation in depression; characteristics and significance. / Affect Disord, $31(4), 261-273$

Gorthardr, U., Schweiger, U., Fahrenberg, J., Lauer, C. J., Holsboer, F, \& Heuser, 1. (1995). Corrisol, ACTH, and cardiovascular response to a cognicive challenge paradigm in aging and depression. Am J Pbysiology, 268(4 Pt 2), R865-873.

Greden, J. F. Gardner, R., King, D., Grunhaus, L., Carroll, B. J., \& Kronfol, Z. (1983). Dexamethasone suppression rests in antidepressant reatment of melancholia. The process of normalization and rest-retest reproducibiliry. Arb Gen Psybiary, 40(5), 493-500.

Grosscup, S. J., 8c Lewinsohn, P. M. (1980). Unpleasant and pleasant events, and mood. J Clim Psychol. $36(1), 252-259$

Halbreich, U., Asnis, G. M., Shindledecker, R., Zumof, B., \& Nathan, R. S. (1985). Contisol secretion in endogenous depression. I. Basal plasma lewels. Anch Gen Pyochiatry, 1201,904-908.

Hall, D. P., Sing, H. C., B. Romanoski, A. I. (1991). Identification and characterization of greater mood variance in depression. Am J Pychiany. $168(10), 1341-1345$.

Harris, T. O., Borsanyi, S., Messari, S., Stanford, K., Cleary, S. E., Shiers, H. M., Brown, G. W. \& Herbert, J. (2000). Morning corvisol as a risk factor for subsequent major depressive disorder in adult

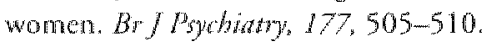

Haug, H. J., \& Fahndrich, E (1990). Diumal waritions of mood in depressed parients in relarion to severity of depression. J Affect Disord, 19(1), 37-41.

Hatg, H. J., \& Wirz-Jusrice. A. (1993). Diumal variation of mood in depression: important or irelevant? Biol Psyluary, 34(4), 201-203.

Heim, C., Mewporr, D. J., Heir, S, Graham, Y. P., Wilcox, M., Bonsall, R., Miller, A. H., \& Wemeroff, C. B. (2000). Pituitary-adrenal and autonomic vesponses to stress in women after sexual and physical abuse in childhood. JAMA, 284(5), 592-597. 
Holsboer, F. (1995). Neuroendocrinology of mood disouders. In F. E. Bloom \& D. J. Kupfer (Eds.),

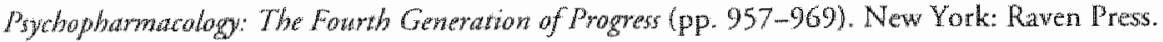

Holsboce, $F .(2000)$. The corticosteroid receptor hyporhesis of depression. Netropsychopharmacology, $23(5), 477-501$

Holsboer, F. (2001). Stress, hypercortisolism and corticosteroid receptors in depression: implicatons for therapy. JAffert Disond, $62(1-2), 77-91$.

Holsboer, F., \& Barden, N. (1996). Antidepresants and hypothalamic-pituitary-adrenocorrical regulation. Endocr Row, $17(2), 187-205$.

Houtman, 1. L., \& Bakker, F. C. (1987). Stress in student teachers during real and simulared standardized tectures. / H hwan Sires, 13(4), 180-187.

Huberr, W. \& de Jong-Meyer, R. (1989). Emotional stress and saliva cortisol response J Clin Chem Clm Biochem, 27(4),235-237.

Hubert, $W_{n}, 2 x$ de Jong Meyer, R. (1991a). Autonomic, neuroendocrine, and subjective responses ro cmotion-inducing film stimuli. Int J Pychophysiol, $M(2), 131-140$.

Huber, W. \& de Jong-Meyer, R. (1991 b). Psychophysiological response parterns to positive and negative film stimuli. Biol Psychol, 37(1), 73-93.

Jeneway, A. \& Paykel, E. S. (1997). Life events and depression. In A. Honig \&. H. M. van Praag (Eds.), Depression: wewrobiological, psychopathologial and werapeutic advances (pp. 279-295). Chichesrer: John Wiley \& Sons.

Jolly, J. B., Muray, J., Kramer, T. A., \& Wherry, J. N. (1994). Integration of positive and negative affectivity and cognitive content-specificity: improwed discrimination of anxious and depressive symptoms. J Abrom Psychol, $103($ no 3.), 544-552.

Judd, L. L. (1997). The clinical course of unipolar major depressive disorders. Anb Gen Psychatry, 54(11), 989-991.

Judd, L. L., Akiskal, H. S., Zeller, D. J., Paulus, M., Leon, A. C., Maser, J. D., Endicota, J., Coryell, W., Kunovac, J. L., Mueller, T. I., Rice, J. P., BC Keller, M. B. (2000). Psychosocial disability during the long-tern course of unipolar major depressive disorder. Arch Gen Pychiary, 57, 375-380.

Karp, D. (1996). Speaking of sadness: Depression, disconnection, and the meanings of illness. New York, USA: Oxford University Press.

Kaufwan, J., Plorsky, P. M., Nemerof, C. B., \& Chamey, D. S. (2000). Effects of early adverse experiences on brain structure and function: clinical implications. Biol Psychiatry, 48(8), 778-790.

Keller, M. B. (1994), Depression. A long term illness. Br J Pychian, 165(Suppl. 26), 9-15.

Kendler, K. S. Kesster, R. C., Neale. M. C., Heath, A. C., \& Eaves, L. J. (1993). The prediction of major depression in women: rowand an integrated etiologic model. Am/ Psychiaty, 150(8), 1139-1148.

Kendler, K. S., Thomton, L. M., \& Gadner, C. O. (2000). Stressful life events and previous episodes in the etiology of major depression in women: An evaluation of the "Kindling" hypothesis. Am / Pychiarm, 157(8), 1243-1251.

Kendler, K. S., Thornton, I. M., \& Gardner, C. O. (2001). Genetic risk, number of previous depressive apisodes, and stressful life events in predicring onser of major depression. Am / Psybatry, $158(4)$, $582,-586$.

Kesster, R. C. (1997). The effects of stressful life events on depression. Ann Rev Psychol, 48, 191-214.

Kesster, R. C. (2000). Gender diferences in major depression: epidemiological findings. In E Frank (Edh). Gender and its effecs on pychopathology (pp. 61-84). Washingron D.C.: American Psychiatric Press.

Kirschbaum, C., \& Hellhammer, D. H. (1994). Salivary cortisol in psychoneuroendocrine researdh: recent developments and applications. Pyychonewoendoctinology, $19(4), 313-333$.

Kudoh, A. Ishihara, H. \& Matsuki, A. (2000). Inlubition of the cortisol response to surgical stress in chronically depressed parients. J Clin Attesth, 12(5), 383-387. 
Lewinsohn, P. M. (1975). The behawioral study and reament of depression. In M. Hersen $\mathrm{R}$. M.

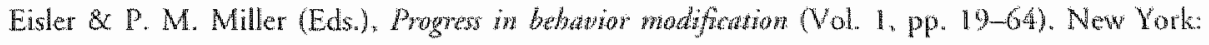
Academic Press.

Lewinsohn, P. M., \& Amenson, C. S. (1978). Some relations berween pleasant and umpleasant mood-related events and depression. J Abnom Psychol, 876), 644-654.

Linkowski, P., Mendlewicz, J., Kerkhots, M., Ledercq, R., Golstein, J., Brasseur, M. Copinschi, G. \& Van Cauter, E. (1987). 24-hour profiles of adrenoconicoropin, contisol, and growth hormone in major depressive illness: effect of antidepressant treament. / Clin Endocrinol Metab, 65(1), 14l-152.

Linkowski, P., Mendlewicz, I., Leclercq, R., Brasseur, M., Hubain " P., Golstein, J., Copinschi, G., \& Van Cauter, E. (1985). The 24-hour profile of adrenocorticotropin and cortisol in major depressive illness. J Clin Endocrmol Metab, 6I(3), 429-438.

Lundberg, U., Melin, B., Fredrikson, M., Tuomisto, M., \& Frankentaeuser, M. (1990). Comparison of neuroendocrine measurements under laboratory and naturalistic condirions. Pharmacol Biochem Behav, 37(4), 697-702.

Maes, M., Calabrese, J., \& Meltzer, H. Y. (1994). The relewance of the in-versus ourpatient status for studies on HPA- axis in depression: spontaneous hypercortisolism is a feature of major depressed inpatients and not of major depression per se. Progr Newropsychophamacol of Brol Psychatiry, 18(3), $503-517$.

Marco C. A., Neale, J. M., Schwartz, J. E., Shiffman, S., \& Stone, A. A. (1999). Coping wirh daily ewents and short-rerm mood changes: an unexpected failure ro obserwe effects of coping. $/$ Consth Clin Psychol, 67(5), 755-764.

MeEwen, B. S. (1998). Protective and damaging effects of stress mediators. $N$ Engl / Med 338(3), $171-179$.

MoQuade, R., \& Young, A. H. (2000). Future therapeutic targets in mood disorders: the glucoconticoid receptor. Br. Pyidiatry, $177,390-395$.

Meyer, S. E., Chrousos, G. P., \& Gold, P. W. (2001). Major depression and the stress system. a life span perspective. Deu Psychopathol, 13(3), 565-580.

Michael, A., Jenaway, A., Paykel, E. S., \& Herbert, J. (2000). Altered salivary delhydroepiandrosterone levels in major depression in adults. Biol Psychiatry, 48(10), 989-995.

Mortola, J. F., Liu, J. H., Gillin, J. C., Rasmussen, D. D., \& Yen, S. S. (1987). Pulsatile thythms of adrenocorticotropin (ACTH) and cortisol in women with endogenous depression: evidence for increased ACTH pulse frequency. J Clin Endocrinol Metab, 65(5), 962-968.

Myin-Germeys, I., van Os, J., Schwartz, J. E., Stone, A. A. \& Delespau, P. A. (2001). Emorional reacm riviry to daily life stress in psychosis. Aroh Gen Psychiatry, 58(12), $1137-1144$.

Nesse. R. M. (2000). Is depression an adaption? Arch Gers Psydyatry. 57. 14-20.

Ormel, J., Oldehirkel, A. J. \& Brilman, E. I. (2001). The interplay and exiological continuity of neuroticism, difficulties, and life events in the etiology of major and subsyndromal, first and recurrent depressive episodes in larer life. Am J Psychiatry, $1586(6), 885$ m91.

Pfohl, B., Sherman, B., Schlechte, J., \& Srone, R. (1985). Pituiraryadrenal axis rhythm disturtbances in psychiarric depression. Apch Gen Pywhatry, 42(9), 897-..903.

Posener, J. A., DeBartista, C., Williams, G. H., Kraemer, H. C., Kalehzan, B. M., Se Scllatberg, A. F. (2000). 24-Hour moniroring of cortisol and corticotropin secretion in psychotic and nonpsychotic major depression. Arah Gen Pyctiatry, 57(8), 755-760.

Rahe, R. H., Karson, S., Howard, N. 5., Jr., Rubin, R. T., \& Polland, R. E. (1990). Psychological and physiological assessments on American hostages freed from captivity in Iran. Pyobosom Med. 52(1). $1-16$.

Ravindan, A. V., Griffiths, J., Waddell, C., 8 Anisman, H. (1995). Stressfullife events and coping styles in relation to dysthymia and major depressive disorder: variarions associated with allewiation of symptoms following pharmacotherapy. Prog Neura-Pydtophormacol of Biol Psych, 19, 637-653. 
Rybakowski, I. K., \& Jwardowska, K. (1999). The dexamethasone/corticonopin-releasing hormone test in depression in bipolar and unipolar affective illness. f Pycthiator Res, 33(5), 363-370.

Sachar, E. J., Hellman, L., Rofwarg, H. P. Hatpern, F. 5., Fukushima, D. K., \& Gallagher, T. F. (1973).

Disrugted 24-hour patrems of corrisol secrevion in psychotic depression. Afot Gen Fsychiatry, 28(1), $19-24$.

Sapolsky, R. M. (1996). Why stress is bad for your brain. Science, 273(5276), 749-750.

Scort, L. V., Salahuddin, F., Cooney, I., Svec, F., \& Dinan, T. G. (1999). Differences in adrenal steroid profile in chronic farigue syndrome, in depression and in health. IAfect Dis, $54(1-2), 129-137$.

Smyth, J. Ockenfels, M. C., Porter, L., Kirschbaum, C. Hellhammer, D. H., \&c Srone, A. A. (1998). Stressors and mood measured on a momentary basis are associated wirh saliwary cortisol secretion. Psychoneturendocrinalogy. 2344),353-370.

Snijders, T. A. B., \& Bosker, R. J. (1999). Mulkilevel analysis: an introduction to bastc and advanced razultilevel modeling. London: Sage Publicarions.

Solomon, A. (2001). The noonday demon. London: Vintage.

Solomon, D. A., Keller, M. B., L.con, A. C., Mueller, T. I., Lavori, P. W., Shea, M. T., Coryell, W., Warshaw, M., Turvey, C., Maser, J. D., \& Endicott, J. (2000). Multiple recurrences of major depressive disorder. Am I Prybiatry, 157(2), 229-233.

Strickland, P., Morris, R. Wearden, A. \&. Deakin, B. (1998). A comparilson of salivary cortísol in chronic farigue syndrome, community depression and healthy controls. J Affect Disord $47(1-3)$, $191-194$.

Strickland, P. L., Deakin, J. F., Percixal, C., Dixon, J., Gater, R. A., \& Goldberg, D. P. (2002) . Bí-social origins of depression in the community: Interactions berween social adversity, cortisol and serotonin neuroranamission. Br J Psychiatry. 180(2), 168-173.

Sryron, W. (1990). Darkness Visible. London: Picador.

Swendsen, J. D. Tennen, H. Camey, M. A. Affleck, G., Willard, A., \& Hromi, A. (2000). Mood and alcohol consumption: an experience sampling rest of the self-medication hypothesis. $J$ Abnom Piyctol. 109(2), 198-204.

Thase, M. E., Dube, S., Bowler, K., Howland, R. H., Myers, I. E., Friedman, E., \& Jarret, D. B. (1996). Hypothalamic-piruitary-adrenocontical activicy and response to cognitive behavior therapy in unmedicated, hospitalized depressed parients. Am J Pychiatvy, 153(7), 886 89 I.

Thase, M. E., \& Howland, R. H. (1995). Biological processes in depression: an updated review and integrarion. In E. E. Beckham \& W. R. Leber (Eds.), Handbook of depression (pp. 213-279). New York: Guillord Press.

Tourangcau, R. (2000). Remembering whar happened memory etrors and survey reports. In A. A. Stone \& J. S. Turkkan \& C. A. Bachach \& J. B. Jobe \& H. S. Kurtzman \& S. C. Cain (Eds.), The science of self-repurt implicatows for reseanch and prackice (pp. 29-47). Mabwah, New Jersey: Lawrence Erlbaturm Associates.

Tresman, R. L., Coccaro, E. F., Bernstein, D. Lawrence, T., Gabriel, S. M., Horwarh, T. B., \& Siever, L. 1. (1991). Cortisol responses to mental andhmetic in acute and remitred depression. Biol Pychiatry. 29(10), 1051-1054.

Trestman, R. L. Yehuda, R. Coccaro, E. Horwath, T., Knote, P. Gabriel, S., \& Siever, L. J. (1995), Diumal netroendocrine and auronomic funcrions in acute and remitred depressed male parients. Biol Pyotziatry, 37(7), 448-456.

van Eck, M. Berkhof, H., Nicolson, N. \& Sulon, ]. (1996). The effecrs of perceived stress, traits, mood states, and stressful daily events on salivary cortisol. Pyobowom Med, 58(5), 447-458.

wan Eck, M., Nicolson, N., Berkhof, H., \& Sulon, J. (1996). Individual differences in cortisol responses ro a laboratory speech task and their relationship to responses to stressful daily events. Biol Psychot,
$43(1), 69-84$. 
wan Eck, M., Nicolson, N. A., 8. Berkhof, J. (1998). Efects of stressful daily events on mood states: relationship to global perceived stress. J Pers So Pyohol 75(6). $1572-1585$.

Van Londen, L., Goekoop, J. G., Zwinderman, A. H., Laneer, J. B. Wiegane, V. M., \& De Wied, D. (1998). Neuropsychological performance and plasma cortisol, arginine vasopressin and oxytocin in patients with major depression. Psychol Med, 28(2), 275-284.

Warson, D. Clark, L., Weber, K., Assenheimer, J. S., Srauss, M., \& McCormick, R. (1995). Tesring a tripartire model: II. exploring the symptom structure of anxiey and depression in student, adulr, and parient samples. JAbnom Psobol 10A (no, 1), 15-25.

Warson, D., Wiese, D. Vaidya, J., \& Tellegen, A. (1999). The two general activation systems of affect: Structural findings, evolutionary considerations, and psychobiological evidence. I Pers Soc Pychol $_{3}$ $76(5), 820-838$

Wefelmeyer, T., \& Kults, H. (1996). Diurnal mood variation in melancholic patients and healthy controls. Psychopathology, 29(3), 184-192.

Wells, K. B., Burnam, M. A., Rogers, W., Hays, R. \& Camp, R. (1992). The course of depression in adult outpatients. Results from the Medical Ourcomes Study. Arch Gen Pychiatry, 49(10), 788-794.

Willner, P. (1997). Stress and depression: insights from animal models. Stress Med, 13, 229-233.

Wolkowiz, O. M., Reus, V. I., Chan, T., Manfredi, F., Raum, W., Johnson, R., \& Canick, J. (1999), Antiglucocorricoid treatment of depression: double-blind ketoconazole. Biol Pyotiary, 45(8), 1070-1074.

Yehuda, R. (1997). Sensirization of the hypothalamic-piruitary-adrenal axis in postratumatic stress disorder. Ann $N$ Y Atad So, 821, 57-75.

Yehuda, R., Boisoneau, D., Mason, J. W., \& Giller, E. L. (1993). Glucocorricoid receptor number and cortisol excrerion in mood, anxiety, and psychovic disorders. Biol Psychiatry, $34(1-2), 18-25$.

Yehuda, R., Teicher, M. H., Trestman, R. L., Lewengood , R. A., \& Siever, L. J. (1996). Cortisol regulation in postraumatic stress disorder and major depression: a chronobiological analysis. Biol Psychi$a t r y, 40,79-88$.

Young, E. A., Lopez, J. F., Murphy-Weinberg, V., Warson, S. J., \& Akil, H. (2000). Hormonal evidence for altered responsiveness to social stress in major depression. Neuropsychopharmacology, 23(4), $411-418$.

Zobel, A. W., Nickel, T., Kunzel, H. E., Ackl, N., Sonntag, A., Ising, M., \& Hollsoer, F. (2000). Effects of the high-affiniry corticotropin-releasing hormone receptor 1 antagonist R121919 in major depression: the first 20 patients treated. J Pychiatr Res, 34(3), 171-181.

Zobel. A. W., Yassouridis, A. Fricboes, R. M., \& Holsboer, F. (1999). Prediction of medium-term autcome by cortisol response to the combined dexamethasone-CRH test in paticnts with reminted depression. Am / Pyydiaty, 156(6), 949-951. 



\section{Daily patterns of mood states in major depressive disorder}

Frenk Peeters, Johannes Berkhof, Philippe Delespaul, Nancy. A. Nicolson. Submitted. 
Changes in mood are common within episodes of major depressive disorder (MDD). Previous studies of mood changes have relied on a unidimensional concept of mood. However, research into the dimensionality of mood has provided evidence for the existence of two relatively independent mood states; negative affect (NA) and positive affect $(P A)$. The aim of the present study was to determine whether daily levels and inter-and intraindividual variability of NA and PA in depressed outpatients differed from healthy individuals.

Data were collected using the Experience Sampling Merhod. Multiple mood measurements were obtained over a 6 -day period from 47 outpatients with MDD and 39 healthy subjects in their everyday environment. We used multilevel regression analysis, controlling for the effects of self-reported daily events, to test for differences in daily levels and inter- and intraindividual variability in NA and PA between the two groups.

NA levels were higher and more variable, whereas PA levels were lower in the depressed subjects in comparison to healthy subjects. NA levels showed a (slight) decline throughout the day in both groups. The pattern of diurnal variation in PA in depressed subjects included an increasing function with an inverted $U$-shape. Daily PA levels in healrhy subjects included an inverted $U$-shape only.

Depressed outpatients show clear differences from healthy individuals in mood states. Distinguishing two dimensions of mood and characterising diurnal patterns through multiple measurements in the daily environment appears to be a useful addition to other methods used in research on affective processes in psychiatric disorders.

\section{INTRODUCTION}

Changes in mood within an episode of major depressive disorder (MDD) are well acknowledged (APA, 1994). To date, diurnal variation (e.g., morning worse) and abnormalities in the moment-to-moment variability of mood have been examined in MDD. Diurnal variation (DV) is a common phenomenon in many depressed subjects, but is not present every day within an episode of MDD (Stallone et al., 1973; Tolle \& Goetze, 1987; Haug \& Fahndrich, 1990; Leibenluft et al., 1992; Gordijn et al., 1994; Wefelmeyer \& Kuhs, 1996). Alrhough incorporated in formal criteria, DV does not appear to be specific for melancholic subcype of MDD (Leibenluft et al., 1992). DV is clinically relevant because it has been shown to be a predictor for response to biological treatments like sleep deprivation (Reinink et al., 1993; Gordijn et al., 1994) and pharmacotherapy (Carpenter et al., 1986). Variability of mood in MDD has been examined as changes in mood within and between 
days. Results of previous srudies inro mood variability in MDD are equivocal, as they indicate both lower (Cowdry et al., 1991; Wefelmeyer \& Kuhs, 1996; Golier et al., 2001) and higher (Eastwood et al., 1985; Hall et al., 1991) variability in comparison to other diagnostic groups and healthy subjects.

A drawback shared by the vast majority of these previous mood studies in MDD is their reliance on a unidimensional mood concept (for example by using a visual analog scale ranging from "worst ever felt" to "best ever felt"). Investigations of the dimensionality of mood, however, have provided evidence for the existence of relatively independent negative and posirive affective states (Diener \& Emmons, 1984; Cacioppo et al., 1999; Watson et al., 1999). The dimension of negative affect (NA) represents the extent to which individuals experience feelings such as nervousness, tension, irritation, and guilt. Positive affect (PA) reflects the level of pleasurable engagement with one's environment, characterised by feelings such as enthusiasm, interest, and satisfaction.

NA and PA are considered to represent the affective elements of rwo biobehavioral, evolutionarily adaptive systems that mediate withdrawal and goal-directed behaviors. The main function of the withdrawal system, also called behavioral inhibition system (BIS; Taylor, 1991; Kring \& Bachorowski, 1999; Watson et al., 1999; Davidson et al., 2002), is to help organisms respond to threatening and aversive stimuli. NA levels remain low and constant throughout the day in the absence of threat or danger, are reactive to (potentiall) threat or danger, and are not influenced by endogenous rhythms (Warson et al., 1999). PA represents the affective component of what is referred to as the behavioral facilitation system (BFS; Depue et al., 1994; Tomarken \& Keener, 1998; Depue \& Collins, 1999; Watson et al., 1999; Miller \& Tomarken, 2001). The basic function of the BFS is to direct organisms "towards siruations and experiences that potentially may yield pleasure and reward" (Watson, 2000 page 24). PA levels show a diurnal pattern, with increases in the morning and decreases in the evening (Clark et al., 1989; Wood \& Magnello, 1992; Watson et al., 1999). This diumal pattern, considered as daytime activation of the BFS, can be seen as functionally adaptive, because during the day rewards are likely and risks are low. Levels of PA have been linked with the circadian rlyythm in body temperature and timing of the sleep-wake cycle (Thayer, 1989; Boivin et al., 1997; Warson er al., 1999; Boivin, 2000). An episode of MDD is characterised by high levels of NA and, more specifically, low levels of PA (Clarker al., 1990; Jolly et al., 1994; Watson et al., 1995). However, nothing is known about levels and variability of NA and PA during the day in depressed individuals.

The current study was therefore designed to examine patterns of NA and PA in clinically depressed and healthy individuals. We used the Experience Sampling Methodology (ESM; Csikszentmihalyi \& Larson, 1987; deVries, 1992), which allows for multiple measurements of self-reported mood in the natural flow of daily life. 
Based on previous studies (Clark er al., 1990; Jolly et al., 1994; Watson et al., 1995), we expected higher NA and lower PA levels in depressed subjects in comparison to healthy subjects. Using multilevel regression, we rested for differences in levels in NA and PA during the day between the rwo groups of subjects. Given that associations between sleep and mood have been reported in both depressed and healthy individuals (Boivin et al., 1997; Riemann et al., 2001), the effects of sleep duration and subjective sleep quality on mood states the following day were examined. We also tested differences in inter- and intraindividual variability of mood states in depressed and healthy subjects. Finally, we examined the association between within-day mood variability and severity and duration of the current episode in the depressed group. Because negative and posirive daily events are known to influence momentary levels of NA and PA (van Eck er al., 1998; Marco et al., 1999; Gable et al., 2000; Peeters et al., in press), the multilevel analysis was carried out while controlling for the effects of self-reported daily events.

\section{METHOD}

\section{Subject recruitment and selection}

Forty-seven subjects diagnosed with MDD were recruited among individuals seeking trearment at the communiry mental healch centre and the outparient clinic of the local psychiatric hospital in Mastricht, the Netherlands. The main inclusion criterium was a primary diagnosis of MDD, as assessed with the Structured Clinical Interview for DSM-IV (SCID; First et al., 1995) by a research psychiatrist (F.P.). Information on length of the current depressive episode and family history for mood disorders was also obtained during this interview. Entry was restricted to individuals between 18-65 years of age with a 17-irem Hamilton Depression Rating Scale (HDRS; Hamilton, 1967) score of $\geq 18$, indicating at least moderate severity of MDD. Exclusion criteria were current substance abuse, psychotic symptoms (both assessed with the SCID), and insufficient fluency in Dutch. None of the subjects was tusing antidepressants, but use of low-dose anxiolytic drugs (which applied to eight subjects) was allowed during the study. All depressed subjects complered the Beck Depression Inventory (BDI; Beck er al., 1961).

Thirty-nine healthy subjects, marched as a group to the patient sample for gender and age, were recruited from available research pools, academic staff, and through an advertisement in a local newspaper. Additional exclusion crireria for the healthy subjects were a lifetime history of any DSM-IV axis-I disorder, or any inpatient treatment for an Axis I psychiatric disorder in a first-degree relative. 
The study was approved by the local medical ethics committee, and written informed consent was obtained from all subjects.

\section{Procedure}

ESM was used to collect dara from subjects at selecred moments during their daily activiries. Subjects received auditory signals (beeps) from a wristwatch programmed to emit 10 beeps between $7: 30 \mathrm{a}$.m. and 10:30 p.m. each day, at semi-random intervals of approximately 90 minutes. After receiving a beep, subjects completed self-report forms concerning current mood, negative and posirive events, and their appraisals. Every day, subjects noted at what time they had fallen asleep the previous evening and awakened in the morning. Furthermore, they rated subjective sleep quality on a 7 -point scale $(1$. = very poor, 7 = very good). Subjects completed ESM reports for 6 consecutive days, including a weekend. During a briefing session, study aims and procedures were explained. In a final session, the ESM booklers were checked for legibility and missing data.

Compliance with the procedure was generally good. The crireria set for inclusion in the analyses (more than 20 ESM reports completed within 25 minutes after the programmed time of the beep) were met by all but one subject (from the depressed group), who was excluded from the analysis. Subjects included in the analyses completed an average of $85 \%$ of all possible responses within the time limit resulting in an average number of walid responses of 50.7 per subject. Mean number of valid responses was somewhat higher in the healthy than in the depressed group, 53.2 vs. $48.6 ; \mathrm{t}(84)=3.3, \mathrm{p}=.003$.

\section{Mood assessment.}

Momentary mood states were assessed with 16 adjectives rated on 7 -point scales ( $1=$ not at all, 7 = very). Factor analyses (principal components analysis with varimax rotation) on mean scores aggregated per subject and on within-subjectz-scores borh identified two mood factors with eigenvalues greater than 1. These factors accounted for $81.1 \%$ of the total variance in subject mean scores and $46.1 \%$ of the variance in within-subject z scores. Ratings on the items anxious, irritated, restless, tense, guilty, irritable, easily distracted, and agitated were averaged to form a NA scale (Cronbach's alpha $=.91$ based on all 4535 ESM reports; irem loadings on factor 1 ranged between .66 and .88 , loadings on factor 2 between -.16 and -.40). Ratings on the items energetic, enthusiastic, happy, cheerful, talkative, strong, satisfied, and self-assured were averaged to form a PA scale (alpha $=.95$; item loadings on factor 1 between -.08 and -.42 , loadings on factor 2 between .73 and .92). The average NA level (aggregared over subject means) was $1.3(\mathrm{~s} . \mathrm{d} .=0.3)$ in healthy subjects and $2.9(\mathrm{~s} . \mathrm{d} .=0.9)$ in depressed 
subjects. Average PA levels were 4.5 (s.d. $=0.9)$ and 2.1 (s.d. $=0.7)$ for healthy and depressed subjects, respectively. Correlations between $\mathrm{NA}$ and PA, based on raw data, were $r=-.19, p<.001$ for depressed and $r=-.33, p<.001$ for healthy subjects.

\section{Daily events.}

At each beep, subjects were asked briefly to describe any positive and/or negative event that may have taken place since the last ESM report. Although subjects were instructed to report only events or situations that actually took place in their daily environment in the preceding interval, some event reports clearly referred to internal states only (e.g., current ruminations about past events, personal health concerns). Following pre-established criteria, the research team identified such internal events by consensus. Reports of internal events were not used in the analysis to avoid confounding of event and mood measures.

\section{Statistical analysis.}

For the examination of the diumal patterns of NA and PA, we applied a multilevel analysis using the program MLwiN (Goldstein et al., 1998). The multilevel model is a variant of mulciple regression appropriate when the data have a nested structure. In this study, we have three levels of nesting: the beep level at which the ESM observations are taken, the day level, and the person level. For each model (NA and PA), we fitted separate quadraric diurnal curves for the mood scores of the depressed subjects and healthy controls. We further examined the effects on mood states of DS (duration of sleep in minutes), SQ (sleep quality), and WK (weekend day $=1$, week day = 0 ), white controlling for the variables BDI (severity of depression, coded 0 for healthy controls), DCE (duration current episode, coded O for healthy controls), PosE ( 1 if a positive event was reported, otherwise 0 ), and $\mathrm{NegE}$ ( 1 if a negative event was reported, orherwise 0 ).

At the beep level, the $i$-th mood score at day $j$ of subject $k$ with group status $s$ is modeled as

$$
\begin{gathered}
\text { Mood }_{i j k s}=\beta_{0 s}+\beta_{1 s} \text { Time }_{i j k s}+\beta_{2 s} \text { TimeSq }_{i j k s}+\beta_{3 s} D S_{i j k s}+\beta_{4 s} S_{i j k s} \\
+\beta_{5 s} W_{i j k s}+\beta_{6 s} W_{K}^{*} \text { Time }_{i j k s}+\beta_{7 s} B D I \\
i j k s
\end{gathered}
$$

Separate regression coefficients $\beta_{0 s}, \ldots, \beta_{10 s}$ are specified for the depressed subjects $(s=1)$ and the heal thy controls $(s=0)$. The diurnal pattern of subject $k$ is characterised 
by the intercept $\beta_{0 \text { s }}$ which represents the average mood level, the linear time effect $\beta_{1 s}$, and the quadraric time effect $\beta_{2 i j k s}$. The covariates Time, DS, SQ, BDI, and DCE are centered around the grand mean, and time-square vector 'TimeSq is centred around the grand mean and around Time.

The residual error $r$ ijks can be decomposed in three terms:

$$
r_{\mathrm{ijks}}=e_{3 \mathrm{ks}}+e_{2 \mathrm{jks}}+e_{1 \mathrm{jjks}}
$$

The residual $e_{3 \mathrm{ks}}$ is a person-level deviation from the average mood score, the residual $e_{2 j \mathrm{ks}}$ is a day-level deviation from the person's average mood score, and $e_{1 \mathrm{ijks}}$ is a beep-level residual. The contribution of each of these three residuals to the total variation in the data is expressed by the relative magnitude of the variances var $\left(e_{3 \mathrm{ks}}\right)$, var $(e$ $2 \mathrm{jks}$ ), and var (e $1 \mathrm{jiks}$ ). A relatively large person-level variance, for instance, indicates that average mood varies strongly from one person to another. The residuals contain a group status index $s$, since the size of the residuals may be different for the depressed subjects and the healthy controls. We further allowed consecutive beep-level residuals to be (auto)correlated and assumed that the correlation decreases exponentially with the length of the interval between consecurive sampling points.

We tested whether the regression coefficients $\beta_{00}, \ldots, \beta_{60}, \beta_{01}, \ldots, \beta_{61}$ are different from zero by dividing the estimated effect by its standard error. This ratio is approximately normally distributed. We also tested whether the regression coefficients are different for depressed versus healthy subjects, i.e., whether the differences $\beta_{01}$ $\beta_{01}, \ldots, \beta_{61}-\beta_{60}$ are significantly larger or smaller than zero. Two-tailed tests were used even when hypotheses were directional. Significance levels were set at alpha = .05. The likelihood ratio (LR) test (Bryk \& Raudenbush, 1992) was used to test for significance of the variances of the residuals and for significant differences between variances for the depressed and control groups. Finally, we applied the LR test to examine whether the beep level variance is dependent on the covariates BDI, DCE, DE, and $S Q$.

\section{RESULTS}

The final sample consisted of 46 depressed ( 26 women) and 39 heal thy (20 women) subjects. Mean scores for the depressed group on the BDI $(28.4 ;$ s.d. $=9.8)$ and HDRS (23.9; s.d. $=3.9$ ) indicate moderate depression severity. Mean duration of the current depressive episode was 20.3 months (range: $2-118$ ). Self-reported sleep quality (averaged over 6 days for each subject) was lower in depressed than in healthy subjects (depressed: 4.0 , s.d. $=1.4$ versus healthy: $5.7, s . d .=0.8 ; t=6.45, \mathrm{df}=83, \mathrm{p}<$ 
$30 \mid \mathrm{CHATER} 2$
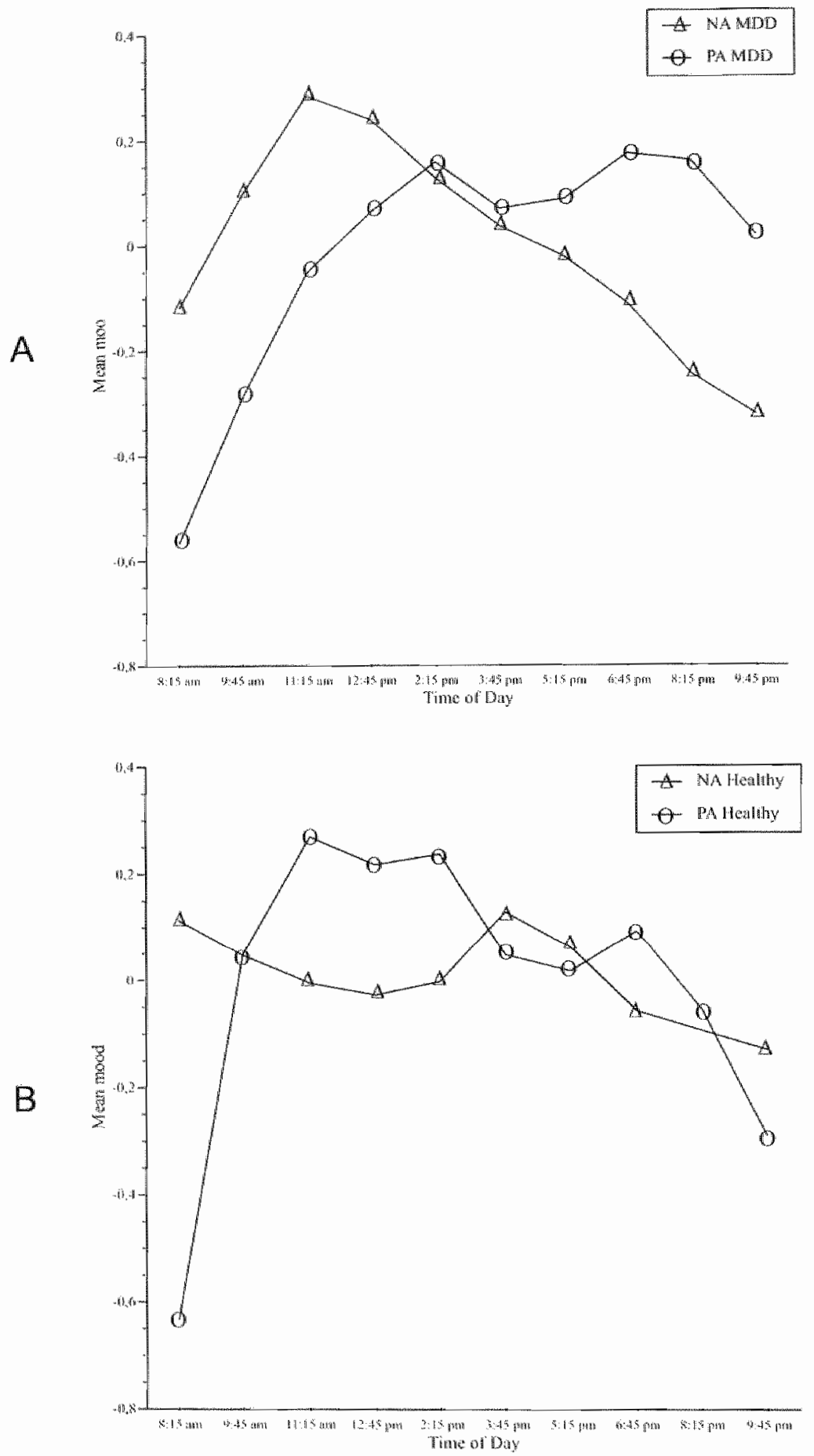

Figure 1. Diumal patrens of man NA and PA in depressed (IA) and healthy subjecrs (IB) 
.001 ). Average duration of sleep was similar in the two groups (depressed: 429 minutes, s.d. $=81$ vs. healthy: $442, s . d .=48 ; \mathrm{t}=.86, \mathrm{df}=82, \mathrm{p}=.39)$.

In order to visualise the differences in daily parterns of NA and PA, we first standarised the mood scores for each subject to eliminate berween-subject variance. Figures $1 \mathrm{~A}$ and $1 \mathrm{~B}$ show the resulting average standarised within-subject scores for NA and PA in the depressed and healthy groups over the course of the day.

We present the results of the multilevel analyses for NA and PA separately in table format for depressed and healthy subjects; the last column shows differences berween both groups.

\section{Negative affect}

Results for NA are shown in Table 1. Depressed subjects experienced higher levels of NA than healthy subjects (see Intercept). NA was further elevated in more severely depressed subjects (BDI) and subjects with longer duration of the current episode. The diurnal partern of NA scores in depressed subjects included a quadratic componenr (maximum NA during the late morning), whereas the diurnal pattern of NA in healthy subjects was largely linear (effect of Time ${ }^{2}$ was not significant). Both groups showed a significant decrease in NA levels over the course of the day (see Figures 1A

Table 1. Multilevel estimates of influences on Negarive Affec (NA)

\begin{tabular}{|c|c|c|c|}
\hline & MDD & Healthy & Difference \\
\hline Intercept & $2.804(.127)$ & $1.350(.052)$ & $1.454(.137)^{* * * 4 t}$ \\
\hline BDI & $.025(.013) *$ & $\ldots$ & - \\
\hline Duration current episode & $.014(.006)^{*}$ & - & - \\
\hline Time & $-.016(.006)^{* *}$ & $-.008(.003)^{* *}$ & $-.008(.007)$ \\
\hline $\operatorname{Time}^{2}$ & $-.006(.001)^{* * *}$ & $-.001(001)$ & $-.005(.001)^{* * * *}$ \\
\hline Duration of sleep & $-.022(.019)$ & $-.001(.015)$ & $-.021(.024)$ \\
\hline Sleep quality & $-.028(.016)$ & $-.033(016)^{*}$ & $-.005(.023)$ \\
\hline
\end{tabular}

Note. The analysis is based upon 4306 observations nested within 510 days, within 85 subjecrs. " p $<.05$. *** $p<.01, * * * 0.001$

Table 2. NA wariance components in the multilevel model

\begin{tabular}{lcc} 
& MDD & Healthy \\
\hline Person lewel & .678 & .085 \\
Day level & .019 & .018 \\
Beep level & .538 & .176 \\
Toral variance & 1.235 & .279
\end{tabular}

Note. All variance escimates are statistically significant, $p<.01$, likelihood ratio test (Bryk \& Raudenbush, 1992). 
and (B). Sleep duration the previous nighr did not influence NA levels in either group, whereas higher self-reported sleep quality was associated with lower NA levels in the healthy group only. We also tested whether NA levels differed for week versus weekend days. During the weekend, NA levels were lower in both the depressed $(\beta=$ -.161 , s.e. $=0.048, z=3.35, p<.001)$ and in the healthy group $(\beta=-.098$, s.e. $=$ $0.032, z=3.06, p<.01$ )

To test the intra- and interindividual variability of NA in the groups, we estimated variances of the multilevel model before addition of independent variables (Table 2). NA was less constant in the depressed group. The significant difference (LR test; $\mathrm{p}<$ .0001 ) berween the two groups in person level variance indicates greater heterogeneity in average NA levels among subjects in the depressed group. The larger beep level variance (LR test; $\mathrm{p}<.0001$ ) in depressed subjects indicates larger variability in NA from moment-to-moment in the depressed group. The difference between the depressed and heal thy group in day level variability was not significant (LR test; $p>.05$ ). Lower sleep quality, bur not sleep duration, was associated with greater beep-level voriability in borh healthy $(\beta=.022$, s.e. $=.005, z=4.40, p<.001)$, and depressed subjects $(\beta=.045$, s.e. $=.009, z=5.0, p<.001)$. We also tested for the contribution of clinical characteristics (severity and duration of the current episode) in the depressed group to beep level variabiliry. Only higher BDI scores were associated with increased beep level variability $(\beta=.009$, s.e. $=.002, z=4.50, p<.001)$.

We also examined the contributions of person, day and beep level variance components to total variance, to assess the relative importance of interindividual (person level) and intraindividual (day and beep level) variability in NA. Based on the values in Table 2, person level variance in the depressed group represented $55 \%$ of the toral variance; day level $1 \%$; and beep level, $44 \%$. In the control group, the distribution of variance components was $30 \%$ at the person level, $6 \%$ at the day level, and $63 \%$ at the beep level. Thus, there was substantial intraindividual (beep level) as well as interindividual (person level) variabilicy in NA in both groups.

\section{Positive affect}

Results for PAare shown in Table 3 . The average PA level was lower in depressed than in healthy subjects, with more severely depressed subjects and those with longer current episodes having even lower levels.

The pattern of diurnal variation in PA in depressed subjects included a positive linear and a negative quadratic component, indicating an increasing function with an inverted U-shape (see Figure 1A). In contrast, daily PA levels in healthy subjecrs included a negative quadratic component only (see Figure $1 B$ ). Sleep duration and quality were not associated with PA in either group. During the weekend, PA re- 
Table 3. Mulrilevel estimares of influences on Posirive Afect (PA)

\begin{tabular}{llll}
\hline & MDD & Heallyy & Difference \\
Intercept & $2.065(.089)$ & $4.502(.149)$ & $2.437(.174)^{* * *}$ \\
BDI & $-.031(.009)^{* * *}$ & - & - \\
Duration current episode & $-.008(.004)^{*}$ & - & - \\
Time & $.020(.006)^{* * *}$ & $.001(.005)$ & $.019(.008)^{*}$ \\
Time & $-.006(.001)^{* * *}$ & $-.009(.001)^{* * *}$ & $.003(.001)^{* * *}$ \\
Deuration of sleep & $-.006(.018)^{* *}$ & $-.034(.025)$ & $.028(.031)$ \\
Sleep quality & $.021(.016)$ & $.022(.026)$ & $.001(030)$
\end{tabular}

Note. The analysis is based upon 4306 observations nested within 510 days, within 85 subjects. $p<.05$. *** $p<.01, * * * * 0.001$

Table 4. PA variance components in the multilevell model

\begin{tabular}{lcc} 
& MDD & Healthy \\
\hline Person level & .310 & .809 \\
Daxylevel & .017 & .053 \\
Beeplevel & .402 & .385 \\
Total variance & .729 & 1.247
\end{tabular}

Note. All variance estimates are statistically significant, $p<.01$, likelihood ratio test (Bryk \& Raudenbush, 1992).

mained at its weekday level in the healthy group $(\beta=-.031$, s.e. $=.055$, n.s. $)$, but was increased in the depressed group $(\beta=.099$, s.e. $=.046, z=2.15, p<.05)$.

To test the intra- and interindividual variability of $\mathrm{PA}$, we estimated variances of the multilevel model before addition of independent variables (Table 4). The smaller person level variance in depressed subjects is evidence for relatively low heterogeneity in average $P A$ levels among depressed subjects (LR test; $p=.004$ ). Variances at the day level (LR test; $p=.08$ ) and at the beep level (LR test; $p=.37)$ were similar in both groups. Duration of the current episode $(\beta=.002$, s.e. $=.0003, z=5.45, p<.001)$, but not depression severity, was associated with reduced beep level variance in the depressed group.

Based on the data in Table 4, we also calculated contributions of the three levels to total variance in the two groups. In the depressed group, person level variance repre-sented $42 \%$ of rotal variance, day $3 \%$, and beep level $55 \%$. The distribution of variance components in the healthy group was $65 \%$ at the person level, $4 \%$ at the day level, and $31 \%$ at the beep level. As for NA, there was substantial inter- and intraindividual variability in PA in both groups. 


\section{DISCUSSION}

The present study compared patterns of NA and PA in depressed and healthy subjects, based on real-time self-reports during everyday life. Mood in MDD is characterised by low levels of PA and high, fluctuating levels of NA. This finding has face validiry, when one considers major symptoms of $M D D$; PA represents the affective component of anhedonia, whereas $\mathrm{NA}$ is the affective representation of fluctuating general distress and anxiety (Clark et al., 1994). In contrast, we found that mood in healthy subjects was characterised by high PA, together with low and more stable NA. In both groups, NA levels decreased slightly, in a linear fashion, throughout the day. NA levels showed a peak in the middle of the day in depressed subjects only. Consistent with previous reports (Clark et al., 1989; Thayer, 1989; Wood \& Magnello, 1992; Watson et al, 1999), we found evidence for a circadian cycle in PA over the course of the day. A linear increase in PA throughout the day was present only in the depressed group.

We found few associations between sleep variables and mood states in the depressed group; only poor sleep qualiry, however, was associated with greater beep-level varuability in NA. It is known that rapid improvement in sleep quality following initial treatment of MDD with benzodiazepines or melatonin can lead to decreases in subjective distress, but not to clinical remission (Birkenhager er al., 1995; Dolberg er al., 1998; Dalton et al., 2000). Our results may help to explain the lack of antidepressive properties of these agents in depression treatment, as they probably help to lower NA variability, but do little or nothing to increase low PA levels typically observed in MDD.

As this is, to our knowledge, the first study of diurnal patterns of NA and PA in $M D D$ in the natural environment, questions arise concerning the underlying sources of differences in mood patterns and variability berween depressed and healthy subjects. Firstly, the low levels of PA and high, fluctuating levels of NA in MDD fit well with neurobiological evidence for low BFS and high BIS activation in MDD (Watson et al., 1999; Drevets, 2001; Naranjo et all., 2001; Davidson et al., 2002). Secondly, given the observed changes in both mood states over the course of the day, it is likely that positive DV of mood in MDD reflects to a large extent increases in PA and to a lesser exrent decreases in NA. The finding of a change in the diurnal temporal pattern in PA in depressed subjects adds to evidence for disrupted circadian rhythms in orher fearures of MDD, such as body-temperature (Barbini et al., 1998; van Londen et al., 2001) and sleep (Boivin, 2000; Riemann et al., 2001). Thirdly, it remains possible that unmeasured environmental factors influenced mood states. In the depressed group, we found higher PA and lower NA in the weekend, which suggests that facrors such as more frequent contact with family or friends and/or changes in daily activities may have influenced mood states. It is likewise possible that the observed daily in- 
crease in PA in MDD comes about through similar environmental factors, racher than through an intrinsic disturbance in mood regulation. The relative contributions of endogenous and exogenous factors to mood dystegulation should be examined in future studies.

The results of the current study have implications for existing conceptualisations and future research on mood in MDD. Firstly, previous studies have reported that depressed and thealrhy subjects cannot reliably assess the presence of DV in mood retrospecrively (Stallone et al., 1973; Tolle \& Goerze, 1987; Haug \& Fahndrich, 1990; Leibenluft et al., 1992; Gordijn et al, 1994; Wefelmeyer \& Kuhs, 1996). The intraindividual variability in borh NA and PA in the current sample underscores the complexities underlying such retrospective mood judgements. Secondly, although DV is generally considered to be a specific characteristic of $M D D$, ir can also be found in parients with other psychiatric disorders (Fahndrich 8 . Haug, 1989) as well as in healthy individuals (Kuhs et al., 1989; Wood \& Magnello, 1992; Wefelmeyer \& Kulhs, 1996). Our results indicate that measurement of DV within a unidimensional mood concept may obscure meaningful differences in the dynamics of NA and PA that may prove useful in discriminating diffenent diagnostic groups (e.g., MDD, borderline personality disorder, schizophrenia) from each other and healthy individuals. Thirdly, the application of a unidimensional mood concept may have contributed to the conflicting results of previous studies into mood variability in MDD (Eastwood et al., 1985; Cowdryet al., 1991; Hall et al., 1991; Wefelmeyer \& Kuhs, 1996; Golier et al., 2001). The current results suggest that variability of unidimensional mood ratings is highly influenced, but in unknown ways, by the considerable inter- and intraindividual variability in NA and PA that we found in both groups. This would call for the use of reliable dimensional mood scales in psychiatric research. Furthermore, we found associations between clinical characteristics, sleep quality, and moment-to-moment wariability in mood states, which suggest that sample characteristics also may have contributed to previous conflicting results. Finally, it has been postulated that the presence of mood labiliry in a depressed parient may be a good predictor of clinical response to various types of treatment (Haug \& Wirz-Justice, 1993; Reinink et al. 1993; Gordijn et al., 1994; Wirz-Justice \& Van den Hoofdakker, 1999). Future studies should test whether intra-individual variability of NA and PA in depressed subjects is related to treatment response.

Finally, a few limitations of this study should be noted. Firstly, mood scales are vulnerable to foor and ceiling effects. In the healthy comparison group, NA scores were skewed roward low levels, which may have constrained variability. Secondly, even though the current analysis controlled for effects of self-reported daily events (Peeters et al., in press) and weekday/weekend effects on mood, the possibility remains that other environmental factors may have influenced the results. Activities and locations, for example, appear to influence mood (Stone et al., 1996); depressed 
and healthy subjects provided mood ratings over a range of daily contexts, which makes the results less vulnerable to these influences than findings based on single point assessments. In the past, some authors have called for rigorous control of environmental influences (e.g., constant routine protocols) in mood regulation studies (Hall et al., 1991; Haug \& Wirz-Justice, 1993). Although such approaches may standarise location, activities, and interpersonal contacts, internal factors like rumination cannot be controlled; these may have an even greater influence on mood when research designs isolate subjects from their daily contexts. The aggregation of multiple mood measurements across a variety of daily life setrings should therefore be considered as an useful and ccologically valid addirion to other methods in mood research.

\section{Acknowledgements}

The authors would like to thank Lilly Finders, Trudla Driessen, and Frieda Van Goethem for research assistance. 


\section{REFERENCES}

APA. (1994). Dragnostic and Statistical Manual of Mental Drsorders (Fourth Edirion ed.). Washington, DC: American Psychiatric Association.

Barbini, B., Benedetri, F., Colombo, C., Guglielmo, E., Campori, E., \& Smeraldi, E. (1998). Perceived mood and skin body remperature rhythm in depression. Eur Ath Psychany Clin Newosi, 248(3), $157-160$.

Beck, A. T., Ward, C. H., \& Mendelson, M. (1961). An inventory for measuring depression. Ards Gen Pychiary, f, 561-571.

Birkenhager, T. K., Moleman, P., \& Nolen, W. A. (1995). Benzodiazepines for depression?. A review of the lirerature. Int Clin Pyshopharmacol, 1063 , 181-195.

Boivin, D. B. (2000). Influence of sleep-wake and circadian thythm disturbances in psychiatric disonders. J Psychiatry Newrosci, 25(5), 446-458.

Boivin, D. B., Caeister, C. A., Dijk, D. J., Duffy, J. F., Folkard, S., Minors, D. S., Totterdell, P., \& Waterhouse, J. M. (1997). Complex interacrion of the sleep-wake cycle and circadian phase modulares mood in healthy subjects. Arch Gen Psychiatry, 54(2), 145-152.

Bryk. A. S. \& Raudenbush, S. W. (1992). Hierardical Linear Madels Applications and Data Analysis Methods. London: Sage Publications.

Cacioppo, J., Gardner, W., \& Bernston, G. (1999). The affect system has parallel and integrative processing components: form follows function. J Pers Soc Psyobl, 76(5), 839-855.

Carpenter, I. L., Kupfer, D. J., \& Frank, E. (1986). Is diumal variacion a meaningful symptom in unipolar depression? J Affect Disord, 1/(3), 255-264.

Clark, D., Beck, A., \& Stewart, B. (1990). Cognitive specificity and positive-negative affectivity: complementary or contradicrory views on anxiery and depression? f Abnow $P_{\text {syd }}$ ol, $99(2), 148-155$.

Clark, I., Watson, D., \& Leeka, J. (1989). Diurnal variation in the positive affects. Motivation and Emotion, 13, 205-234.

Clark, L. A., Watson, D., \& Mineka, S. (1994). Temperament, personality, and the mood and anxiety disorders. J Abnorm Psychol, 103(1), 103-116.

Cowdry, R. W., Gardner, D. L., O'Leary, K. M., Leibenluft, E., \& Rubinow, D. R. (1991). Mood variability: as study of four groups. Am J Psychiatry, $148(11), 1505-1511$.

Csilsanentmihalyi, M., \& Larson, R. (1987). Validity and retiabiliny of the Experience Sampling Method. JNerw Men Dis, 175(9), 526-536.

Dalron, E. J., Rorondi, D. Levitan, R. D., Kennedy, S. H. \& Brown, G. M. (2000). Usc of slow relense melatonin in treatment-resistant depression. J Psyblidy Nearosi, 25(1), 48-52.

Davidson, R. J., Pizzagalli, D., Nitschke, J. B., \& Putmam, K. (2002). Depression: perspectives from affective neuroscience. Anm Rew Pychal, 53, 545-574.

Depue, R. A. \& Collins, P. F. (1999). Neurobiology of the structure of personality: dopanine, facilitacion of incentive motivation, and extraversion. Behat Bram So, 22(3), 491 -517; discussion $518-469$

Depue, R. A. luciana, M., Arbisi, P., Collins, P. \& Leon, A. (1994). Dopamine and the structure of personality: relation of agonist-induced dopamine activiry to posinte emorionality. J Pers Sor lsychol. $67(3), 485-498$.

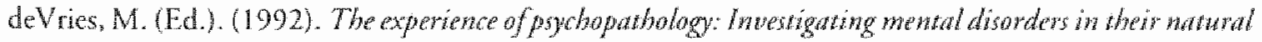
setrings. Cambridge: Cambridge University Press.

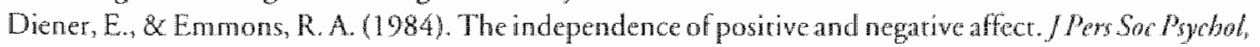
$47(5), 1105-1117$.

Dolberg, O. T. Hirschmann, S. \& Grunhas, L. (1998). Melaronin For the treamen of sleep disturbances in major depressive disorder. Am / Psychratry. 155(8), 1119-1121. 
Drevers, W. (2001). Neuroimaging and neuropathological sudies of depression: implications for the

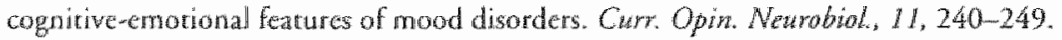

Eastwond, M. R., Whincon, J. L., Kramer, P. M. \&e Peter, A. M. (1985). Infradian rhythms A comparuson of affecrive disorders and normal persons. Arch Gen Psychiary, 42(3), 295-299.

fahndrich, $\mathrm{E}$. \& Haug, H. J. (1989). Diunal variations of mood in psychiatric patients of different nosological groups. Neuropsychobiol, 20(3), $141-144$.

First, M. B., Spiczer, R. L., Gibbon, M, Be Willams, J. B. W. (1995). Structured Clinical Interview for DSM-IV Axis IDisorders. New York: Biometrics Research Deparment, New York State Psychiarric insuitute.

Gable, S. L., Reis, H. T., E. Elliot, A. J. (2000). Behavioral activation and inhibition in everyday life. J Pers Soc Pyohol, 78(6), $1135-1149$.

Goddstein, H., Rasbash, J., Plewis, I., Draper, D., Browne, W., Yang, M., Woodhouse, G., \& Healy, M. (1998). A User"s Gtide to MLwiN. London: Mulcilevel Models Project, Institute of Educarion, University of London.

Golier, I. A., Yehuda, R., Schmeidler, J., \& Siever, I. J. (2001). Variability and severity of depression and anxiery in post rraumatic stress disorder and major depressive disorder. Depress Amextety $13(2)$, $97-100$.

Gordinn, M. C., Beersma, D. G. Bouhuys, A. L., Reinink, E., \& Van den Hoofdakker, R. H. (1994). A longitudimal study of diumal mood variation in depression; characteristics and significance. J Affect Disord, $31(4), 26 \rrbracket-273$.

Hall, D. P., Sing, H. C., \& Romanoski, A. J. (1991). Identification and characterizarion of greater mood variance in depression. Am / Psychiatry, 148(10), 1341-1345.

Hamilton, M. (1967). Development of a rating scale for primary depressive illness. Bry Sac Clin Psychol, $6(4), 278-296$

Haug, H. J., \& Fahndrich, E. (1990). Diumal variacions of nood in depressed patients in retation to severity of depression. J Affect Disord, $19(1), 37-41$.

Haug, H. J., \& Wirz-Justice, A. (1993). Diurnal variation of mood in depression: important or irrelewant? Biol Pystriaty, 34(4), 201-203.

Jolly, J. B., Muray, J., Kramer, T. A., \& Wherry, J. N. (1994). Integation of posirive and negative affectivity and cognitive content-specificity: improved discriminarion of anxious and depressive symptoms. J Abnom Pychol, 103(3), 544-552.

Kring, A., \& Bachorowshi, J. (1999). Emotions and psychopathology. Cogrition and emotion, 13(5), $575-599$.

Kuhs, H., Hermann, W., Kammer, K., \& Tolle, R. (1989). The daily course of the sympromatology and the impariced rime estimarion in endogenous depression (melancholia). I Affer Disord, $I 7(3)$, $285-290$.

Lcibenluf, E., Nownan, B. M., \& Wehr, T. A. (1992). Diurnal wariation: reliabilicy of measurement and relationship ro rypical and arypical symproms of depression. / Affer Disond, 26(3), 199-204.

Marco, C. A. Neale, J. M. Schwartz. J. E., Shiffman, S., \& Stone, A. A. (1999). Coping with daily events and short-term mood changes: an unexpecred failare to observe effects of coping. I Consult Chin Pyolol, $67(5), 755-764$.

Miller. A. \& Tomarken, A. J. (2001). Task-dependent changes in frontal brain asymmetry: effects of incentive cues, outconte expectancies, and motor responses. Psydoploysiology, 38(3), 500-511.

Namio, C. A., Tremblay, I. K, \& Busto, U. E. (2001). The rolle of the brain reward system in depres-

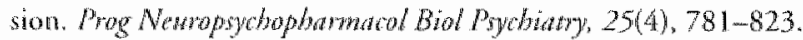

Pecters, F. P. M. L., Nicolson, N. A., Berkhot, J., Delespaul, P., \& DeVries, M. (2002). Effects of daily events on mood sates in major depressive disorder. (J Abnorm Psychol, in press) 
Reinink, E., Bouhuys, A. L., Gordin, M. C. \& Van Den Hoofdakker, R. H. (1993). Prediction of the anridepressant response to total slep deprivation of depresed patients: longitudinal versus single day assessment of diumal mood wariation. Biol Pychiatry, 34(7), 471-481.

Riemann, D., Berger, M. \& Voderholzer, U. 2001). Sleep and depression-results from psychobiological studies: an overnew. Biol Psychol 57(1-3), 67-103.

Stallone, F., Huba, G. J., Lawlor, W. G., \& Fieve, R. R. (1973). Longitudinal studies of diurnal variations in depression: a sample of 643 patient days. Br/ Psychiatry, $23(574), 311-318$

Stone, A. A., Smyth, J. M., Pickering, T., \& Schwartz, J. (1996). Daily mood variability: forms of diumal parterns and determinans of diurnal parterns. / App/ Soc Pochol, 26(14), 1286-1305.

Taylor, S. E (1991). Asymmetrical effects of positive and negarive events: the mobilization minimizarion hypothesis. Psyrol Bull, $710(1), 67-85$.

Thayer, R. (1989). The bropsyctology of mood and awowal. New York: Oxford University Press.

Tolle, R. \& Goerze, U. (1987). On the daily thythm of clepression sympromatology. Psychopathalogy. $20(5-6), 237-249$.

Tomarken, A., \& Keener, A. (1998). Frontal brain asymmetry and depression: a self-regularory perspecrive. Cognition and emotion, 12(3), 387-420.

wan Eck, M. Nicolson, N. A., \& Berkhof, J. (1998). Effecs of stressful daily events on mood states; relationship to global perceived stress. I Pen Soc Psphob, 75(6), 1572-1585.

van Londen, L., Goekoop, J. G., Kerkhof, G. A., Zwinderman, K. H., Wiegant, W. M., \& De Wied. D. (2001). Weak 24-h periodicicy of body tempenture and increased plasma wasopressin in melancholic depression. Ear Neuropsychophamatol, 11(1), 7-14.

Watson, D. (2000). Mood and temperament. New York: Guilford Press.

Warson, D., Clark, L., Weber, K., Assenheimer, J. S., Strauss, M., \& McCormick, R. (1995). Testing a

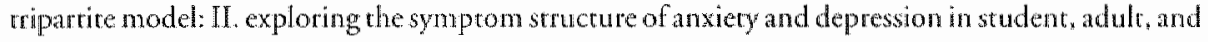
patient samples. J Abnom Pychol, 104(1) $15-25$.

Warson, D., Whese, D., Vaidya, I., \& Tellegen, A. (1999). The rwo general activation systems of affect: Structural findings, evolucionary considerations, and psychobiological ewidence. / Pers Sor Psychod, $76(5), 820-838$.

Wefelmeyer, T., \& Kuhs, H. (1996). Diurnal mood variarion in melandholic parients and healthy controls. Psychopathology, 29(3), 184-192.

Wirz-Justice, A., \& Van den Hoofdakker, R. H. (1999). Sleep deprivation in depression: what do we know, where do we go? Brot Pycliatsy, 46(4), 445-453.

Wood, C. \& Magnello, M. E. (1992). Diurnal changes in perceptions of energy and mood. /R Sac Mod, $85(4), 191-194$ 



\section{CHAPTER 3}

\section{Levels and variability of daily life cortisol secretion in major depression}

Frenk Peeters, Nancy. A. Nicolson, Johannes Berkhof.

Submitted. 
Dysfunction of the hypothalamic-pituitary-adrenal (HPA) axis is an important feature of major depressive disorder (MDD), but relatively little antention has been given to variability of hormone secretion over time. Because most studies have been conducted in hospital setrings, little information about naturally occurring patterns of cortisol secretion throughout the day in depressed outpatients is available. Mulriple salivary cortisol samples were obrained over a 6 -day period from 47 outpatients with MDD and 39 healthy controls in their everyday environment. We used multilevel regression analysis to estimate the effects of MDD and associated clinical characteristics on cortisal levels and intraindividual variability. Although more severe symproms were associated with small elevations in cortisol levels, we found no clear evidence for hypercortisolism in MDD outpatients. MDD was characterized by a more erratic partern of basal cortisol secretion, especially in patients with more severe or recurrent episodes. A chaotic pattern of cortisol secretion may be a more central feature of HPA axis dysregulation than elevated levels, especially in MDD outpatient populations.

\section{INTRODUCTION}

Dysfunction of the hypothalamic-pituitary-adrenal (HPA) axis is thought to play a role in the etiology of major depressive disorder (MDD) (Arborelius et al., 1999; Holsboer, 2000). For several decades, studies have reported abnormalities in cortisol secretion. In addition to elevated cortisol levels (Halbreich et al., 1985a; Linkowski et al., 1985; Mortola er al., 1987; Pfohl et al., 1985; Sachar et al., 1973; Trestman et al., 1995; Yehuda et al., 1993), disturbances in the temporal partern of secretion have been observed, including a flattened circadian curve (Deuschle et al., 1997), a reduction in the length of the nocturnal quiescent period (Halbreich et al., 1985b), an earlier nadir (Linkowski et al., 1985; Pfohl et al., 1985), and changes in the duration (Mortola et al., 1987), amplitude (Linkowski er al., 1985), and frequency of pulsatile episodes (Deuschle et al., 1997; Halbreich et al., 1985b). These findings provide evidence that normal periodicities in HPA activity are disturbed, one of the criteria for a dystegulated biological system, as formulated by Siever and Davis (Siever \& Davis, 1985). Another criterion, erratic basal output, has rarely been investigated in depression. One study that used chronobiological methods to characterize patterns of basal cortisol release did find more random fluctuations in MDD than in PTSD or normal control groups (Yehuda et al., 1996).

Although HPA dysfunction is considered to be a core feature of MDD, only about $50 \%$ of inpatients show abnormalities in measures such as overall hypersecretion and 
DST non-suppression (Rush et al., 1996; Thase \& Howland, 1995). Clinical characteristics may explain some of the variability. Studies have reported relationships berween HPA abnormalities and severity (Nelson \& Davis, 1997), endogenicity (Rush et al., 1996), psychotic fearures (Nelson \& Davis, 1997; Posener er al., 2000), anxiery (Sachar et al., 1973; van Praag, 1996), length of the current depressive episode (Posener et al., 2000), and number of previous episodes (Rybakowski \& Twardowska, 1999).

It is important to note that most research into secretory patterns of cortisol in MDD has been done in inparient-dominated samples, which raises questions about the generalizability of findings to the outpatient majority of patients with MDD. In fact, studies in outpatient or communiry populations have provided little evidence of hypercortisolism (Maes et al., 1994; Michael et al., 2000; Posener et al., 2000; Scott et al., 1999; Strickland er al., 1998; Strickland et al., 2002; Yehuda et al., 1996). Other aspects of HPA dysregulation have not been investigated outside the clinic or laboratory. The divergent results obtained in different treatment setrings may to some extent reflecr an overrepresentation of more severe and endogenous forms of depression in inpatient samples; in addition, there is evidence that stress generated by the admission process and the inpatient regimen may contribute to HPA hyperactiviry (Maes et al., 1994). Similarly, cortisol results from outpatient studies conducted under controlled laboratory conditions may be influenced by the novelty of the setting (Mason, 1968) or by imposed bedrest (Rivest et al., 1989). If HPA axis dysregulation plays a central role in the etiology of depression, abnormalities should be evident in community and outpatient samples, as well as in inpatients. Extending the range of patient samples and research methods used can therefore provide new insights into the nature and extent of HPA abnormalities in MDD.

The current study examined salivary cortisol secretion in unmedicated outparients with MDD and healthy control subjects, with multiple measurements taken over a 6-day period in the natural daily environment. Salivary cortisol can be collected non-invasively, is highly correlated with plasma levels, and is a reliable indicator of the, biologically active, free cortisol in plasma (Kirschbaum \& Hellhammer, 1994). Goals of the study were to determine whether MDD outpatients differed from healthy controls in (a) cortisol. levels over the course of the day, or (b) intraindividual variability in cortisol secretion. We used multrilevel regression to test the hyporheses that depressed patients display elevated basal cortisol levels and a more random pattern of cortisol secretion, with either larger or more frequent fluctuarions over the day than controls. Based on the literature reviewed above, we predicted that certain clinical characteristics (symptom severity, anxiety, duration of the current episode, and recurrent subrype) would be associared with greater abnormalities in cortisol levels and fluctuations. In addition, we examined the possible effects of a family history for mood disorder on corrisol secretion (Holsboer et al., 1995). 


\section{METHOD}

\section{Subjects}

Forty-seven depressed subjecrs were recruited among parients seeking treatment at the local communiry mental health center or the outpatient clinic of the regional psychiatric hospital in Maastricht, the Netherlands. The main inclusion criterium was a primary diagnosis of major depressive disorder, as assessed with the Structured Clinical Interview for DSM-IV (SCID-I; First et al., 1995) by a research psychiatrist (F.P.). The SCID also provides information on length of the current episode and the presence of previous episodes. Information on family history for mood disorders was also obtained. Entry was restricted to patients $18-65$ years of age with a score of $\geq 18$ on rhe 17-item Hamilton Depression Rating Scale (HDRS; Hamilton, 1967). Exclusion criteria were substance abuse in the last six months, psychotic symptoms, bipolar disorder, pregnancy, weight loss exceeding $15 \%$ in the previous 6 months, endocrine and rheumatic disorders, medications (including antidepressants) known to affect the HPA axis, and insufficient fluency in Dutch. At intake, five subjects had been taking antidepressants that were judged to be clinically ineffecrive; these drugs were tapered off, and subjects were rhen allowed to participate in the study after a medicarion-free interval of at least one week (none used fluoxetine). Use of previously prescribed low-dose benzodiazepines was allowed.

Thirty-nine control subjects, matched as a group to the patient sample for gender and age, were recruited from the community. Addirional exclusion criteria for controls were a lifetime history of any DSM-IV axis-I disorder or a history of inpatient treatment for an Axis I psychiatric disorder in a first-degree relative. The study was approved by a medical ethics committee, and written informed consent was obrained from all subjects.

\section{Questionnaires}

Both patients and control subjects completed the Symptom Check List (SCL-90; Derogatis et al., 1973) and the Perceived Stress Scale (PSS; Cohen et al., 1983). Patients also completed the Beck Depression Inventory (BDI; Beck et al., 1961).

\section{Ambulatory sampling procedure}

The Experience Sampling Method (ESM; Csikszentmihalyi \& Larson, 1987; deVries, 1992) was used to collect data from subjects in their natural daily environment. After a training session, subjects completed. ESM forms and simultaneously collecred saliva samples for 6 consecurive days, including 2 weekend days. Ten times 
each day, at semi-random intervals of approximately 90 minutes between $7.30 \mathrm{a} . \mathrm{m}$. and 10.30 p.m., subjecrs received auditory signals ("beeps") from a programmed wristwatch. Following each beep, they completed a brief self-report form. Based on this information, the following measures were used in the analysis to control for possible extraneous influences on cortisol secretion: recent physical exertion (rated on a 7-point scale) and any food intake, alcohol, coffee, smoking, or benzodiazepines in the interval between the current and the previous beep. At the same time, subjects collected saliva with cotton dental rolls (Salivette, Sarstedr). Subjects were instructed to rinse their mouth before taking samples when appropriate (e.g., after recent tooth brushing or eating). Subjects stored new saliva samples in their home freezers at the end of each day.

Before going to bed, subjects completed another short questionnaire, including information on time spent at work that day. In the morning, subjects recorded the time of awakening and rated sleep quality the previous night (7-point scale).

\section{Salivary cortisol}

Uncentrifuged saliva samples were stored at -20 degrees Celsius until analysis. Salivary free cortisol levels were determined in duplicate by direct radioimmunoassay, using ${ }^{125}$ iodohistamine coupled to corrisol-3CMO. The lower detection limit of the assay was $0.33 \mathrm{nmol} / \mathrm{L}$, with mean inter-and intra-assay coefficients of variation of $8.3 \%$ and $4.3 \%$, respecrively. All samples from an individual were analyzed in the same assay to reduce sources of variability.

\section{Statistical analyses}

To examine the effects of major depression and clinical characteristics on daily corrisol secretion, we applied the multilevel or hierarchical linear model, using the program MLwiN (Goldstein et al., 1998). The multilevel model is a variant of multiple regression, appropriate for data sets with a hierarchical structure. In this study, momentary cortisol measurements were nesred within days within subjects; we refer to these three level's as beep-level, day-level, and person-level.

Log transformation of the raw corrisol values yielded an unskewed response variable. We fitted the diurnal secretory curve of logcorrisol by a fourth-degree polynomial; this yielded an accurate and smooth fit in which estimated cortisol values closely approximated the observed values $(r=997, \mathrm{p}<.001)$. To account for residual dependencies among the logcortisol values at the day-and person-levels, we modeled random separate logcorrisol intercepts and slopes for each person and for each day within persons. We accounted for residual dependencies at the beep-level by estimat- 
ing tha autocorrelation berween subsequent cortisol measurements (Goldstein et al., 1994), which was assumed to decay exponentially over the time interval.

Fixed effects estimated at the beep-level included a number of potential confounders. First, the secretory peak in cortisol that occurs after morning awakening (Pruessner et al., 1997) was modeled by including a variable that took the value "1" if the saliwa sample was collected less than 1 hr after awakening and ' 0 ' orherwise. Second, intake of food, alcohol, coffee, nicotine, and benzodiazepines in the interval preceding a beep were also dummy-coded. Finally, level of physical exertion in the interwal was included in the model. At the day level, we included the variable sleep quality. Ar the person-level, we included wherher the subject worked on a regular basis.

To test our hypotheses, the effect of depression (coded 1 for patients and 0 for controls) and of variables representing the interactions between depression and the orthogonalized time terms were estimated. In a second step, the following clinical variables for the patient sample were entered: severity of depression (BDI score cenrered around overall mean), duration of current depressive episode (centered around overall mean), recurtent depressive episode (coded-1 or 1), anxiery ( $\mathrm{CL}-90$ subscale centered around overall mean), and positive family history for mood disorders (coded-1 or 1). To test the statistical significance of the regression coefficients, $z$-scores were calculated by dividing the estimated effect by its standard error. Simultaneous testing of a ser of regression coefficients was done by means of the likelihood ratio test (Bryk \& Raudenbush, 1992).

In addition to elevation in cortisol levels, we hypothesized that MDD patients would display greater intraindividual variability in cortisol secretion over the day than healthy controls. In the multilevel model, intraindividual variability has two components: beep-level variance (which reflects the magnitude of cortisol fluctuations around individual mean levels at each time of the day) and autocorrelation (which reflects momentro-moment cortisol fluctuations with the day). To investigate whether patients differed from controls on either or both of these measures, we compared the following 3 models: (a) wariance estimate over the combined groups and separare autocorrelation estimates for each group, (b) separate variance estimates and a combined autocorrelation estimate, and (c) separate variance and atucocolrelation estimates for each group.

For testing the significance of the variance terms at each level and the effects on log-autocorrelation, we applied the likelihood ratio (LR) test. T-tests and $\chi^{2}$-tests were used ro assess the significance of differences between MDD and control groups. Unless otherwise noted, statistical rests are two-railed. Significance levels were set at $\alpha$ $=.05$. 


\section{RESULTS}

\section{Mising data}

The 86 subjects ( $47 \mathrm{MDD}$ and 39 controls) completed both an ESM report and a saliva sample in response to 4388 beeps. Of these, 101 samples were considered invalid because they were collected more than 30 minutes after a scheduled beep. Cortisol values $>44 \mathrm{nmol} / \mathrm{L}$ were considered physiologically abnormal and therefore excluded. This resulted in the exclusion of 12 values from different individuals; all data (38 samples) from one depressed subject who exhibited 11 extreme cortisol values were also excluded. Another 319 values were excluded because of incomplete ecological information (e.g., missing data on prior food intake). The final data set included 3918 valid observations with both complete ecological information and a cortisol level, or $76 \%$ of the maximum possible observations. Study compliance was somewhat higher in the control group than in the MDD group $(83 \%$ vs. $74 \%$ samples fully completed; $\mathrm{t}=2.7, \mathrm{~d} f=83, \mathrm{p}<.01)$. SCL-90 scores were missing for one depressed subject.

\section{Sample characteristics}

Demographic and clinical data for the final sample of 46 depressed and 39 healthy control subjects are shown in Table 1. The two groups did not differ significantly in sex distribution, age, or body mass index. The MDD group scored significantly higher than controls on SCL-90 total score, SCL-90 anxiety subscale, and the Perceived Stress Scale.

\section{Cortisol levels}

Figure 1 shows observed cortisol values over the day in MDD and control groups. Both groups displayed a clear diurnal pattern, with high cortisol values in the early morning declining over the rest of the day.

Results of the multilevel regression analysis are summarized in Table 2. As expected, time of day had a strong effect on cortisol levels; the linear component explained most of the diurnal variation and is therefore shown in Table 2. Of the porential confounders evaluated at the beep-level (recent awakening, physical exertion, smoking, alcohol, coffee, food intake, and use of benzodiazepines), only recent awakening and food intake had significant positive effects on cortisol secretion. Subjects who worked during the sampling period showed higher cortisol levels; sleep quality, in contrast, had no significant effect. In the depressed group as a whole, cortisol levels were not significantly higher than in controls. Simultaneous resting of all MDD by 
Table 1. Demographic and clinical characteristics of MDD patients and concrols

\begin{tabular}{|c|c|c|}
\hline & $\operatorname{MDD}(n=46)$ & Controls $(\mathrm{n}=39)$ \\
\hline Maleufemale ratio & $20: 26$ & $16: 23$ \\
\hline Age; $y$ & $40.2(10.9)$ & $44.5(11.6)$ \\
\hline Body mass index & $24.2(5.1)$ & $24.8(3.6)$ \\
\hline SCL-90 total score* & $262.4(53.1)$ & $109.8(21.7)$ \\
\hline SCL-90 anxiety" & $29.1(8.0)$ & $11.7(3.6)$ \\
\hline $\operatorname{PSS}$ & $23.6(3.5)$ & $16.1(5.1)$ \\
\hline Duration current episode (months) & $20.3($ range $2-118)$ & - \\
\hline Recurrent subrype & $n=20(44 \%)$ & - \\
\hline HDRS & $239(3.9)$ & - \\
\hline $\mathrm{BDI}$ & $28.7(9.8)$ & - \\
\hline Posinive family history & $\mathrm{n}=25(54 \%)$ & - \\
\hline
\end{tabular}

Note: Mean (SD) shown for continuous variables. \$CL-90 indicates Symprom Checklist-90; PSS, Perceived Srress Scale; HDRS, 17-item Hamiton Depression Raning Scale; BDI, Beck Depression Inventory. Statistical comparisons between the rwo groups are two-tailled. * $t c=16.4, \mathrm{~d} f=82, \mathrm{p}<.00 \pi \dagger ; \mathrm{c}$ $=12.4, \mathrm{df}=82, \mathrm{p}<.001 \mathrm{f} ; \mathrm{r}=8.1, \mathrm{df}=83, \mathrm{p}<.001$

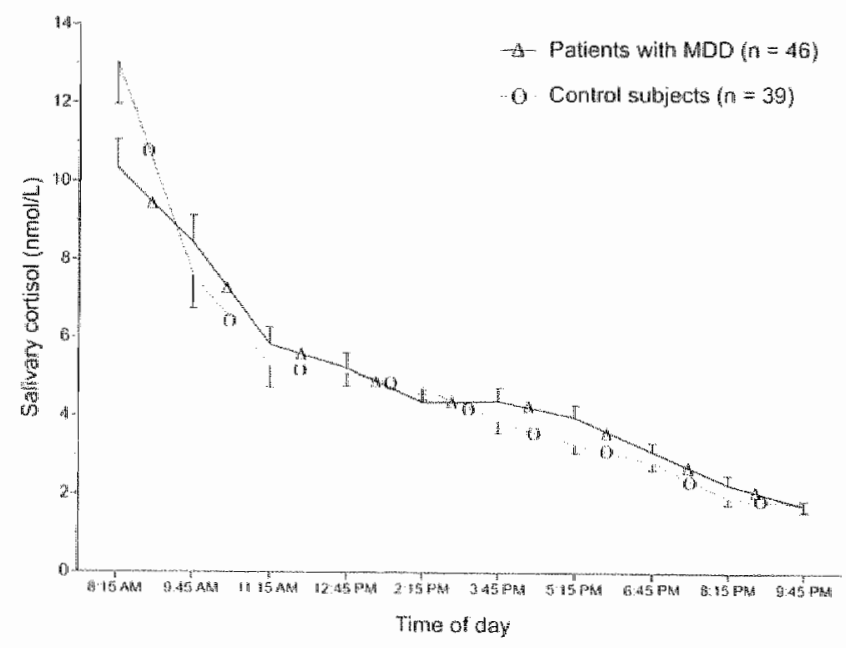

Figure 1. Salivary cortisoll levels in ourpatients with MDO and healthy control subjects. Mean levels for each time of day were furst calculated for each subject over the 6-day sampling period. Values shown are the mean and SEM for each of the rwo groups. 
Table 2. Multilevel estimates of influences on cortisol secretion

\begin{tabular}{lcccc} 
& Estimare & SE & $Z$ & \\
\hline Beep-level & & & & \\
Consrant & 5.196 & .319 & 16.28 & $<.001$ \\
Time (cemtered) & -.127 & .0047 & 27.02 & $<.001$ \\
Extraneous influences & & & & \\
$\quad$ Awakening & .179 & .038 & 4.71 & $<.001$ \\
$\quad$ Food intake & .106 & .014 & 7.57 & $<.001$ \\
Person-level & & & & \\
Worked & .166 & .085 & 1.95 & .05 \\
MDD & .042 & .119 & 0.35 & .73 \\
$\quad$ MDD x Time (centered) & .010 & .006 & 1.67 & .09 \\
Clinical characteristics & & & & \\
BDI & .011 & .005 & 2.20 & .03 \\
SCL-90 anxiety & -.007 & .006 & 1.16 & .23 \\
Duration current episode & .002 & .002 & 1.00 & .31 \\
Recurrent subtype & .066 & .049 & 1.35 & .16 \\
Posirive family history & .014 & .047 & .29 & .98 \\
\hline
\end{tabular}

Note: The multilevel analysis was based on 3918 cortisol samples nested within 85 subjects 39 controls: subjecrs and 46 subjects with MDD). The dependent measure is logcortisol. The following variables had non-significant effects and are not shown in the table beep-level: physical exertion, smoking, alcoliol, coffec, benzodiazepines; day-level: sleep quality; person-level: age, gender, perceived stress, oral contraceptives.

time interaction terms indicated a significant difference between the shapes of the estimated diumal curves of the two groups (LR test; $\chi^{2}=18.27, \mathrm{df}=5, \mathrm{p}=.003$ ). Age, gender, perceived stress, and oral contraceptives had no significant effects, either alone or in interaction with depression.

The effects of patient clinical chatacteristics on cortisol secretion are summarized at the bottom of Table 2. Patients with more severe depressive symptoms had significantly higher corrisol levels, although this effect was small. With the exception of anxiery, the effects of the remaining clinical variables were in the predicted direction, but did not reach significance.

As allowed by the protocol (see Method), eight depressed subjects reported day-time use of benzodiazepines during the study (on 68 out of 2039 ESM reports). These subjects reported higher anxiety ( SCL-90 anxiery: 35.4 vs. 27.6, $\mathrm{t}(43)=-2.75$, $\mathrm{p}=.009)$, but did not differ from the other depressed subjects on any of the other clinical measures (all p's $>.05$ ). To exclude the possibility that benzodiazepine use contribured to the results at the person-level, we repeated the analysis after excluding these 8 subjects. All results remained the same, except that severity of depression no 
longer had a significant effect on cortisol $(z=.78, \mathrm{p}=.43)$, and that recurrent subtype was now associated with higher cortisol $(z=2.52, p=.01)$ in the patient sample.

\section{Intraindividual variability in cortisol secretion}

Next, we tested the hypothesis that corrisol secretion would be less stable in MDD than in healthy controls. Comparison of different models of cortisol beep-level variance and autocorrelation (see Statistical analysis, above) indicated significant differences between MDD and control groups in autocorrelation but not in variance, when borh autocorrelation and variance were included in the same model. Controlling for possible differences in variances between the rwo groups, the autocorrelation was significantly lower in $\mathrm{MDD}(0.31$ ) than in healthy controls (0.50) ( $L R=24.0$, $\mathrm{p}<$ .000001 ), indicaring greater beep-to-beep cortisol fluctuations in MDD. In contrast, the beep-level variance estimates obtained after controlling for separate autocorrelation estimates were not significantly different from each other $(L R=0, p$ > 5), meaning that the magnitude of cortisol fluctuations at each time of the day were similar in MDD and healthy controls.

As a next step, we obtained multilevel estimates of the influence of MDD and clinical variables on the autocorrelation, as shown in Table 3. The large negative effect of MDD confirms the pattern of greater cortisol fluctuations in depressed parients noted above. Additional significant effects for BDI and recurrent subtype indicate even more pronounced dysregulation in patients with more severe or recurrent episodes. To exclude any possible influence of benzodiazepine usage, we also repeated this analysis after exclusion of the 8 benzodiazepine-users. All significant findings remained unchanged.

Table 3. Estimated effects of major depression (MDD) and clinical characteristics on corrisol aturocorretation

$\begin{array}{lccc} & \text { Estimate } & \begin{array}{c}\text { Likelihood } \\ \text { ratio(df }=1)\end{array} & p \\ \text { Constant } & -.830 & 54.6 & .001 \\ \text { MDD } & -.460 & 13.1 & .001 \\ \text { BDI } & -.034 & 11.3 & .001 \\ \text { Recurrent subtype } & -.235 & 6.1 & .01 \\ \text { Duration of current cpisode } & -.001 & .2 & .65 \\ \text { Positive family history } & -.085 & 1.1 & .29 \\ \text { SCL_-90 anxicty } & .011 & 2.8 & .09\end{array}$

None: The analysis was based on 3918 cortisol samples nested within 85 subjects ( 39 controls subjects and 46 subjects with MDD). The dependent measure is the log-autocorrelation of logcortisol. 


\section{DISCUSSION}

We found no evidence for daytime hypercorrisolism in the depressed outparient group, although self-reported symptom severity was associared with higher cortisol levels. In addirion, the form of the daily salivary cortisol curves in MDD ourpatients differed significantly from those of healthy controls. There appears to be a general consensus in the literature that HPA abnormalities are more likely in more severe cases of MDD, but not all studies have shown a clear link. The normal cortisol levels observed in the current sample adds to a growing body of evidence that hypercortisolism is not a characteristic of MDD in outpatient and community samples (Maes et al., 1994; Michael et al., 2000; Orth et al., 2001; Posener er al., 2000; Scott et al., 1999; P. Strickland et al., 1998; Strickland et al., 2002; Yehuda et al., 1996).

A more striking finding of this study was the greater instability in cortisol secretion in MDD patients than controls, which was even more pronounced in patients with more severe or recurrent episodes. The observed effects of recurrent subtype are consistent with the hypothesis that repeated episodes result in more severe, perhaps structural, changes in HPA funcrion (Bremner et al., 2000; Sheline et al., 1999). These results confirm and extend earlier reports of chaotic cortisol secretory patterns in MDD, based on 24-hr blood sampling in a smaller sample $(N=14)$ of outparients (Yehuda et al., 1996). Although the sampling interval of roughly 90 minutes in the current study does not yield sufficient resolution for identifying pulsatile episodes (Pincus et al., 1999), breaking intraindividual variability in cortisol levels down into variance and autocorrelation components in the multilevel analysis provides new insights into the nature of secretory patterns. MDD could thus be differentiated from controls in having more frequent corrisol fuctuations over the course of the day. Taken together with evidence for erratic acrivity of other systems in MDD, such as heightened intraindividual variability in plasma noradrenaline secretion (Kelly \& Cooper, 1998) and in circadian remperature rhythms (Tsujimoto et al., 1990), this suggests that disturbances in regulatory processes may be widespread in depression; erratic basal activity thus deserves more research attention than it has previously received.

Given the pauciry of previous information on diurnal corrisol patterns in MDD in the natural environment, questions arise concerning the underlying source of increased intraindividual variability. As suggested by controlled laboratory studies, erratic cortisol release may be the result of a primary disturbance of circadian regulatory processes (Deuschle et al., 1997; Yehuda et al, 1996). Secondly, heightened mood lability in MDD (Hall et al., 1991) could contribute to cortisol flucruations, as ESM studies in normal individuals indicate that short-term changes in affective states influence cortisol levels in daily life (Smyth et al., 1998; wan Eck et al., 1996). To inves- 
tigate this possibility, we repeated the multilevel analysis of the current data set, now controlling for mood states, and found an unchanged pattern of increased cortisol variability in MDD (for detailed description of mood measurements; see Peeters, Nicolson, Berkhof et al., in press. Finally, depressives may differ from healthy individuals with regard to exposure, appraisal, or response to everyday stressors, which can also trigger corrisol release (van Eck et al., 1996). As reported elsewhere, the MDD group showed blunted corrisol responses to negative daily events compared to healthy controls (Peeters, Nicolson, \& Berkhof, 2002). To test whether group differences in cortisol reactivity in daily events might contribute to the low cortisol autocorrelation in MDD, we added negative events as predictors in the multilevel model, but the group difference in autocorrelation remained. In other words, observed patterns of variability did not appear to reflect stress-related changes in cortisol secretion.

Observed effects of awakening, food intake, and working are consistent with findings obtained experimentally (Adam \& Gunnar, 2001; Follenius et al., 1982; Schmidt-Reinwald et al., 1999). As it is not always possible or even desirable to standarize conditions in a naturalistic study, these and other extraneous influences on corrisol levels were taken into account in the statistical analysis.

An important contribution of this study is the extension of observations on cortisol secretory patterns in depression to the context of daily life. Our results cannot have been distorted by the srress of hospital admission, the inparient regimen (Maes er al., 1994), laboratory procedures (Mason, 1968; Rivest er al., 1989). Given the very high correlation between free cortisol levels in serum and saliva (Kirschbaum $\& x$ Hellhammer, 1994), it is unlikely that the use of salivary measures in the current study is responsible for the absence of hypercortisolism in the depressed subjects. Compared to the few previous studies (Michael er al. 2000: P Srrirklant ar al 1008. Strickland et al., 2002) that have used salivary cortisol measures outside the laboratory in depressed aclults (e.g., twice a day for 3 to 4 days), samples were collected more frequently each day ( 10 times) and over a longer period ( 6 days), thus allowing a more reliable characterization of diurnal patterns. Willingness to participate in the study and the observed high compliance with the protocol by MDD as well as control subjects shows that intensive sampling is feasible in the context of daily life, thus paving the way for future applications. However, some limirations should be kept in mind. The ambularory sampling methodology prevents analysis of circadian rhythm and total cortisol secretion as no samples were collected during sleep. It remains possible that cortisol secretion was elevated during the night in $\mathrm{MDD}$, as reported in previous studies (Halbreich et al., 1985b; Linkowski er al., 1985). And, al though cortisol samples were taken relatively frequently ( 10 times each day), much more intensive sampling is required for a detailed analysis of secretory episodes (e.g., Wong et al., 2000). 
Finally, depressed subjects were recruited in secondary care settings, so that caution is needed in generalizing results to primary care and communiry populations.

Inconsistent results in the literature concerning basal cortisol elevation in MDD, together with our finding of greater abnormalities in variability of daily cortisol secretion than in absolute levels, suggest that erratic activity may be a more widespread and core feature of HPA dysregulation in MDD than hyperactivity per se. According to the dysregulation hypothesis of depression (Siever \& Davis, 1985), a dysregulared system is characterized by impairment of homeostasis, erratic output, disrupted periodicities, abnormal responsivity to environmental stimuli, slower return to basal activity after pertubation, and normalization following effecrive treatment. It may well be that aspects of vulnerability (e.g., familial loading, early adversity) combine with clinical characteristics (e.g., severity, recurrence) to produce a spectrum of HPA disturbances in MDD, perhaps progressing over time towards more severe or irreversible forms. Subtle changes in HPA axis function, like those observed: in the current outpatient sample, may be one of the first manifestations of dysregulation. Longirudinal studies are needed to evaluate the prognostic value of cortisol variability and the effects of pharmacorherapy, other treatments, and clinical recovery on this aspect of HPA dysfunction.

\section{Acknowledgments}

The authors would like to thank Dr. J. Sulon, University of Liège, Belgium, for performing the cortisol assays, and Lilly Finders, Truda Driessen, and Frieda Van Goethem for research assistance. 


\section{REFERENCES}

Adam, E. K., \&\& Gunnar, M. R. (2001). Relarionship functioning and home and work demands predict individual differences in diumal corrisol parterns in women. Psybonewroendocrinology, 26(2), $189-208$.

Arborelius, L. Owens, M. J., Plorsky, P. M., \& Nemeroff, C. B. (1999). The role of corticotropin-teleasing factor in depression and anxiety disorders. J Endoctinol, $160(1), 1-12$.

Beck, A. T., Ward, C. H. \& Mendelson, M. (1961). An inventory for meastring depression. Arch Gen Pyowiatry, 4.561-571.

Bremner, J. D., Narayan, M., Anderson, E., Staib, L. H., Miller, H. L., \& Charney, D. S. (2000). Hippocampal volume reduction in major depression. Ami / Psyblatory, 157(1), 115-117.

Bryk, A. S., \& Raudenbush, S. W. (1992). Hienarchical Linear Models: Applications and Data Analysis Methads. London: Sage Publications.

Cohen, S., Kamarck, T., \& Mermelstein, R. (1983). A global measure of perceived stress. / Health Soc Behan, 24(4), 385-396.

Csikstentmihalyi, M, \& Larson, R. (I\%87). Validiry and reliability of the Experience-Sampling Method. J Nerv Ment Dis, $175(9), 526-536$.

Derogaris, L. Lipman, R. \& Cori, L. (1973). SCL-90, an ourpatient rating scale. Preliminary report. Psychophatmatogy Bulletin. 9, 542-575.

Deuschle, M., Schweiger, U., Weber, B., Gothardt, U., Korner, A., Schmider, J., Srandhardt, H., Lammers, C. H., \& Heuser. I. (1997). Diurnal activity and pulsatility of the hypothalamus-pituitary-adrenal system in male depressed patients and healthy controls. J Clin Endocrimol Metab $82(1)$, $234-238$.

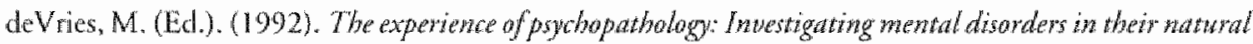
setrings. Cambridge: Cambridge Universiry Press.

First, M. B., Spitzer, R. L., Gïbbon, M., \& Williams, J. B. W. (1995). Stractured Clinical Intevview for DSM-IV Axis I Disorders. New York: Biometrics Research Department, New York State Psychiatric Instikure.

Follenius, M., Brandenberger, G. \& Hietter, B. (1982). Diumal corrisol peaks and their relationships to meals. I Clin Endocrinol Metab, 55(4), 757-761.

Goldstein, H., Healy, M. J. R., \& Rasbash, J. (1994). Multilevel time series models with applications to repcated mealsures data. Stat Med, 13.1643-1655.

Goldstein, H, Rasbash, J., Plewis, I., Draper, D., Browne, W., Yang, M., Woodhouse, G., \& Healy, M. (1998). A Users Gride to MLwiN. London: Multilevel Models Project, Institute of Education, Universiry of London.

Halbreich, U., Asouis, G. M., Shindledecker, R., Zumoff, B, \& Nathan, R. S. (1985a). Corrisol secrerion in endogenous depression. 1. Basal plasma levels. Arb Gen Pychiatry, $42(9), 904-908$.

Halloreich, U., Asnis, G. M. Shindledecker, R., Zumoff, B., \& Narlan, R. S. (1985b). Corrisol secretion in endogenous depression. II. Time-related functions. Amh Gen Pswhatry, 42(9), 909-91 4.

Hall, D. P., Sing, H. C., \& Romanoski, A. J. (1991). Identification and characterization of greater mood wriance in depression. Amerina lournal of Pychiatry $148(10), 1341-1345$.

Hamiltom. M. (1967). Development of a rating scale for primary depressive illness. BrJ Soc Clin Psychol, $6(4), 278-296$

Holsboer, F. (2000). The corticosteroid receptor hypothesis of depression. Nerbropsychopharmacology, $23(5), 477-501$.

Holshoer, F., Later, C. J. Schreiber, W, \& Krieg, J. C. (1995). Altered hypothalamic-piruirary-adrenocorrical regulation in healthy subjects at high familial risk for affective disorders. Netwerdocrinology, 62(4), 340-347. 
Kelly, C. B., \& Cooper, S. I. (1998). Differences and variabiliry in plasma noradrenaline berween depressive and anxiety disorders. J. Psychophamatol., 12(2), 161-167.

Kirschbaum, C., Hellhammer, D. H. (1994). Salivary corrisol in psychoneuroendocrine rearch: recent developments and applications. Psychonewoendocrimolagy, $19(4), 313-333$.

Linkowski, P., Mendlewicz, J., Ledercq, R., Brasseur, M., Hubain, P., Golstein, J., Copinschi, G., \& Van Cauter, E. (1985). The 24-hour profile of adrenocorticotropin and cortisol in major depressive illness. J Clin Endocrinol Metab, 61(3), 429-438.

Maes, M., Calabrese, J., \& Melzer, H. Y. (1994). The relevance of the in- wersus outpaticnt status for studies on HPA-axis in depression: spontaneous hypercorisolism is a farure of major depresed

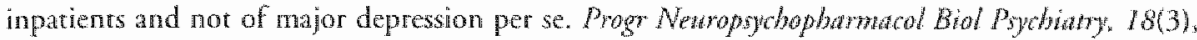
$503-517$.

Mason, ]. W. (1968). A review of psychoendocrine research on the piruitary-adrenal cortical system. Psyclosom Med, 30, 576-607.

Michael, A., Jenaway, A., Paylkel, E. S., \& Herberr, J. (2000). Altered salivary dchydroepiandrosterone levels in major depression in adults. Biol Psychiatry, 48(10), 989-995.

Mortola, J. F., Liu, J. H., Gillin, J. C., Rasmussen, D. D., \& Yen, S. 5. (1987). Pulsatile rhythms of adrenocorticotropin (ACTH) and corrisol in women with endogenous depression: evidence for increased ACTH pulse frequency. J Clin Endocrinol Metab, 65(5), 962-968.

Nelson, J. C., \& Davis, J. M. (1997). DST studies in psychotic depression: a meta-analysis. Am J Psychiatry, 154(11), $1497-1503$.

Orth, D. N., Shelton, R. C., Nicholson, W. E., Beck-Peccoz, P., Tomarken, A. J., Persani, L., \& Loosen, P. T. (2001). Serum thyrotropin concentrations and bioactivity during sleep deprivation in depression. Arch Gen Psychiaty, 58(1), 77-83.

Peerers, F. P. M. L., Nicolson, N. A., \& Berkhof, J. (2002). Cortisol responses to daily events in major depressive disorder subwitted.

Peerers, F. P. M. L., Nicolson, N. A., Berkhof, J., Delespaul, P., \&. DeVries, M. Effects of daily events on mood states in major depressive disorder. J Abnom Psychol (in press).

Pfohl, B., Sherman, B., Schlechte, J., \& Scone, R. (1985). Pituitary-adrenal axis rhythm discurbances in psychiatric depression. Arch Gen Psychiatry, 42(9), 897-903.

Pincus, S. M., Hartman, M. L., Roelfsema, F., Thorner, M. O., \& Veldhuis, J. D. (1999). Homone

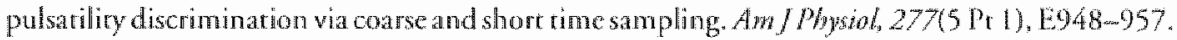

Posener, J. A., DeBartista, C., Williams, G. H., Kraemer, H. C., Kallohan, B. M., \& Schataberg. A. F. (2000). 24-Hour monitoring of corrisol and corricorropin secrerion in psychotic and nonpsychoric major depression. Amb Gen Psychiany, 57(8), 755-760.

Pruessner, J. C., Wolf, O. T., Hellhammer, D. H., Buske-Kirschbatum, A., won Auer, K., Jobst, S., Kaspers, F., Ke Kirchbaum, C. (1997). Free cortisol levels after awakning: a teliable biological marker for the assessment of adrenocortical activity. Life Sciences, 61(26), 2539-2549.

Rivest, R. W., Schulz, P., Lustenberger, S., \& Sizonenko, P. C. (1989). Differences berween circadian and ultradian organization of cortisol and melatonin shythms during acrivity and rest. I Clin Endocrinol Metab, 68(4), 721-729.

Rush, A. J., Giles, D. E., Schlesser, M. A., Orsulak, P. J., Parker, C. R., Jr., Weissenburger, J. E., Crowlcy, G. T., Khatami, M., \& Vasavada, N. (1996). The dexamethasone suppression test in patients with mood disorders. J Chin Psybiaty, 57(10), 470-484.

Rybakowski, J. K, \& Twardowska, K. (1999). The dexamethasonelcorricotropin releasing homone kest in depression in bipolar and unipolar affective illness. / Pychiot $R e x_{3}, 33(5), 363-370$.

Sachar, E. J., Hellman, L., Roffwarg, H. P., Haipern, F. S. Fukushima, D. K., \& Gallagher, T. F. (1973). Disrupted 24-hour parterns of corrisol secretion in psychoric depression. Arch Gen Pychiatry, 28(1), $19-24$. 
Schmidt-Reinwald, A., Pruessmer, I. C., Hellhammer, D. H., Federenko, I., Rohleder, N., Schumeyer, T. H. \& Kirschbaum, C. (1999). The corrisol response to awakening in relation to different challenge tests and a 12-hour corrisol rhythm. Life Sciences, 64(18), 1653-1660.

Scotr, L. W., Salahudditi, F., Cooney, J., Svec, F., \& Dinan, T. G. (1999). Differences in adrenal steroid profile in chonic fatigue syndrome, in depression and in health. J Affect Dis, 54(1-2), 129-137.

Sheline, Y. I., Sanghavi, M. Mintun, M. A., \& Gado, M. H. (1999). Depression durarion but nor age predicrs hippocampal volume loss in medically healthy women with recurrent major depression. J. Newrosti. $19(12), 5034 \ldots 5043$.

Siever, 1. J., \& Dawis, K. L. (1985). Owerview: roward a dysregulation hypothesis of depression. Am J Psychiaty, 172(9), 1017-1031.

Smyth, J. Ockenfels, M. C., Porter, L., Kirschbaum, C. Hellhammer, D. H., \& Stone, A. A. (1998). Stressors and mood measured on a momentary basis are associated with salivary cortisol secretion. Psychonetwoerdoctinology, 23(4), 353-370.

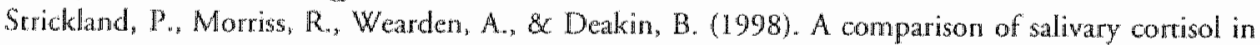
chronic farighe syndrome, community depression and healthy controls. I Affect Dis, $47(1-3)$, 191-194.

Strickland, P. L., Deakin, J. F., Percival, C., Dixon, J., Gater, R. A., \& Goldberg, D. P. (2002). Bio-social otigins of depression in the community: Interactions berween social adversity, cortisol and serotonin neurocransmission. Br/ Psychistry, 180(2), 168-173.

Thase, M. E., \& Howland, R. H. (1995). Biological processes in depression: an updared review and integration. In F. E. Beckham \& W. R. Leber (Eds.), Handbook of depression (pp. 213-279), New York: Guilford Press.

Trestman, R. L., Yehuda, R., Coccaro, E., Horwath, T., Knort, P., Gabriel, S., \& Siever L. J. (1995). Diurnal neuroendocrine and autonomic functions in acute and remitted depressed male patients. Biol Psychiarry, 377), $448-456$.

Tsujimoto, T., Yamada, N., Shimoda, K., Hanada, K., \& Takahashi, S. (1990). Circadian rhychms in depression. Part II: Circadian thythms in inpatients with warious mental disorders. I Affert Disord, 18(3), 199-210.

van Eck. M., Berkhof, H., Nicolson, N., \& Sulon, J. (1996). The effects of perceived stress, traits, mood states, and stressful daily events on salivary corrisol. Psychosom Med, 58(5), 447-458.

van Prag. H. M. (1996). Faulty contisol/serotonin interplay. Psychopathological and biological characverisation ol a new, hyporherical depression subtype (SeCadepression). Psychiatry Res, 65, $143-157$.

Wong. M. L., Kling, M. A., Munson, P. J., Listwak, S., Licinio, J., Prolo, P., Karp, B., McCurcheon, I E. Geracion, T. D., Ir.., DeBellis, M. D., Rice, K. C., Goldstein, D. S, Veldhuis, J. D., Chrousos, G. P., Oldfield, E. H., McCann, S. M., \& Gold, P. W. (2000). Pronounced and sustained central hypernoradenergic function in major depression with melancholic features: relation ro hypercortisolism and corricotropin-reteasing hormone. Proc Natl Acad Sci USA, 97(1), 325-330.

Ychuda, R., Boisoncau, D., Mason, J. W., \& Giller, E. L. (1993). Gilucocorticoid receptor number and cortisol excretion in mood, anxicty, and psychotic disorders. Biol Psychiary, 34(1-2), 18-25.

Ychuda, R., Teicher, M. H., Tresman, R. L., Levengood, R. A., \& Siever, L. J. (1996). Cortisol regularion in prostraumaric stress disorder and major depression: a chronobiological analysis, Biol Psychiatoy, 40.79-88. 


\section{CHAPTER 4}

\section{Effects of daily events on mood states in major depressive disorder}

Frenk Peeters, Nancy Nicolson, Johannes Berkhof, Philippe Delespaul and Marten deVries. Journat of Abnormal Psychology, in press. 


\section{ABSTRACT}

Major depressive disorder (MDD) is characterized by high negative affect (NA) and low positive affect (PA), but litte is known about emorional reactivity in daily life. We used experience sampling methodology to investigate changes in NA and PA following minor negative and positive events in MDD compared to healthy participants. Contrary to expectation, MDD participants did not report more frequent negative events, alchough they did report fewer positive events and appraised both rypes of events as more stressful. Multilevel regression showed that both $\mathrm{NA}$ and $\mathrm{PA}$ responses to negative events were blunted in the MDD group, whereas responses to positive events were enhanced. NA responses to negative events persisted longer in MDD. Depressed participants with a posintive family history or longer current episode showed relatively greater NA responses to negarive events. Clinical intervencions focused on daily experiences may be useful in improving affective symptoms.

\section{INTRODUCTION}

Investigarions of the dimensionality of mood states have provided evidence for the existence of relatively independent negative and positive affective states (Diener $\&$ Enmons, 1984; Watson, 2000). The dimension of negative affect (NA) represents the extent to which individuals experience feelings such as nervousness, tension, irritation, and guilt. Positive affect (PA) reflects the level of pleasurable engagement with one's environment, characterized by feelings such as enthusiasm, interest, and satisfaction. Previous studies have shown that the symptomatic phase of an episode of major depressive disorder (MDD) is characterized by high levels of $\mathrm{NA}$ and, more specifically, low levels of PA (Clark et al, 1990, Jolly et al., 1994; Warson er al., 1995). However, the dynamics of these mood states in MDD are nor well understood.

Minor events in daily life are known to induce momentary changes in NA and PA. Negarive events lead to increases in NA (Sulser al., 1998; van Eck et al., 1998; Marco et al., 1999: Gable et al., 2000), whereas their effect on PA is generally modest (David etal., 1997; wan Ecket al., 1998; Gable et al., 2000). Changes in PA are more strongly related to the occurrence of posirive than negative minor events (Langsron, 1994; David et al., 1997; Gable et al., 2000). The fact that low PA appears to be a specific feature of MDD makes a better understanding of factors that infuence this mood dimension important. Research investigating responses to both negative and positive evenrs could therefore add to our knowledge about mood disturbances in the daily life of depressed people.

The interplay berween minor events and mood states during episodes of MDD is important for a number of teasons. First, fluctuations in mood are a common but 
poorly understood phenomenon in people with MDD. As in healthy people, it can be assumed that mood states of clinically depressed individuals are influenced by daily negative and positive events. Second, changes in neuroendocrine and immunological systems are thought to be important elements of the pathophysiology of MDD (Connor \& Leonard, 1998; Holsboer, 2000). Because these physiological systems are activated by emotional responses to stress (van Eck et al., 1996; Segerstrom et al., 1998), information about mood responses to daily events can fill some gaps in theoretical models linking stress to $\mathrm{MDD}$. Third, cognirive-behavioral treatment for MDD is based, at least in part, on the assumption that changes in daily behavior and cognirive appraisal of daily events are ingredients of a successful therapy (Beck et al., 1979; Jacobson et al., 1996). Knowledge about the interplay between minor daily events and mood can contribute to a better understanding of mechanisms underlying these assumptions.

Daily process designs, such as the experience sampling method (ESM), have been shown to be valid and reliable rechniques for the simultaneous assessmenr of mood, behaviors, and cognitions in the natural environment (Csikszentmihalyi \& Larson, 1987; deVries, 1992; Delespaul, 1995; van Eck et al., 1998; Marco et al., 1999; Swendsen et al., 2000). Events and mood are measured at frequent intervals during the day, which allows the study of temporal relationships berween events and mood states that cannot be captured by end-of-day reports. The difficulties that many people have in accurately detecting contingencies between events and mood are also bypassed. Furthermore, ESM reduces bias in recall, which is especially relevant in research on mood disorders (Morris, 1999).

The present study used ESM to examine momentary mood changes following naturally occurring negative and positive events in the daily life of clinically depressed and healthy people. Previous research reported larger NA responses to negative daily events in neuroric or distressed individuals (Suls et al., 1998; Swendsen, 1998; van Eck et al., 1998). A larger decrease in PA in response to negative events was found in individuals who reported greater perceived stress (van Eck et al., 1998). Given the ab. sence of comparable studies in clinically depressed individuals and uncertainty about the generalizability of results from studies in 'analog' populations (Coyne, 1994; Flett et al., 1997; Santor \& Coyne, 2001), we made no a-priori hypotheses concerning the direcrion of differences in mood reactivity between clinically depressed and healthy people. We expected the average levels of NA to be high in depressed participants and PA levels to be low, in comparison to healthy participants. We predicted that NA would increase and PA would decrease following negative events in both depressed and healthy participants. Following positive events, we predicted a decrease in NA and an increase in PA.

Within the framework of transactional stress theory, how an event is appraised is an important determinant of its impact on mood (Lazarus \& Folkman, 1984). Pri- 
mary appraisals such as unpleasantness and stressfulness of negative events are associated with larger changes in mood (van Eck et al., 1998; Marco et al., 1999). Expecring that depressed individuals would appraise events differently than healthy individuals (Beck et al., 1979), we predicted that these subjective evaluations would be significant dererminants of differences in mood reactivity between depressed and healthy parcicipants. Previous studies reported that the effects of minor events on mood are generally transient, but may be longer lasting in anxious or stressed individuals (Bolger \& Zuckerman, 1995; van Eck et al., 1998). In other words, mood recovery is delayed. We therefore examined differences in the persisting effects of prior events on mood states between depressed and healthy participanrs.

To gain broader insight into possible mechanisms, we investigated the effects of clinical characteristics on mood reactivity within the group of depressed participants. Firstly, we hypothesized that severity of episode would influence mood reactivity to daily events. Secondly, longer duration of the current episode and a history of previous depressive episodes have been associated with an increased vulnerability to psychosocial stressors (Kendler et al., 2000), changes in self-concept and coping strategies (Coyne et al., 1998), and increased use of dysfunctional cognitive styles (Segal et al., 1996). We therefore hypothesized that duration of the current episode and a history of previous episodes of MDD would increase reactivity in NA and PA to negative events and decrease reactivity of both mood states to positive events. Thirdly, given evidence that genetic vulnerability for mood disorders may express itself in heightened neuroticism as well as in alterations in regulation of the hypothalamus-pituitary-adrenal (HPA) axis (Maier et al., 1992; Krieg er al., 2001), we expected that depressed participants with a family history for mood disorders might show greater affective responses to negative events. Finally, many depressed individuals show a diurnal pattern in symptom severity with some alleviation during the course of the day (APA, 1994). We therefore tested whether effects of events on mood states were influenced by time of their occurrence.

\section{METHOD}

\section{Participant recruiment and selection}

Forty-seven participants diagnosed with MDD were recruired among individuals seeking treatment at the community mental health center and the outpatient clinic of the local psychiatric hospital in Maastricht, the Nerherlands. The main inclusion criterium was a primary diagnosis of MDD, as assessed with the Structured Clinical Interview for DSM-IV (SCID; First, Spitzer, Gibbon, \& Williams, 1995) by a research psychiatrist (F.P.). Entry was restricted to individuals between $18-65$ years 
of age with a 17 -item Hamilton Depression Rating Scale (HDRS; Hamilton, 1967) score of $\geq 18$, indicating at least moderate severity of MDD. Exclusion criteria were current substance abuse or psychotic symptoms (both assessed with the SCID), and insufficient fluency in Durch. None of the participants was using antidepressants, but use of low-dose anxiolytic drugs was allowed during the study. One depressed participant was excluded from the analysis because of inadequate compliance with the research protocol (see Procedure, below).

Thirty-nine healthy participants, matched as a group to the patient sample for gender and age, were recruited from available research pools, staff from academic affiliations, and through an advertisement in a local newspaper. Additional exclusion criteria for the healthy participants were a liferime history of any DSM-IV Axis I disorder (assessed with the initial screening section of the SCID), or any inpatient treatment for an Axis I psychiatric disorder in a first-degree relative. Of the 55 potential controls who were screened, 16 were excluded: 8 due to a history of psychiatric disorder, 3 due to inpatient psychiatric treatment in a first-degree relative, 3 due to somatic disorders that could affect the HPA axis (an exclusion criterion for cortisol measures in the same study), and 2 for other reasons (e.g., hearing impairment). The study was approved by the local medical ethics committee, and written informed consent was obtained from all participants. Participants were paid $\$ 30$ for completing the study.

The final sample consisted of 46 depressed and 39 healthy participants. Demographic characteristics and Symptom Checklist scores (SCL-90; Derogatis, Lipman, \& Cori, 1973) for the two groups are presented in Table 1. In the depressed group $67 \%$ were married or living with a partner, compared to $76 \%$ in the healthy group $\left(\chi^{2}\right.$ $(1, \mathrm{~N}=85)=.95, \mathrm{p}=.33)$. Educational level (dichotomized as at least high school completed or not) was higher in the healthy than in the depressed group ( $89 \%$ versus $56 \%$ high school completers; $\left.\chi^{2}(1, N=85)=11.49, \mathrm{p}<.001\right)$. Employment status differed, $\chi^{2}(1, N=85)=15.53, p<.001$, with only $36 \%$ of participants with MDD currently working compared to $79 \%$ of healthy participants).

MDD participants completed the Beck Depression Inventory (BDI; Beck, Ward, \& Mendelson, 1961), a self-report measure of symptom severity. Information on length of the current depressive episode was obtained during the SCID interview. Family history for mood disorders in first-degree relatives (treated or untreated) was obtained in an unstructured interview on the basis of a genogram. Clinical characteristics of the MDD participants are summarized in Table 1 . In addition to the primary diagnosis of MDD, 21 patients $(46 \%)$ had a secondary Axis I diagnosis, as follows: generalized social phobia $(\mathrm{N}=9)$, dysthymic disorder $(\mathrm{N}=5)$, panic disorder with agoraphobia $(N=4)$, posttraumatic stress disorder $(N=4)$, specific phobia $(N=4)$, bulimia nervosa $(N=1)$. Of these, four MDD parricipants had three or more Axis $]$ diagnoses. 
Table 1. Demographic and clinical charactersuics of depressed and healthy participants

\begin{tabular}{|c|c|c|c|}
\hline Variable & $\mathrm{MDD}$ & Healthy & $p$ \\
\hline $\mathbb{N}$ & 46 & 39 & \\
\hline Men & 20 & 16 & $>50$ \\
\hline Women & 26 & 23 & \\
\hline Age in years & $40(11)$ & $44(12)$ & .09 \\
\hline SCL-90 total scort & $259.8(53.9)$ & $109.8(21.8)$ & $<.001$ \\
\hline SCL 90 dopression & $57.1(11.6)$ & $18.9(4.1)$ & $<.001$ \\
\hline HDRS & $23.9(3.9)$ & - & na. \\
\hline $\mathrm{BDI}$ & $28.4(9.8)$ & - & 月.a. \\
\hline Durarion atrent episode in months & 20.3 (range $2-118)$ & - & n.a. \\
\hline Previous episode(s) & $20(44 \%)$ & - & ma. \\
\hline Positive family history & $25(54 \%)$ & - & n.à. \\
\hline
\end{tabular}

Note. Mean (SD) shown for continuous variables. Means were compared using tr-tests, categorical variables were compared with the use of $\chi^{2}$ rests. SCL 90 indicates Symprom Checklist-90; HDRS, 17-irem Hamilton Depression Raring Scale; BDI, Beck Depression Inwentory; n.a. = not applicable.

\section{Procedure}

ESM was used to collect data from participants at selected moments during their daily activities. Participants received auditory signals (beeps) from a wristwatch programmed to emit 10 beeps between 7:30 a.m. and 10:30 p.m. each day, at semi-random intervals of approximately 90 minutes. After receiving a beep, participants completed self-report forms concerning current mood, negative and posirive events, and their appraisals. Participants completed ESM reports for 6 consecutive days, including a weekend. During a briefing session, study aims and procedures were explained. In a final session, the ESM booklets were checked for legibility and missing data.

Compliance with the procedure was generally good. The criteria set for inclusion in the analyses (more than 20 ESM reports completed within 25 minutes after the programmed time of the beep) were met by all participants excepr one depressed parricipant. Participants included in the analyses completed an average of $85 \%$ of all possible responses within the time limit, resulting in an average number of valid responses of 50.7 per participant. Mean number of valid responses was somewhat higher in the healthy than in the depressed group, $53.2 \mathrm{vs.} 48.6 ; \mathrm{t}(84)=3.3, \mathrm{p}=.003$. 


\section{Medsures}

Mood assessment. Momentary mood states were assessed with 16 adjectives rated on 7 -point scales $(1=$ not at all, $7=$ very). Factor analyses (principal components analysis with varimax rotation) on mean scores aggregated per subject and on within-subject $z$ scores borh identified two mood factors with eigenvalues greater than 1 . These factors accounted for $81.1 \%$ of the total variance in subject mean scores and $46.1 \%$ of the variance in within-subject $z$ scores. Ratings on the items anxious, irritated, restless, tense, guilty, irritable, easily distracted, and agitated were averaged to form a NA scale (Cronbach's alpha $=.91$ based on all 4535 ESM reports; item loadings on factor 1 ranged between .66 and .88 , loadings on factor 2 between -. 16 and -.40 ). Ratings on the items energetic, enthustatstic, happy, cheerful, talkative, strong, satisfied, and self-assured were averaged to form a PA scale (alpha $=.95$; item loadings on factor 1 between -.08 and -.42 , loadings on factor 2 berween .73 and .92). The average NA level (aggregated over participant means) was $\mathbb{1} .3(S D=.3)$ in healthy participants and $2.9(S D=.9)$ in depressed participants. Average PA levels were $4.5(S D=.9)$ and $2.1(S D=.7)$ for healthy and depressed participants, respecrively. Correlations between NA and PA, based on raw data, were $r=-.19, p<.001$ for depressed and $r=$ $-33, p<.001$ for healthy participants.

Stressful events. At each beep, participants were asked briefly to describe any positive and/or negative event that may have taken place since the last ESM report. Although participants were instructed to report only events or situations that actually took place in their daily environment in the preceding interval, some event reports clearly referred to internal states only (e.g., current ruminations about past events, personal health concerns). Following pre-established criteria, the research team idenrified such internal events by consensus. Reports of internal events were not used in the analysis to avoid confounding of event and mood measures. In the depressed group, $16 \%$ of all event reports referred to internal states compared to $8 \%$ in the healthy group. We identified events as prior when the previous ESM report on the same day ( $\mathrm{r}-1)$ mentioned an event, to address persisting effects on mood states in the analysis.

Appraisals. On 7-point scales $(1=$ not at all, $7=$ very $)$, participants rated positive events on the dimensions pleasant, important, and stressful; negative events were rated on the dimensions unpleasant, important, and stressful. Correlations, over all ESM reporrs from all participants, between the appraisals of positive events were low to moderate (pleasant with important: $r=.49, \mathrm{p}<.001$; pleasant with stressful: $r=-.25, \mathrm{p}<$ .001 ; important wirh stressful: $r=.01, \mathrm{p}=.6)$. The correlations between appraisals of negative events were moderate to strong (unpleasant with important: $r=.30, \mathrm{p}<.001$; unpleasant with stressful: $r=.55, \mathrm{p}<.001$; important with stresf ful: $r=.32, \mathrm{p}<.001$ ). 


\section{Statistical model}

Because the experience sampling observations are nested within days within participants, we estimated the effects of daily events, depression, and individual characteristics on mood states with multilevel or hierarchical linear analysis, which is a variant of multiple regression appropriate for nested dara. Separate models for NA and PA were estimated using the program MLwiN (Goldstein et al., 1998).

The regression equation can be expressed as follows:

$$
(\text { Mood })_{j i j}=b_{0, s, s}+\sum_{q=1}^{q} b_{q m} x_{q j j \mathrm{i}}+r_{i j t}
$$

where $\operatorname{mood}_{i j \mathrm{r}}$ is the NA or PA score of participant $i$ at the $t$-th beep on day $j$. The intercept is denoted by $b_{0 m}, x_{q i j t}$ is an entry of explanatory variable $\mathrm{x}_{\mathrm{q}}, \mathrm{b}_{\mathrm{qm}}$ is the corresponding regression coefficient, and $\mathrm{r}_{\mathrm{ijt}}$ is an error term. The index $m$ indicares whether the participant is depressed $(m=1)$ or heal thy $(m=0)$. By indexing all regression coefficients with label $m$, we estimated all effects separately for the depressed and heal thy groups. The error term is irself a function of error terms that capture the dependencies among the mood observations. Such dependencies occur because two observations tend to be more similar if (1) taken at points closer in time on the same day, (2) taken on the same day rather than on two different days, and (3) taken from one participant rather than from different participants. To account for these sources of dependency, we (1) modeled the autocorrelation between two subsequent observations as an exponentially decaying function of the time interval between these observations, (2) estimared day level variance to account for day-to-day variability, and (3) modeled a random intercept to account for interindividual variability in mood levels. Ignoring rhese dependencies biases the estimared standard errors of the regression coefficients and may lead to incorrect inferences about the effecrs of the explanatory variables. It should be noted that autocorrelation controls for the influence of the previous mood score on the current mood score (after having adjusted for the level of the covariates).

The following dummy-coded $(0-1)$ variables were predictors in the model: PosEvent ( $\mathbb{1}$ if a positive event was reported), NegEvent (1 if a negative event was reported), Prior PosEvent ( 1 if a positive event was reported ar the previous beep), and PriorNegEvent ( 1 if a negative event was reported at the previous beep). The values of PriorPosEvent and PriorNegEvent were set to 0 at the first beep of the day. We also estimated the effects of a positive or negarive event at the last beep of the day on the mood scores at the first beep of the next day. These effects were negligible and were therefore excluded from the model.

Additional explanarory variables were either centered around the grand mean or effect coded $(-1,1$ instead of 0,1$)$ so that inclusion in the model would not automati- 
cally change the previously estimated effects of events on mood. The event appraisal scores were centered around the grand mean, or set to zero if no event was reported. To examine the effect of gender on the relation between depression, events, and mood states, we included the variable Gender ( -1 if female, 1 if male), as well as its interactions with PosEvent, NegEvent, PriorPosEvent, and PriorNegEvent.

To assess the impact of clinical characteristics in MDD on mood responses, the following variables were included in the model: severity of depression (BDI score centered around mean), duration of current depressive episode (in months, centered around mean), episode ( 1 if previous episode; -1 if first episode), and family history for mood disorders ( 1 if positive history; -1 if negative history). Because these clinical variables can have an effect in the MDD group only, they were modelled as interactions with group; as a result, scores for healthy participants take the value 0. Interactions between clinical characteristics and events (PosEvent, NegEvent, PriorPosEvent, and PriorNegEvent) were also estimated.

Finally, we modeled the diurnal pattern in mood states with a linear function. The time variable (CTIME) was centered around the midpoint of the sampling times (3:06 p.m.) and included as a covariate in the model.

Significance of the regression coefficients was rested by dividing the estimated effects by their standard errors. These ratios are approximately normally distributed. Two-tailed tests were used even when hypotheses were directional. Significance levels were set at alpha $=.05$.

\section{RESULTS}

\section{Frequency and appraisals of daty events}

Group differences in frequencies and appraisals of events are presented in Table 2 . In total, 1762 events were reported during the six days. Four participants (two in each group) reported no events. The frequency of negative events was similar in both groups, but the depressed group reported fewer positive events. Negative events were appraised as more unpleasant, more important, and more stressful by the depressed then by healthy participants. Positive events were appraised as less pleasant, equally important, and more stressful by the depressed participants.

\section{Effects of events on mood states}

We present the results of the multilevel analyses for changes in NA and PA separately in table formar. In each table, the effects of negative and positive events on mood states are shown for depressed and healthy participants; the last column shows the 
Table 2. Mean (SD) frequencies and appraisal ratings of daily events in depressed $(n=44)$ and holthy $(\mathrm{n}=37)$ participants

Frequency of negative events

Unipleasant

Important

Suressful

Frequency of positive events

Pleasant

Important

Stressful

\begin{tabular}{llcc} 
MDD & Healny & $|i(79)|$ & $p$ \\
\hline $16 \%(12)$ & $17 \%(13)$ & .35 & .7 \\
$5.6(1.0)$ & $4.7(0.8)$ & 4.33 & $<.001$ \\
$4.6(1.4)$ & $3.9(1.2)$ & 2.18 & .03 \\
$5.4(1.3)$ & $3.3(1.2)$ & 7.27 & $<.001$ \\
$21 \%(16)$ & $34 \%(24)$ & 3.03 & .003 \\
$5.3(1.0)$ & $5.8(0.9)$ & 2.35 & .02 \\
$5.3(1.3)$ & $5.1(1.0)$ & .58 & .56 \\
$2.4(1.3)$ & $1.6(0.8)$ & 3.36 & $<.001$
\end{tabular}

Frequency of reports of negative and positive events within same cime-interval

$8 \%(9)$

$13 \%(13) \quad 1.26 *$

.21

Nore. Frequency of events expressed as percentage of coral beeps in which an event was reported. ${ }^{*} \mathrm{~d} f=38$

differences between the groups. Because event and mood reports were collected simultaneously, it is important to note that significant effects in the multilevel model cannot firmly establish a causal relationship between event occurrence and subsequent changes in mood.

Negative affect. Basal NA levels were higher $(\beta=2.834, S E=.097$ versus $\beta=1.220$, $S E=.141$ ) in depressed than in healthy participants (difference; $\beta=1.614, S E=.176$, $\mathrm{z}=9.17, \mathrm{p}<.001)$. NA was further elevated in more severely depressed participants $(\beta$ $=.032, S E=.010, z=3.20, \mathrm{p}<.001)$ and in depressed participants with episodes of longer duration $(\beta=.012, S E=.004, z=3.0, p<.01)$. A previous episode or a positive family history were not associared with additional increases in NA levels.

In both groups, negative events led to increased NA (see left half of Table 3). Although levels of unpleasantness (valence) and importance had no additional effects on NA reactiviry, events appraised as more stressful further increased NA. Depressed parricipants showed significantly smaller increases in NA in response ro negarive events than healthy participants. Prior negative events, on the other hand, had a persistent effect in MDD only.

In the healthy group, positive events only minimally decreased NA; positive events appraised as relatively stressful resulted in a slight increase in NA (see right half of Table 3). In comparison, depressed participants showed a more pronounced decrease in NA in response to positive events, particularly in the case of events appraised as relatively importanc. In the MDD group, stressful positive events were followed by a significantly greater increase in NA than observed in the healthy group. Prior positive events had no persistent effect on NA in either group.

In contrast to results for the healthy group, depressed women showed higher basal $N A$ than depressed men $(\beta=.264, S E=.099, z=2.67, p<.01)$. Jn addicion, depressed 


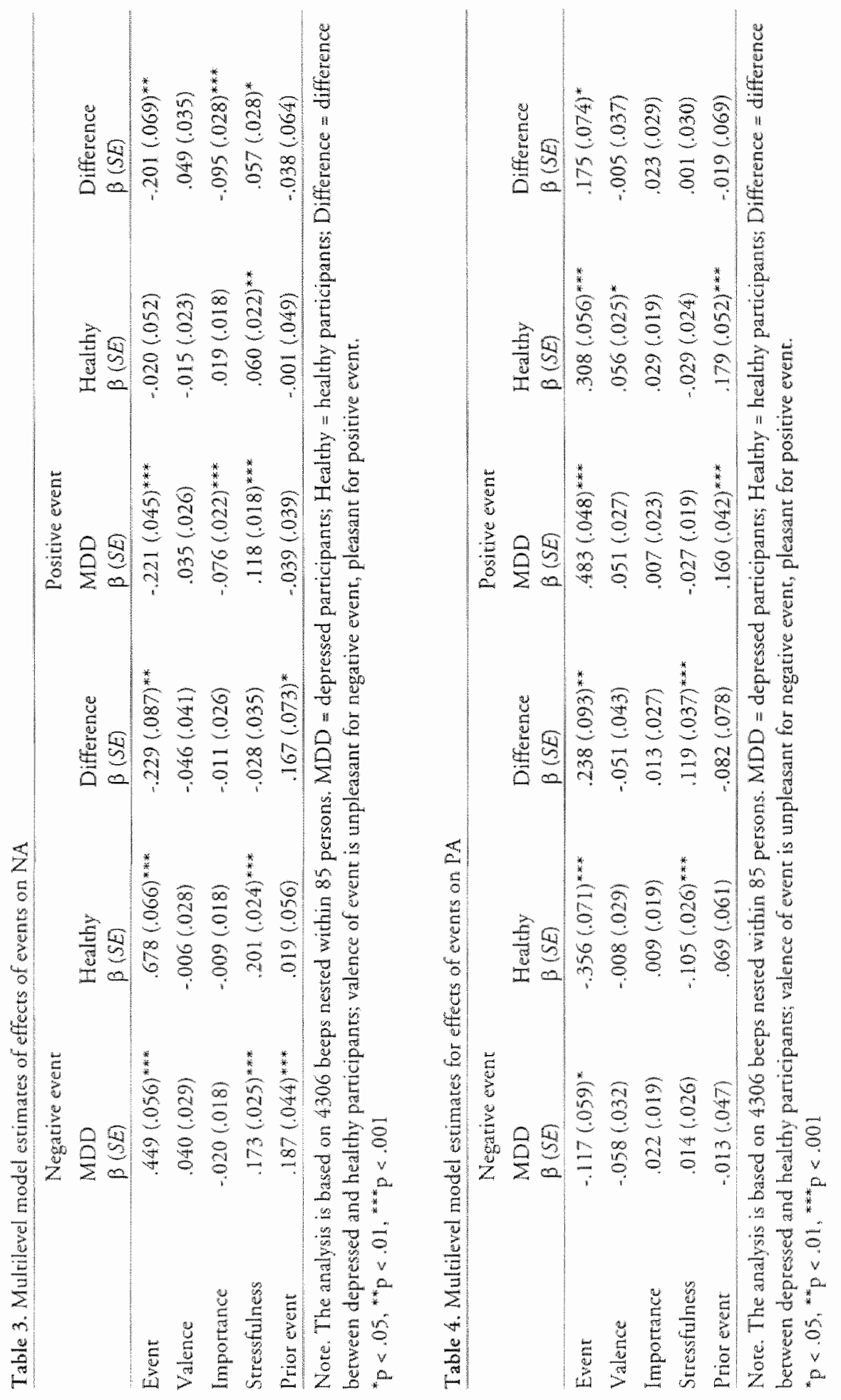


women responded with larger decreases in NA following positive events than depressed mon $(\beta=-.143, S E=.039, z=3.67, \mathrm{p}<.001)$. Other gender effects in depressed and healthy participants were non-significant.

We also tested for the ffects of interactions between clinical characteristics (severity of depression, durarion of the current episode, previous episode, positive family history) and daily events on NA within the depressed group. NA responses to negative events were further elevated in depressed participants with longer current episodes of depression $(\beta=.004, S E=.002, z=2.32, p=.02)$, and in those with a positive family history $(\beta=.111, S E=.043, z=2.58, \mathrm{P}=.01)$. Depression severity and previous episodes had no significant influence on NA reactivity to negative events. For NA reactivity, we found no significant effects of interactions between dinical characteristics and positive events. Clinical characteristics showed no influence on NA reactivity to prior events, either negative or positive.

Within the depressed group, NA levels declined significantly over the day $(B=$ $-.031, S E=.004, z=7.42, \mathrm{p}<.001)$. Increases in NA following negative events remained unchanged, but decreases in NA following positive events were slightly smaller later in the day $(\beta=.024, S E=.009, z=2.60, \mathrm{p}<.01)$.

Positive affect. Basal PA levels were lower $(\beta=2.001, S E=.112$ versus $\beta=4.447$, $S E=.162$ ) in depressed than in healthy participants (difference; $\beta=2.447, S E=.202$, $z=12.11, p<.001)$, with more severely depressed participants thaving even lower levels $\left(\beta=-{ }_{n} 029, S E=.012, z=2.41, p={ }_{n} 02\right)$. Other clinical characteristics showed no significant influence on basal PA levels.

Negative events decreased PA in all participants (see left half of Table 4 ), but these decreases were significantly smaller in depressed participants. Negative events that were appraised as more stressful were followed by further decreases in PA in healthy parricipants only. Prior negative events had no persisting effect on PA in either group.

Current and prior posirive events were associated with increases in PA (see right half of Table 4). However, positive events resulted in larger increases in PA in depressed than in healthy participants. Current events that were appraised as more pleasant were followed by further significant PA increases in healthy participants and a similar trend in depressed participants. In contrast to the findings for negative events, stressfulness of posirive events had no effect on PA for either healthy or depressed participants. None of the results for $\mathbb{P} A$ were influenced by gender.

In contrast to the results for $N A$, there were no significant interaction effects between clinical characteristics and a current event on PA. However, prior negative events led to a persistent lowering of PA in depressed participants who had experienced a previous episode $(\beta=-.095, S E=.045, z=2.11, \mathrm{p}=.04)$.

PA levels increased slighty over the course of the day in depressed participants $(\beta$ $=.024, S E=.005, z=5.07, p<.001)$, but PA reactivity following negative and positive events showed no diunal partern. 
The finding that MDD participants reported relarively few positive events raises the question whether individual differences in event frequency may have influenced mood responses to events. To address this question, we added person-level mean frequencies for both positive and negative events as explanatory variables in the multilevel model. Event frequencies had no significant effect on either NA levels or NA reactivity to events. For PA, event frequencies had no effects on mood levels; individuals (in particular, healthy participants) who reported relatively many positive events showed marginally larger PA responses to these events. Differences, however, between MDD and healthy groups in the effects of events (both positive and negative) on PA remained significant.

Finally, because few MDD participants were currently working, differences between the two groups in daily activities might have resulted in exposure to different sorts of events. If so, one might expect to find larger weekday versus weekend effects on mood reactivity in the heal thy group. We therefore examined weekend/weekday patterns of mood and mood reactivity in the multilevel model. MDD participants showed a slight increase in PA levels on the weekend, but we found no evidence that weekends had any effect on either PA or NA reactivity (data not shown).

\section{DISCUSSION}

To our knowledge, this is the first study of the influence of negarive and posirive minor events on mood states in clinically depressed and healthy individuals in their natural environment. Some of the findings are surprising or counterintuitive. For example, MDD participants did not report more frequent negative events, al though they did report fewer positive events and appraised both types of events as more stressful. Mood responses to negative events were more pronounced in the healthy participants, whereas mood responses to positive events were larger in depressed participants. Events experienced as more stressful influenced the magnitude of the responses of NA and PA and contributed further to the different effects on mood reactivity in the two groups. Within the MDD group, duration of current episode and a positive family history for mood disorders enhanced NA responses to negarive events, but responses remained blunted compared to healthy participants.

The finding that healthy and depressed participants reported similar numbers of negative events contradicts results of most previous studies. Using retrospective research designs, these studies found more frequene negative daily events in people with MDD (Grosscup \& Lewinsohn, 1980; Lewinsohn, 1975; Lewinsohn \& Amenson, 1978; Ravindran, Griffiths, Waddell, \& Anisman, 1995; for an exceprion, see Coyne, Aldwin, \& Lazarus, 1981). Given the methodological limitations inherent in retrospecrive designs, especially in people diagnosed with $M D D$, our results may pro- 
vide a more accurate picture of negative event frequency in MDD. The fact that we explicilly drew a distinction berween external and internal events to avoid confounding of event and disorder contributes to the robustness of our finding. Consistent with the previous studies, depressed participants reported fewer positive events than healthy participants. According to Gable et al. (2000), positive events are more likely to be actively initiated by an individual, whereas negative events are more likely to happen spontaneously in daily life. In line with this hypothesis, symptoms like lack of energy and anhedonia in MDD could reduce the likelihood of positive event occurrence, as we found. Taken together, our findings underscore the need to assess both negative and positive events in daily life, in order to obtain the best indicator of the effects of depressive symptomatology on well-being (Kanner et al., 1981; Holahan er al., 2000).

Negative events were followed by increases in NA and decreases in PA; as in previous studies (Suls et al., 1998; van Eck et al., 1998; Marco et al., 1999; Gable er al., 2000), these changes were enhanced when the negative event was appraised as stressful. Surprisingly, although depressed participants experienced negative events as more unpleasant, important, and stressful, their mood responses were blunted in comparison to heal thy participants. On the one hand (event appraisals), these results can be interpreted as evidence for environmental hypersensitivity-on the other hand (mood changes), as evidence for hyposensitivity. Objective aspects of the events and their timing might help reconcile the two interpretations, but these details cannot be obtained in a naturalistic study. It has been argued that a strong and immediate response to negative events (including physiological, affective, cognitive and behavioral changes), followed by a rapid return to homeostasis, is beneficial for the organism in both the short and the long term (Taylor, 1991). Given the characteristic fatigue, cognitive dysfunctions, and motivational problems in $\mathrm{MDD}$, it is plausible that individuals suffering from MDD respond less strongly to negative events, but recover more slowly. The observed reduced mood reactivity to negative events and a more persistent effect of prior negative events on NA in MDD are consistent with this hyporhesis.

Could the current findings on mood reactivity be due to ceiling or floor effects? Given that mean NA level in depressed participants was only 2.8 on a 7-point scale, a ceiling effect for $N A$ responses in MDD seems unlikely. PA responses in MDD might potentially be blunted due to a floor effect, as mean PA was very low in this group ( 2.0 on a $1-$ to -7 scale). However, because most appraisals of negative events moderated PA responses similarly in both groups, a floor effect seems unlikely. In addirion, depressed participants with more severe symptoms displayed lower mean PA levels but did not exhibir a greater blunting of $\mathrm{PA}$ response than participants with less severe symptoms. It remains possible that low mean NA levels in the healthy group reduced the likelihood of further decreases and that this floor effect artificialiy inflated the ob- 
served difference between the wo groups in NA reactivity to positive events. Ceiling effecrs for PA in the healthy participants are less probable, as their mean PA level was only 4.5 on a 7 -point scale.

The literature on mood changes in daily life is dominated by studies of daily hassles. The current results indicate that daily uplifts are also important determinants of mood, in both depressed and healthy people. As in a previous study (David et al., 1997), the effects of positive events on mood stares were smaller than the effects of negative events. Compared to healthy participants, depressed participants appraised positive events as less pleasant, more stressful, but equally important. In contrast to the findings for negative events, the participants with MDD showed greater mood reacrivity than controls, with larger decreases in NA and increases in PA. More stressful positive events resulted in a larger increase in NA in the depressed group, whereas more important positive events led to a further decrease in NA. Previous research has shown that intense PA is often preceded by periods of low PA (Diener etal., 1991), a phenomenon that is explained by an "opponent process" model (Solomon, 1980; Bolger et al., 1989). In short, this theory states that intense reactions are followed by intense opposing reactions. The observed heightened mood reactivity to positive events in MDD may find its origin in such opponent processes.

In the depressed group, observed changes in mood states over the day are suggestive of a diurnal pattern with more severe symptoms in the morning, as has been previously described (APA, 1994). Mood reacrivity was largely unaffected by this diurnal pattern, as only decreases in NA following positive events were slightly attenuated over the course of the day.

Although mood responses to daily events were small in magnitude, the results provide important information about the daily lives of clinically depressed individuals. The relarively strong response to positive events in participants with MDD may ex. plain why behavioral accivation in itself, intended to increase the frequency and enjoyability of pleasant events, is an effective treatment for MDD (Jacobson er al., 1996). Positive events may help change the attentional and behavioral focus of depressed individuals (Watkins \& Teasdale, 2001), and act as a buffer against the damaging effects of neuroendocrine abnormaliries associated with stress (McEwen, 1998). Our results suggest that engagement in positive events may pose a complicated challenge for depressed people, as they tend to appraise them as relatively stressful. In addition to an increase in PA, stressful positive events lead to an additional increase in NA in depressed people. This can be understood in light of symptoms such as feeling insecure, fatigue, diminished ability to think or concentrate, and psychomotor retardation. Two examples of posirive events in the same depressed woman may illustrate this point. In the first example, drinking coffee with the parner was rated as rather pleasant (5), rather imporrant (5) and not stressful (1). Having breakfast with all family members, which was rated as rather pleasant (5), highly im- 
portant (6), but at the same time moderately stressful (4). Although both events were considered pleasant and important, the second event appears to have been more challenging. This may help clarify why it is important in behavioral therapy for MDD to introduce more complex and strenuous activities in daily life only after an initial improvement in clinical condition (Beck et al., 1979).

Significant effects of clinical characteristics in MDD on reactivity of mood states were all related to negative events. Of particular interest is the finding of greater NA reactivity in depressed participants with a positive family history. This may point towards a heritable component in mood reactivity to daily hassles, which has allso been found in the reacrivity of the HPA axis (Holsboer et al., 1995).

A few limitations of the study should be noted. With respect to the clinical assessments, all SCID interviews were administered by the same person, so that reliability of the diagnosis of MDD cannot be directly evaluated. However, given that the full SCID was administered by an experienced psychiatrist in a specialized affective disorder outpatient clinic, and that severity of the current episode was confirmed by HRSD and BDI data, it seems improbable that many patients were misdiagnosed. Alrhough information about previous episodes and family history of mood disorders was obtained systematically, 'false negarives' cannot be rulled out; any underreporring of these clinical wariables could lead to underestimation of their effects on mood reactivity.

Sample characteristics place some constraints on generalization of results. The current MDD sample consisted of individuals presenting for outpatient rreatment at a mental health care facility, and results may not necessarily apply to depressed people in the community or in other treatment settings. The healthy comparison group differed from the MDD group in educational level and in employment status (mainly due to MDD-related work disabiliry) - sociodemographic variables that potentially influence exposure to different kinds of daily events. Their actual influence cannor be determined. However, the absence of significant weekend vs. weekday effects suggests that work-relared differences in daily actiwnty parterns or stressors are unlikely to explain the differences in mood reactivity in the two groups. Similarly, mood reactivity results were essentially unchanged after addition of educational level as a predictor in the multilevel model.

Mood and event data may also have been vulnerable to certain sources of error. Even with a time sampling approach like ESM, retrospective bias cannot be entirely ruled out. Event assessment was based on self-reports only, as there was no practical means of verifying event occurrence. The method of event assessment makes it also impossible to clarify if similar events were classified differenty (either positive or negarive) by depressed and healthy participants. This may have affected the comparison of event frequencies between the groups. Furthermore, the causal association between events and mood states cannot be firmly established, as event and mood reports 
were collected at the same points in time. Current mood levels could, for example, influence the probability of reporting positive or negative events in the preceding interval. The finding that prior events, controlling for effects of current events, were associated with persistent changes in both mood states does support our assumption that events influenced mood and not vice versa. The multilevel model used in this analysis did not allow us to test the hypothesis that current mood alters the probability dhat furure events will occur; this could be the case if, for example, high NA increased the probability of getting involved in an argument in the near furure. Finally, there may have been inaccuracies in parricipants' reports of the rimes at which they completed the ESM forms (Litt et al., 1998). Salivary corrisol measures collected at the same times as the ESM measures show clear diurnal curves (Peeters er al., 2002), suggesting that most of the participants were able to comply with the procedure most of the rime. More importantly, we have no reason to suspect that MDD and healthy participants differed in their compliance with the protocol in any way that could have systematically biased the results.

This study contributes new information about the effects of daily events on mood states in clinically depressed individuals. Results indicate thar depressed individuals responded less strongly to negative events, but exhibited larger mood responses to positive events than non-depressed individuals. Given that low PA is a key feature of mood in MDD, these findings suggest that clinical interventions focused on daily experience may be useful in elevaring posirive mood states. Future studies should address neuroendocrine responses associated with changes in mood states in depressed people. Finally, it is important to investigate whether mood reactivity normalizes following clinical recovery.

\section{Acknowledgements}

We thank Lilly Finders, Truda Driessen, and Frieda Van Goethem for research assistance. 


\section{REFERENCES}

American Psychiatric Associanon. (1994). Diagrostic and Statistical Manual of Mental Disorders (Fourth Edirion). Washington, DC. American Psychiatric Association.

Beck, A. T., Rust, A. J., Shaw, B. F, \& Emery, G. (1979). Cogmitive wherapy of dopression. New York: The Guilford Press.

Beck, A. T., Ward, C. H. \& Mendelson, M. (1961). An inventory for measuring depression. Arch Gers Psychiary, 4.561-571.

Bolger, N., Dellongis, A. Kestler, R. C., \& Schilling, E. A. (1989). Effects of daily stress on negarive mood. J Pers Soc Psychol, 57(5), 808-818.

Bolger, N., BC Zuckerman, A. (1995). A framework for studying personality in the stress process. / Pers Soc Psychol, 6915), 890-902.

Clark, D., Beck, A., \& Stewart, B. (1990). Cognitive specificity and positive-negative affectivity: complemencary or contradictory vicws on anxiery and depression? J Abmom Psychol, 99(2), 148-155.

Connor, T. J., \& Leonard, B. E. (1998). Depression, stress and immunological activation: the role of cytokines in depressive disonders. Life $S c, 62(7), 583-606$.

Coyne, J. C. (1994), Self-reporred distress: analog or Ersate depression? Pyohol Bull, 116(1), 29-45.

Coyne, J. C., Aldwin, C. \& Lazarus, R. S. (1981). Depression and coping in stressful episodes. J Abnow Psyolol, $90(5), 439-647$.

Coyne J. C., Gallo, S. M., Klinkman, M.S., \& Clarco, M. M. (1998). Effecrs of recent and past major depression and distress on self-concept and coping. / Abnorm Psychol, $107(1), 86-96$.

Csikszentmihalyi, M., \& Larson, R. (1987). Validity and reliability of the Experience-Sampling Method. J Nerv Men Dis, 17599), 526-536.

David, J. P., Green, P. J., Martin, R, \& Suls, J. (1997). Differential roles of neuroticism, exrraversion, and event desirability for mood in daily life: an integrative model of top-down and bottom-up influcnces. J Pers Soc Psychol, 73(1), 149-159.

Delespaul, P. (1995). Assessing schizophrevia in daty life, the experience sampling method. Maastricht: Uniwersity Press Maastricht.

Derogaris, L., Lipmatn, R. \& Cori, L. (1973). \$CL-90, an outparient rating scale. Preliminary report. Prychoptiontuarol Bull, 9, 542-575.

deVrics, M. (Ed.). (1992). The experiene of psyoloputhology: Investigating mental disordens in their waturat settings. Cambridge: Cambridge Uniwersicy Press.

Diener, E... Colwin, C. R. Patrot, W. G. \& Allman. A. (1991). The psychic costs of intense positiveaffect. JPers Sor Pydbol, 6l(3), 492-503.

Diener, E. \& Emmons, R. A. (1984). The independence of posirive and negarive affecr./Pers Soc Psychal, $475), 1105-1117$.

First, M. B., Spitzer, R. L., Gibbon, M., \& Willams, J. B. W. (1995). Structurad Clnical Interview for DSM-V Axis I Disorders. New York: Biometrics Research Department, New York State Psychiatric Institute.

Flete, G. L., Vredenburg, K., \& Krames, L. (1997). The continuity of depression in clinical and nondinical samples. Psychol Bull, 12/3), 395-416.

Gable, S. L., Reis. H. T., \& Elliot, A. J. (2000). Bellavional acrivation and inhibition in everyday life. $J$ Pers Soc Pyot $78(6), 1135-1149$.

Goldstein, H. Rasbash, I. Plewis, I., Draper, D., Browne, W., Yang, M., Woodhouse, G., \& Healy, M. (1998). A User'; Gude to MLwiN London: Multilevel Models Project, Institure of Educarion, University of London.

Grosscup, S. J., \& Lewinsolun, P. M. (1980). Unpleasant and pleasant events, and mood. / Clin Psychol, $36(1), 252-259$ 
Hamilon. M. (1967). Development of a raring scale for primary depressive illness. Brifibly / Pers Soc Pyychol, 6(4), 278-296.

Holaham, C. J., Moos, R. H., Holahan, C. K., \& Cronkite, R. C. (2000). Long-terin postreament funcrioning among parienrs with unipolar depression: an integrative model. f Consult Clin Pychol, $68(2)$, $226-232$.

Hoisboer. F. (2000). The corticasteroid receptor hypothesis of depression. Neuropsy bophanmasol, 236), $477-501$.

Holsboer, F., Lauer, C. J., Scheiber, W., \& Krieg, J. C. (1995). Altered hypothalamic-piruitary-adrenocortical regularion in healthy subjects at high familial risk for affecrive disorders. Neuroendowinol, 62(4), 340-347.

Jacobson, N. S., Dobson, K. S., Truax, P. A., Addis, M. E, Koerner, K., Gollan, J. K., Gonmer, E. \& Prince, S. E. (1996), A component analysis of cognitive-bchavioral reatment for depression. I Consult Clin Psychol, 64(2), 295-304.

Jolly, J. B., Murray, J., Kramer, T. A., \& Wherry, J. N. (1994). Integrarion of poxitive and negarive affecrivity and cognirive content-specificity: improved discrimination of anxious and depressive symptoms. J Abnorm Psychol, $103(3), 544-552$.

Kanner, A. D., Coyne, J. C., Schaefer, C., \& Lazarus, R. S. (1981). Comparison of two modes of stress measurement: daily hassles and uplifts versus major life events. J Beh Med, 4(1), 1-39.

Kendler, K. S., Thornton, L. M. \& Gardner, C. O. (2000), Stressful life events and previous episodes in the eriology of major depression in women: An evaluation of the "Kindling" bypothesis. Am / Pswbiatry, $157(8), 1243-1251$.

Krieg, J. C., Lauer, C. I., Schreiber, W., Modell, S., \& Holsboer, F. (2001). Neuroendocrine, polysomnographic and psychometric observations in healthy subjects at high familial risk for affective disorders: the current swate of the "Munich vulnerability study. "J Afect Disord, 62(1-2), 33-37.

Langston, C. A. (1994). Capitalizing on and coping with daily-life events: expressive responses to positive events. JPers Soc Pychol, 67, 1112-1125.

Lazarus, R. S., \& Folkman, S. (1984). Stress, appraisal, and coping. New York: Springer.

Lewinsolan, P. M. (1975). The behavioral study and rreatment of depression. In M. Hersen \& R. M. Eisler \& P. M. Miller (Eds.), Progress in behatior modifacanion (Vol. 1, pp. 19-64). New York: Academic Press.

Lewinsohn. P. M., \& Amenson, C. S. (1978). Some relations between pleasant and umpleasant mood-related events and depression. / Abnom Psychol, 87(6), 644-654.

Lier, M. Cooney, N., \& Morse, P. (1998). Ecological Momentary Assesment (EMA) with treated alcoholics: methodological problens and potential solutions. Health Psychol, 17(1), 48-52.

Maier, W., Lichtermann, D., Minges, J., \& Heun, R. (1992). Personality traits in subjecrs at risk for unipolar major depression: a family study perspective. JAffer Disond, 24(3), 153-163.

Mareo, C. A., Neale, J. M., Schwartz, J. E., Shiffman, , $_{\text {, }}$ Srone, A. A. (1999). Coping with dally events and short-term mood changes an whexpected failure to observe efects of coping I Cowsalt Clin Psychol, 67(5), 755-764.

McEwen, B. S. (1998). Prorective and damaing effects of stress mediators. N Engl/ Med, 338(3), $171-179$.

Morris, W. N. (1999). The mood system. In D. Kahneman \& E. Diener \& N. Schwar (Eds.), Well-being the foundations of hedonic psychology (pp. 169-189). New York: Russell Sape Foundarion.

Peeters, F. P. M. L. Nicolson, N. A., \& Berkhof, J. (2002). Levels and variability of daily life cortisol secrerion in major depression. (sabmitted).

Ravindran, A. V., Griffiths, J., Waddell, C., \& Anisman, H. (1995). Stressful life events and coping styles in relation to dysthymia and major depressive disorder: variarions associated with allewation of

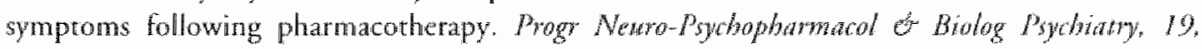
$637-653$. 
Santor, D. A. \& Coyne, J. C. (2001). Evaluaring the conninuiry of sympromatology berween depressed and nondepressed individuals. JAbnown Pychol, 1/0(2), 216-225.

Segal, Z. V., Willams. J. M., Teasdale, I. D. $8 \mathrm{c}$ Cemar, M. (1996). A cognitive science perspective on kindling and episode sensitization in recurrent affective disorder. Psychol Med, 26, 371-380.

Segerstrom, S. C., Taylor, S. E. Kemeny, M. E., \& Fahey, J. L. (1998). Optimism is associated with mood, coping, and immune change in response to stress. I Pers Soc Pychol, 746), 1646-1655.

Solomon, R. L. (1980). The opponent-process theory of acgured motivation: the costs of pleasure and the benefits of pain. Am Psychol, 35(8), 691-712.

Suls; J., Green, P., \& Hillis, S. (1998). Emorional reactivity ro everyday problems, affective inertia, and neuroticism. Pers Soe Psychol Bull, 24(2), 127-136.

Sweridsen, J. D. (1998). The helplessness-hopelessness theory and daily mood experience: an idiographic and cross-situational perspective. / Pers Soc Psychol 74(5), 1398-1408.

Swendsen, J. D., Tennen, H., Carney, M. A., Affleck, G., Willard, A.. \& Hromi, A. (2000). Mood and alcohol consumption: an experience sampling test of the self- medication hyporhesis. I Abnom Psychol, 109(2), 198-204.

Taylor, S. E. (1991). Asymmetrical effects of positive and negative events: the mobilizationminimization hypothesis. Psycbol Bull. $110(1), 67-85$.

wan Eck, M., Berkhof, H., Nicolson, N., \& Sulon, J. (1996). The effects of perceived stress, traits, mood states, and stressful daily events on salivary cortisol. Psychorom Med, 58(5), $447-458$.

van Eck, M. Nicolson, N. A. \& Berkhof, I. (1998). Effects of stressful daily events on mood stares: relarionship to global perceived stress. I Pers Soc Pyychal, 75(6), 1572-1585.

Wratkins, E., \& Teasdale, J. D. (2001). Rumination and overgeneral memory in depression: effects of self-focus and analytic thinking. / Abmom Psychol, 110(2), 353-357.

Watson, D. (2000). Mood and temperannent. New York: Guilford Press.

Watson, D., Clark, Lu, Weber, K., Assenheimer, J. S., Stranss, M., \& McCormick, R. (1995). Testing a tripartite model: II. exploring the symptom structure of anxiety and depression in student, adult, and patient samples. Abnom Psychol, 104(1), 15-25. 


\section{CHAPTER 5}

\section{Cortisol responses to daily events in major depressive disorder}

Frenk Peeters, Nancy A. Nicolson, Johannes Berkhof.

Under revision, Psychosomatic Medicine. 
Abnormal responses of the hypothalamic-pituitary-adrenal (HPA) axis to stress are thought to be involved in the pathophysiology of major depressive disorder (MDD). The aim of the present study was to determine whether cortisol responses to negative and positive daily events in depressed participants $(n=47)$ differed from such responses in healthy participants $(n=39)$. We also examined the influence of clinical characteristics and possible gender differences in cortisol responses to events. Finally, the role of mood changes in mediating cortisol responses was assessed.

Experience sampling methodology (self-reports of mood and events, with simultaneous saliva samples, 10 times each day for 6 consecurive days) and multilevel regression analysis were used to examine the relationship between events in daily life and salivary corrisol levels.

In contrast to healthy participants, depressed participants showed no increase in cortisol following negative events. Responses were even more blunted in depressed participants with a family history of mood disorders. Although the effects of negative events on cortisol responses appeared to be mediated by changes in mood, negative affecr tended to be less closely associated with cortisol levels in depressed participants. Depressed women showed larger cortisol responses to negative events than depressed men. Positive events had no effect on cortisol levels in either group.

These results suggest that responses of the HPA axis to negative daily events and mood changes are blunted in MDD. Future studies will need to address whether these abnormalities disappear after clinical recovery.

\section{INTRODUCTION}

Over the past decades, many studies have documenred that abnormalities at various levels of the hypothalamic-piruirary-adrenal (HPA) axis are involved in development and course of major depressive disorder (Holsboer, 2001; McQuade \& Young, 2000). Altered responsivity of the HPA axis to stress is thought to be one of these abnormalities. To date, normal or blunted cortisol responses to experimental stress in major depressive disorder (MDD) have been reported following exposure to surgical (Breier et al., 1988; Kudoh er al., 2000), cognirive (Croes et al., 1993; Gorthardr er al., 1995: Trestman er al., 1991) or social stressors (Heim et al., 2000; Young, Lopez er al., 2000). However, it is not clear whether responses to experimental stressors provide a valid representation of the affective and neuroendocrine processes that occur in individuals reacting to stressors in their daily lives. Studies that have addressed this issue reported non-significant correlations between cortisol responses to laboratory tasks and corrisol responses to stressful events in the field (Houtman \& 
Bakker, 1987; Lundberg et al., 1990; van Eck et al., 1996). If abnormal HPA axis responses to stress are indeed involved in the pathophysiology of MDD, they should also manifest themselves in everyday life. Therefore, the most direct test for the existence of abnormal HPA axis responsivity in MDD is the study of stress responses in the everyday environment.

Negative daily events are followed by increases in negative affecr (NA) and decreases in positive affecr (PA) (Gable et al., 2000; Marco et al., 1999; van Eck et al., 1998). Mood changes have been found to mediate cortisol responses to everyday stressors (Buchanan et al., 1999; Smyth et al., 1998; van Ecket al., 1996). Given our recent finding that changes in NA and PA following negative daily events are blunted in depressed outpatients compared to healthy subjects (Peeters et al., in press), we hypothesize that cortisol responses to such events in MDD may also be blunted.

In the psychiatric and psychological literature, much attention has been paid to affective and biological responses to negative events, whereas the effects of positive daily events have been much less intensively investigated. Posirive events are associated with lower NA and higher PA (Clark \& Watson, 1988; David et al., 1997; Gable et al., 2000; Peeters et al., 2002a). Evidence for effects of positive events on cortisol secretion is equivocal. Previous work reported decreases (Berk ex al., 1989; Hubert \& de Jong-Meyer, 1989), increases (Brown et al., 1993) or no changes (Clark et al., 2001; Hubert \& de Jong-Meyer, 1991a, 1991b) in corrisol levels following experimental induction of positive mood. Effects of positive events in daily life on cortisol have never been studied. Such knowledge is clinically potentially relevant, given suggestions that positive daily events and subsequent mood changes may act as a buffer against damaging effects of HPA axis abnormalities resulting from chronic stress and MDD (McEwen, 1998; Sapolsky, 1996).

In recent years, daily process designs such as the Experience Sampling Method (ESM) (deVries, 1992) have been shown to be valid and reliable techniques for the simultaneous assessment of events, mood, and cortisol in the natural environment (Smyth et al., 1998; van Eck et al., 1996). In this study, we used ESM to examine cortisol responses to negative and positive events in the daily lives of depressed and healthy individuals. Our first aim was to test whether cortisol responses to daily events differ in magnitude berween depressed and heal thy individuals. Secondly, abnormalities of the HPA axis in MDD have been reported to be influenced by clinical characreristics such as severity (Nelson \& Davis, 1997), length of the current depressive episode (Oldehinkel et al., 2001; Posener et al., 2000), number of previous episodes (Rybakowski \& Twardowska, 1999), and positive family history (Holsboer et al., 1995). Therefore, associations between these characteristics in depressed subjecrs and cortisol responses to events were tested. Thirdly, associations between changes in mood states and cortisol levels in both groups were investigared. Fourthly, we examined whether the influence of daily events on cortisol is mediated by mood changes. 
Finally, we tested the influence of gender on cortisol responses, as stronger responses of the HPA axis to stress have been hypothesized to contribute to the higher prevalence of MDD in women (Young \& Korszun, 1999).

\section{METHHOD}

\section{Subjects}

Forry-seven depressed subjects were recruited among patients seeking treatment at the local community mental health center or the outpatient clinic of the regional psychiatric hospital in Maastricht, the Netherlands. The main inclusion criterium was a primary diagnosis of major depressive disorder, as assessed with the Structured Clinical Interview for DSM-IV (SCID-I; First et al, 1,995) by a research psychiatrist (F.P.). The SCID-I also provides information on length of the current episode and the presence of previous episodes. Information on family history for mood disorders was also obtained. Entry was restricted to patients 18-65 years of age with a score of $\geq$ 18 on the 17-item Hamilton Depression Rating Scale (HDRS; Hamilton, 1967). Exclusion criteria were substance abuse in the last six months, psychotic symptoms, bipolar disorder, pregnancy, weight loss exceeding 15\% in the previous 6 months, endocrine and rheumatic disorders, medications (including antidepressants) known to affect the HPA axis, and insufficient fluency in Dutch. In cases where previously prescribed antidepressants were judged to be clinically ineffective, these drugs were tapered off; subjecrs were then allowed to participate in the study after a medication-free interval of at least 1 week (this applied to 5 subjects, none of whom used Aluoxetine). Use of previously prescribed low-dose benzodiazepines was allowed ( 8 subjects).

Thirry-nine healthy subjects, matched as a group to the patient sample for gender and age, were recruited from available research pools and through a local newspaper advertisement. Additional exclusion criteria for healthy subjects were a lifetime history of any DSM-IV axis-I disorder, or a history of inpatient treatment for an Axis I psychiarric disorder in a first-degree relative. The study was approved by a medical ethics commirtee, and written informed consent was obtained from all subjects.

\section{Questionnaires}

Both patienrs and healthy subjects completed the Symptom Check List (SCL-90; Derogatiset al., 1973). Patients also completed the Beck Depression Inventory (BDI; Beck et al., 1961). 


\section{Ambulatory sampling procedure}

The Experience Sampling Methodology (ESM; Csikszentmihalyi \& Larson, 1987; deVries, 1992) was used to collect data from participants at selected moments during their daily activities. Participants received auditory signals (beeps) from a wristwatch programmed to emit 10 beeps between 7:30 a.m. and 10:30 p.m. each day, at semi-random intervals of approximately 90 minutes. After receiving a beep, participants completed self-report forms concerning current mood, negative and positive events, and extraneous influences on cortisol secretion. Participants completed ESM reports for 6 consecutive days, including a weekend. During a briefing session, study aims and procedures were explained. In a final session, the ESM booklets were checked for legibility and missing data. Compliance with the procedure was generally good. The criteria set for inclusion in the analyses (more than 20 ESM reports completed within 25 minutes after the programmed time of the beep) were met by all participants except one depressed participant.

\section{Measures}

Mood assessment. Momentary mood states were assessed with 16 adjectives rated on 7 -point scales ( $1=$ not at all, $7=$ very). Factor analyses (principal components analysis with varimax rotation) on mean scores aggregated per subject and on within-subject $z$ scores identified two mood factors with eigenvalues greater than 1. These factors accounted for $81.1 \%$ of the total variance in the analysis of the subject mean scores and $46.1 \%$ of the variance in the analysis of the within-subject $z$ scores. Ratings on the items anxious, irritated, restless, tense, guilty, irritable, easily distracted, and agitated were averaged to form a negative affect (NA) scale (Cronbach's alpha $=.91$ based on 4535 reports). Ratings on the items energetic, enthusiastic, happy, cheerfwl, talkative, strong, satisfied, and self-assured were averaged to form a positive affect (PA) scale (alpha $=.95)$. Mean NA (aggregated over parricipant means) was $1.3(S D=.3)$ in healthy participants, and $2.9(S D=.9)$ in depressed participants. Mean PA levels were $4.5(S D=.9)$ and $2.1(S D=.7)$ for healthy and depressed participants, respectively.

Stressful events. At each beep, participants were asked briefly to describe any positive and/or negative event that may have taken place since the last ESM report. Although participants were instructed to report only events or situations that acrually took place in their daily environment in the preceding interval, some event reports clearly referred to internal states only (e.g., current ruminations about past events, personal health concerns). Following pre-established criteria, the research team identified such internal events by consensus. Reports of internal events were not used in the analysis to avoid confounding of event and mood measures. In the depressed 
group, $17 \%$ of all event reports referred to internal states compared to $7 \%$ in the healthy group.

Salivary contusol. At the same time $\mathrm{ESM}$ forms were being completed, subjects collected saliva with cotton Salivettes (Sarstedt). They stored new saliva samples in their home freezers at the end of each day. On the ESM forms, the following information was also obtained to control for possible extraneous influences on cortisol secretion: recent physical exertion (rated on a 7 -point scale) and any food intake, alcohol, coffee, smoking, or medication (e.g., benzodiazepines) in the interwal between the current and the previous beep. In the morning, subjects recorded the time of awakening and rated sleep quality the previous night (7-point scale).

Uncentrifuged saliva samples were stored at -20 degrees Celsius until analysis. Salivary free cortisol levels were determined in duplicate by direct radioimmunoassay, using 125 iodohistamine coupled to cortisol-3CMO. The lower detection limit of the assay was $0.33 \mathrm{nmol} / \mathrm{L}$, with mean inter- and intra-assay coefficients of variation of $8.3 \%$ and $4.3 \%$, respectively. All samples from an individual were analyzed in the same assay to reduce sources of variability. Extreme cortisol values $>44$ nmol/L) were excluded, which applied to 12 values from different individuals, and all data (38 samples) from one depressed subject who exhibited 11 extreme cortisol values.

\section{Statistical analysis}

Because the experience sampling observations are nested within days within participants, we estimated the effects of daily events, mood states, and individual characteristics on cortisol secretion with multilevel or hierarchical linear analysis, which is a variant of multiple regression appropriate for nested data. The multilevel model was estimated using the program MLwiN (Goldstein et al., 1998).

A natural log transformation of the raw cortisol values yielded an unskewed response variable. "The regression equation for cortisol at the beep level can be expressed as follows:

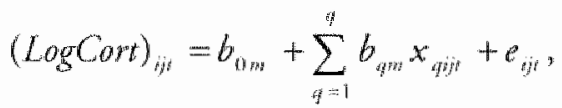

where Cort $\mathrm{ij}$ is the raw cortisol level of participanc $i$ at the $t$-th beep on day $j$. The incercept is denoted by $b_{0 m}, x_{q i j t}$ is an entry of explanatory variable $x_{q}, b_{q m}$ is the corresponding regression coefficient, and $\mathrm{e}_{\mathrm{ij}}$ is an error term. The index $m$ indicates whether the participant is depressed $(m=1)$ or healthy $(n=0)$. By indexing all regression coefficients with label $m$, we estimated all effects separately for the depressed and healthy participants. The error term $e_{i j r}$ is itself a function of error terms that capture the dependencies among the cortisol measurements. Such dependencies occur because rwo observations tend to be more similar if (a) taken at points closer in cime on 
the same day, (b) taken on the same day rather than on two different days, and (c) taken from one participant rather than from different participants. To account for these sources of dependency, we (a) modelled the autocorrelation between two subsequen observations as an exponentially decaying funcrion of the time interval berween these observations, (b) estimated day level variance to account for day-to-day variability, and (c) estimated person level variance to account for interindividual variability in cortisol levels. Ignoring these dependencies biases the estimated standard errors of the regression coefficients and may lead to incorrecr inferences abour the effecrs of the explanatory variables.

We fitted the diurnal pattern of cortisol secretion by a fourth-degree polynomial. Fixed effects estimated at the beep-level included a number of potential confounders. Of these, only the two variables with significant effects (recent awakening and food intake) were retained in the final model. The secretory peak in corrisol that occurs afrer morning awakening (Pruessner et al., 1997) was modeled by including a variable that rook the value ' 1 ' if the saliva sample was collected less than $\mathbb{1}$ hr afrer awakening, and ' 0 ' otherwise. Food intake in the interval preceding a beep was also dummy-coded. The effects of other potential confounders (beep-level: physical exertion, smoking, alcohol, coffee, benzodiazepines; day-level: self-reported sleep quality; person-level: age, use of oral contraceptives, and SCL-90 anxiety score) appeared to be not statistically significant and were excluded from the final model.

To test our main hypotheses, we included the following variables at the beep-level: negative event ( 1 if a negatiwe event had occurred, and 0 otherwise), positive event ( 1 if a positive event had occurred, and 0 otherwise), gender ( 1 if female, -1 if male), severity of depression (BDI score centered around overall mean), duration of current depressive episode (centered around overall mean), recurrent depressive episode (coded-1 or 1), and positive history for mood disorders (coded-1 or 1). To examine the influence of gender and clinical characteristics on corrisol reactivity to events, we estimated the interaction effects of daily events (both negative and positive) with these variables. In a second step, we entered the variable NA (negative affect, scaled 0-6), as well as the interactions of NA with negative and positive events.

To test the significance of the regression coefficients, $z$-scores were calculated by dividing the estimared effect by its standard error. This ratio is approximately normally distributed. We also tested whether the regression coefficients were statistically different for the parient and control group. Two-tailed tests were used even when hypotheses were directional. Significance levels were set at alpha $=.05$. 


\section{RESULTS}

\section{Subjects}

Data from 84 subjects ( 45 depressed and 39 healthy) were used, including 3861 responses with both ecological information and a cortisol level, or $76.6 \%$ of the maximum possible observations. The mean number of responses was higher in the healthy group than in the MDD group $(82.6 \%$ ws. $73.3 \% ; \mathrm{t}=2.76, \mathrm{df}=82, \mathrm{p}=$ .007). Demographic and clinical characteristics of depressed and healthy subjects are presented in Table 1.

Table 1. Demographic and clinical characteristics of depressed (MDD) and healthy subjects

\begin{tabular}{llll} 
Variable & MDD & Healthy & P \\
\hline N & 45 & 39 & \\
$\quad$ Men & 19 & 16 & .9 \\
$\quad$ Women & 26 & 23 & \\
Age (years) & $40(11)$ & $44(12)$ & .08 \\
SCL-90 total score & $261.4(53.3)$ & $1109.8(21.8)$ & $<.001$ \\
SCL-90 depression & $57.4(11.6)$ & $18.9(4.1)$ & $<.001$ \\
HDRS & $24.0(3.9)$ & - & \\
BDI & $28.6(9.9)$ & - & \\
Duration current episode (months) & $20($ range 2-120) & - & \\
Recurrent subtype & $18(40 \%)$ & - & \\
Positive family history & $25(56 \%)$ & - & \\
\hline
\end{tabular}

Note. SCL-90 scores were missing for one depressed subjecr.

\section{Frequency of daily events}

In total, 1624 events were reported during the six days, including 591 negative and 1033 positive events. Four participants ( 2 in each group) reported no events. As reported elsewhere (Peeters et al., in press), the frequency of negative events was similar in the two groups. The healthy group, however, reported more positive events.

\section{Effects of diturnal cycle, extraneous influences, and depression on cortisol secretion}

Borh groups displayed a clear diurnal patrern in cortisol secretion, with high values in the early morning declining over the rest of the day. Recent awakening and food 
Table 2. Multilevel estimates for effecrs of daily evenrs and negarive affect on corrisol lewels in depressed and healthy subjects

\begin{tabular}{|c|c|c|c|}
\hline & $\begin{array}{c}\text { Depressed subjects } \\
\beta(\text { s.e. })\end{array}$ & $\begin{array}{l}\text { Healdhy subjecs } \\
\qquad \beta(s, e)\end{array}$ & $\begin{array}{l}\text { Differmen berwen groups } \\
\beta(\text { ses) }\end{array}$ \\
\hline \multicolumn{4}{|l|}{ Model 1} \\
\hline Intercept & 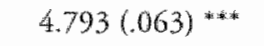 & $4.857(.117)^{\text {k:k }}$ & $-.063(.133)$ \\
\hline Negative event & $-.005(.031)$ & $.109(.028)$ & $-.114(041)^{* *}$ \\
\hline Positive event & $-.003(.030)$ & $.000(.025)$ & $-.003(.039)$ \\
\hline Gender & $-.007(.052)$ & $-.015(.054)$ & $.008(.075)$ \\
\hline Gender $x$ neg. event & $.067(.029)^{*}$ & $.029(.028)$ & $.038(.041)$ \\
\hline Gender $x$ pos. event & $-.019(.028)$ & $.019(.025)$ & $-.038(.037)$ \\
\hline \multicolumn{4}{|l|}{ Model 2} \\
\hline Intercept & $4.708(.069)^{* * * k}$ & $4.833(116)$ & $-.124(135)$ \\
\hline Negative event & $-.030(.032)$ & $.086(.029)^{* * *}$ & $-.116(.043)^{k *}$ \\
\hline Positive event & $.005(.030)$ & $-.005(.025)$ & $.000(.039)$ \\
\hline Gender & $.011(.058)$ & $-.009(.054)$ & $.020(.079)$ \\
\hline Gender x neg. event & $.071(.031)^{*}$ & $.034(.029)$ & $.036(.043)$ \\
\hline Gender x pos. event & $-.024(.028)$ & $.016(.025)$ & $-.039(.038)$ \\
\hline $\mathrm{NA}$ & $.041(.015)^{* * *}$ & $.079(.026)^{* *}$ & $-.038(.029)$ \\
\hline NAx gender & $-.003(.014)$ & $-.007(.026)$ & $.004(.029)$ \\
\hline
\end{tabular}

Note. The dependent measure is logcortisol. Estimated effects of diurnal and extraneous influences are not shown. Model 1 provides separate estimates for basal corrisoll levels (intercepe), and effects of daily events and gender. Model 2 adds estimates for negative affecr. The multilevel analysis was based on 3861 observations nested within 85 subjecrs ( 45 depressed and 39 healthy subjects).

${ }^{*} \mathrm{p}<.05,{ }^{* * *} \mathrm{p}<.01,{ }^{* * *} \mathrm{p}<.001$

intake resulted in comparable increases in cortisol levels in both groups (results not shown). In Table 2, corrisol levels are shown for depressed and healthy participants separately; differences between both groups are displayed in the last column. As can be seen in the upper half (Model 1) of Table 2, depressed participants showed no elevation in basal cortisol levels in comparison to healthy participants.

\section{Effects of daily events and mood states on cortisol secretion}

Model 1 (upper half of Table 2) estimated the influence of negative and positive events on cortisol secretion in depressed and healthy subjects. Although negative events were associated with significant cortisol increases in healthy subjects, there was 
no evidence of a cortisol response in depressed subjects. Positive events had no significant effect on cortisol levels in either group.

With respect to clinical characteristics in the depressed group, subjects with a family history for mood disorders showed additional blunting of cortisol responses ( $\beta=$ -.083 , s.e. $=.028, \mathrm{z}=2.96, \mathrm{p}<.01)$. No orher clinical characteristics significantly moderated cortisol responses.

The next model (see Model 2 in Table 2), added NA as a predictor to evaluate the effect of mood on cortisol. In general, increases in NA were associated with higher cortisol levels, with a trend towards a smaller effect in the depressed group. It should be noted that after addition of NA, the effect of negative events on cortisol were attenuated in healthy subjects. In other words, it appears that affect mediates to some extent the relationship between negative events and cortisol found in the first model.

Finally, we examined the influence of gender on cortisol reactivity. As can be seen in Model 1 in Table 2, gender did not influence basal cortisol levels, but depressed women showed larger corrisol responses to negative events than depressed men. This gender difference was not found in healthy subjects. After addition of NA in Model 2, negative events remained associated with higher cortisol levels in depressed women. However, cortisol responses to increases in NA were not dependent on gender in eilther group. Cortisol responses to positive events were similar in women and men.

\section{DISCUSSION}

This study examined salivary cortisol responses following naturally occurring events and mood changes in the daily lives of depressed outpatients. In contrast to healthy subjecrs, depressed subjects showed no increase in cortisol following negative events. Moreover, the positive association between negative affect and cortisol levels was weaker in depressed than in healthy subjects. As previously reported (Buchanan et al., 1999; Smyth et al., 1998; van Eck et al., 1996), the effects of negative events on cortisol levels appeared to be mediated by changes in NA. Positive events had no significant effect on cortisol levels in either group.

The obserwed increase in salivary cortisol following negative daily events in healthy subjects replicates earlier findings (Smyth et al., 1998; van Eck et al., 1996). Consistent with results from these studies, the corrisol responses to minor stressors were apparently mediated by associated increases in NA, as addition of NA to the model resulted in a decrease of the event effect. The reduced cortisol reactivity to negarive events observed in the depressed group requires some explanation. Previous reports of blunred corrisol responses in MDD have been linked to higher basal cortisol levels (Gotthardt et al., 1995; Trestman et al., 1991; Young, Lopez et al., 2000). In the current outpatient sample, however, basal levels were normal. Additionally, 
Trestman et al. (Trestman et al., 1991) reported a trend towards blunted cortisol responses in a subsample of remitted depressed subjects characterized by normal basal levels. The lack of corrisol response may result from blunted mood responses following negative events in depressed subjects, even though they appraise such events as more unpleasant, important, and stressful than healthy individuals (Peeters et al., 2002a). Additionally, our results showed a trend towards smaller corrisol responses after similar changes in NA in depressed subjecrs as compared to healthy subjects, which may indicate hyporesponsivity of the HPA axis to external stimuli.

Previously, we found more erratic corrisol levels in MDD (Peeters et al., 2002), but the current results indicate that these are not directly linked to daily life experiences. Cortisol responses to acute stressors are thought to be highly adaptive to the organism, ensuring physiological, affective, cognitive, and behavioral changes, followed by a rapid rerurn to homeostasis (Taylor, 1991). In this sense, blunted responses are evidence of a general dysregulation of the HPA axis in MDD (Siever \& Davis, 1985). Even greater blunting in depressed subjects with a family history of mood disorders suggests that altered responsiveness of the HPA axis may reflect a genetic vulnerabiliry; this is in agreement with previously reported generic influences on MDD related abnormalities in basal cortisol levels (Young, Aggen et al., 2000), and in feedback mechanisms of the HPA axis (Holsboer et al., 1995).

Positive events had no effect on cortisol. Results of previous studies are equivocal in this respect (see Introduction). As reported elsewhere (Peeters et al., in press), mood changes following positive events in daily life were smaller than the mood changes seen after negative events and may thus be insufficient to influence the HPA axis. Moreover, characteristics of stimuli capable of lowering cortisol are poorly understood.

Depressed women showed larger cortisol responses to negarive events than depressed men. This cannor be explained by larger mood responses following daily events, as these were similar in depressed women and men in the same sample (Peeters et al., in press). Also, the current results show that larger cortisol responses to similar changes in mood cannot be held responsible. It is possible that additional variables such as social support (Kirschbaum et al., 1995), cognitive processes (e.g., rumination; Nolen-Hoeksema et al., 1999\%, modulatory effects of gonadal steroids (Young \& Korszun, 1999), and behavioral responses (Taylor et al., 2000) contribute to the observed heightened HPA reactivity of depressed women.

This study has some limitations. Even in a time sampling approach like $\mathbb{E} S M$, retrospecrive bias cannot be entirely ruled out. Event assessment was based on self-reports only, as there was no practical means of verifying event occurrence. Secondly, the causal association between events, mood, and corrisol cannot be firmly established, as data were collected at the same points in time. However, prior events, controlling for effects of current events, were associated with persistent changes in both 
mood states, which supports our assumption that events influenced mood and cortisol and not wice versa (Peeters et al., in press). Thirdly, a small subgroup of depressed subjects used low dose benzodiazepines, which may have influenced corrisol reactivity (Checkley, 1991). This seems unlikely as we previously found no association berween benzodiazepine use and corrisol levels in this sample (Peeters et al., 2002).

The finding that small hassles and mood fluctuations in daily life influence contrisol levels differently in depressed and healthy subjects points to differences in both psychological experience and biological systems in their daily lives. More generally, our results fit well with a dysregulation hypothesis of MDD (Siever \& Davis, 1985); a dysregulated system is characterized by impairment of homeostasis, erratic output, disrupted periodicities, abnormal responsivity to environmental stimuli, slower return to basal activity after pertubation, and normalization following effecrive treatment. The clinical significance of these psychological and biological alterations for illness course and response to treatment requires further examination. Finally, future studies should investigate whether abnormal responses to daily events in MDD are normalized after clinical recovery.

\section{Acknowledgments}

The authors would like to thank Dr. J. Sulon, University of Liège, Belgium, for performing the cortisol assays, and Lilly Finders, Truda Driessen, and Frieda Van Goethem for research assistance. 


\section{REFERENCES}

Beck. A. T., Ward, C. H., \& Mendelson, M. (1961). An inventory for measuring depression. And Gen Pychiatry, 4, 561-571.

Berk, L. S., Tan, S. A., Fry, W. F., Napier, B. J., Lee, J. W., Hubbard, R. W., Lewis, J. E., \& Eby. W. C. (1989). Neuroendoctine and stress homone changes during niwhul tangher. Am $/ \mathrm{Mm} S \mathrm{C}$. $298(6), 390-396$.

Breier, A., Wolkowitz, O. M., Doran, A. R., Bellar, S., 2 Pickar, D. (1988). Neurobiological effects of Lumbar puncture stress in psychatric patients and healthy volunters. Psyohory $R e_{0}, 25,187-194$.

Brown, W. A., Sirota, A. D., Niaura, R., \& Engebretson, T. O. (1993). Endocrine correlates of sadness. and elation. Pyychosm Med. 55(5), 458-467.

Buchanan, T. W., al'Absi, M., \& Lovallo, W. R. (1999). Cortisol Auctuates with increases and decreases on negative affece. Psychonewoendoctinology, 24, 227-241.

Checkley, 5. (1991). Neuroendocrine effects of psychorropic drugs. Batleres Clin Endowinal Metab. $5(1), 15-33$.

Chark, L., Iversen, S. D., \& Goodwin, G. M. (2001). The infuence of positive and negarve mood states on risk taking, verbal fluency, and sallivary corrisol. J Affect Disord, $63(1-3), 179-187$.

Clark. L. A., \& Watson, D. (1988). Mood and the mundane: relations berween daily life events and self-reported mood. I Pers Soc Fychol. 54(2), 296-308.

Croes, S., Merz, P., \& Netwer, P. (1993). Cortisol reaction in success and failure condition in endogenous depressed patients and controls. Psychonewroendocrinology, 18(1), 23-35.

Csikszentmihalyi, M., \& Larson, R. (1987). Validityand reliability of the Experience-Sampling Merhod. JNerv Ment Dis, 175(9), 526-536.

David, J. P., Green, P. J., Martin, R. \& Suls, J. (1997). Differential roles of neuroticism, extraversion, and event desirabidity for mood in daily life: an integrative model of top down and borrom-up influences. J Pers Soc Pychot, 73(1), 149-159.

Defogatis, L, Lipman, R, \& Cori, L. (1973). SCL-90, an outpatient rating scale. Preliminary report. Psychophamacol Bull, 9, 542-575.

deVries, M. (Ed). (1992). The experience of psychopathology Inuestigating mental dironders in thet wat wal settingr. Cambridge: Cambridge University Press.

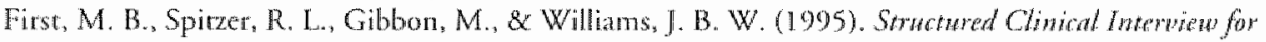
DSM-IV Axis I Dewerders. New York: Biometrics Research Department, New York Sare Psychiaric Instirure.

Gable, S. L., Reis, H. T., \& Elliot, A. J. (2000). Behawional activation and inhibition in everyday life. J Pers Soc Pryolibol, $78(6) \times 1135-1149$

Goldstein, H., Rasbash, J., Plewis, I., Draper, D., Browne, W., Yang, M., Woothouse, G. \& Healy, M. (1998). A Users Guide to MLaiN London: Mulniled Models Project, Institute of Eduation, Universiry of London.

Gothardt, U., Schweiger, U., Fahrenberg, I. Latuer C. J., Holsboer, F., \& Heuser, I. (1995). Contisul, ACTH, and cardiowascular response ro a cognitivechallenge paradigm in aging and depression. Am/ Phyrol, $268(4$ Pe 2). R865-873.

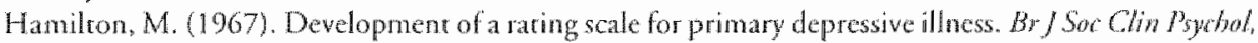
$6(4), 278-296$

Heim, C., Newpore, D. J., Heit, S., Grahan, Y. P., Wilcox, M., Bonsall, R, Miller, A. H. \& Nemerof, C. B. (2000). Piturary-adrenal and autonomic responses to stress in women after sexual and physical abuse in chilldhood. JAMA, 284(5), 592-597.

Holsboer, F, (2001). Seress, hypercortisolism and corticosteroid receptorin in depression implicatons for therapy. Affect Disond, 62(1-2), 77-91. 
Holsbor, E., Lauer, C. J. Schreiber, W., \& Krieg, J. C. (1995). Alrered hypothalamic-pituitary-adrenocortical regulation in healthy subjects at high familial risk for affectiwe disorders. Neuroendocrinolog, 62(4), 340-347.

Houman, I. L., \& Bakker, F. C. (1987). Stress in student teachers during real and simulated standardized lectures. I Human Swess, 13(4), 180-187.

Huberr, W. \& de Jong Meyer, R. (1989). Emotional stress and saliva contisol response. / Clin Chem Clin Bioclyom, 27(4), 235-237.

Hubert, W. \& de Jong-Meyer, R. (1991a). Auronomic, newroendocrine, and subjective responses ro cmation-inducing film stimuli. Int/Psychophysiol. 1/(2), 13,1-140.

Hubert, W., \& de Jong-Meyer. R. (1991b). Psychophysiological response parterns to positive and negative film stimuli, Biol Psychol, 31(1), 73-93.

Kirschbaum, C, KJauer, T., Filipp, S. H. \& Hellhanmer, D. H. (1995). Sex-specific effects of social support on corrisol and subjecrive responses to acute psychological stress. Psychosom Med, $57(1)$, $23-31$.

Kudoh, A. Ishihara, H., \& Matsuki, A. (2000). Inhibition of the contisol response ro surgical stress in chronically depressed patients. / Clin Anesth, 12(5) 383-387.

Lundberg, U., Melin, B., Fredrikson, M., Tuomisto, M. \& Frankenhaenser, M. (1990). Comparison of neuroendocrine measurements under laboratony and naturalistic conditions. Pharmacol Brochem Behav, 37(4), 697-702.

Marco, C. A. Neale, J. M., Schwarrz, J. E., Shiffman, S., \& Srone, A. A. (1999). Coping with daily events and shorterm mood changes: an unexpecred failure to observe effects of coping. $\int$ Consult Clin Psychol, 67(5), 755-764.

McExwen, B. S. (1998). Protective and damaging effects of stress mediators. N Engl) Med, 338(3), $171-179$.

McQuade, R., \& Young, A. H. (2000), Furure therapeutic targets in mood disorders the glucocorticoid receptor. Br J Psychiatry, $177,390-395$.

Nelson, J. C.. \& Davis, J. M. (1997). DST studies in psychoric depression: a meta-analysis. Am J P $3 y c h i-$ atry, 154(11), 1497-1503.

Nolen-Hoeksema, S., Larson, 1., \& Grayson, C. (1999). Explaining rhe gender difference in depressive symproms. J Pers Soc Psychol, $77(5), 1061-1072$.

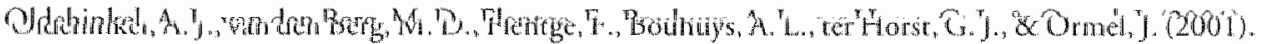
Urinary frec corrisol excretion in elderly persons with minor and majot depression. Psyliaty Ros, $104(1), 39-47$.

Peeters, I. P. M. L., Nicolson, N. A., Berkhof, J. Delespau, P., \& DeVries, M. (2002a), Effects of daily events on mood stares in major depressive disorder. J Alowom lsychol in press.

Pecters, F. P. M. L.. Nicolson, N. A., \& Berkhof, J. (2002). Levals and variability of daily life corrisol secretion in major depression. strbmitted.

Posener, I. A., DeBatrista, C. Willams, G. H., Kraemer, H. C. Kalehzan, B. M., \& Schatzerg, A. F. (2000). 24-Hour montoring of cortisol and corticotropin secrecion in psychoric and monpsychoric major depression. Arb Gen Psyiatry, 578), 755-760.

『ruessner. J. C., Wolf, O. T. Hellhammer. D. H. Buske Kirschbaum, A., von Auer, K., Jobse, S., Kaspers, F., \& Kirchbaum, C. (1997). Free cortisol levels after awakening: a reliable biological marker for the assessment of adrenocontical activity. Life Seiences, 6/(26), 2539-2549.

Rybakowski, J. K. \& Twardowska, K. (1999). The dexamethasone/corticotropin-releasing hormone test in depression in bipolar and unipolar affecrive illness. J Pychiatm Res, 33(5), 363-370.

Sapolsky, R. M. (1996). Why stress is bad tor your brain. Science, 273(5276), 749-750.

Siever. L. J., \& Davis. K. L. (1985). Overwew: roward a dysegulation hyporthesis of depression. Am J Pspchiaty, $142(9), 1017-1031$. 
Smyth, J., Ockenfels, M. C., Porter, L., Kirschbaum, C., Hellhammer, D. H., \& Stone, A. A. (1998). Stressors and mood measured on a momentary basis are associated with salivary cortisol secretion. Psychoneturoendacrimology, 23(4), 353-370.

Taylor, S. E. (1991). Asymmerrical effects of positive and negarive events: the mobilization minimization hyporhesis. Psychol Bull, $110(1), 67-85$.

Taylor, S. E, Klein, L. C., Lewis, B. P., Gruenewald, T. L., Gurung, R. A., \&c Updegraff, J. A. (2000). Biobehavioral responses to stress in females: rend-and-befriend, not fight-or-flighr. Pyochol Rev. $107(3), 411-429$.

Trestman, R. L., Coccaro, E. F., Bernstein, D., Lawrence, T., Gabriel, S. M., Horwath, T. B., \& Siever, L. J. (1991). Cortisol responses to mental asithmeric in acute and remitted depression. Brol Pyothatry, 29(10), 1051-1054.

van Eck, M., Berkhof, H., Nicolson, N., \& Sulon, J. (1996). The effects of perceved stress, tratits, mood states, and stressful daily events on saliwary cortisol. Pyychosom Med, 58(5), 44.4 458 .

van Eck, M. Nicolson, N., Berkhof, H., \& Sulon, J. (1996). Individual differences in cortisol responses to a laboratory speech task and their relationship to responses co stressful daily events. Biol Pydoht. $43(1), 69-84$

van Eck, M. Nicolson, N. A., \& Berkhof, J. (1998). Effects of stressful daily events on mood states: relationship to global perceived stress. / Per Soc Psychol, 75(6), 1572-1585.

Young, E., \& Korszun, A. (1999). Women, stress, and depression: sex differences in hypothalamic-pituitary-adrenal axis regulation. In. E. Leibenluft (Ed), Gewder differences in mood andanxich disorders (Vol. 18,3, pp. 31-52). Washington, DC: American Psychiatric Press.

Young, E. A, Aggen, S. H. Prescont, C. A., \&. Kendler, K. S. (2000). Similariry in saliva corrisol measures in monozygotic twins and the influence of past major depression. Bial Psyciriatry, 48(1),70-74.

Young, E. A., Lopez, J. F., Murphy-Weinberg, V., Watson, S.J., \& AkiJ „H. (2000). Hormonal evidence for altered responsiveness ro social stress in major depression. Newropsychophanzacology, 23(4), $411-418$. 


\section{CHAPTER 6}

Cortisol responses to a speech task in major depression and their relationship to cortisol responses to negative events in daily life

Frenk Peeters, Nancy A. Nicolson, Johannes Berkhof.

Submitted. 
Abnormal responses of the hypothalamic-pituitary-adrenal (HPA) axis to stressful stimuli are considered to be an element of the pathophysiology of major depressive disorder. Normal or blunted cortisol responses to various experimental stressful stimuli have been reported previously in clinically depressed individuals. However, no evidence exists that cortisol responses following laboratory stressors represent stress responses occurring in daily life.

The aims of the present study were to examine cortisol responses to an experimental stressor (speech task) in clinically depressed outpatients compared to healthy subjects, to investigate gender differences in both types of stress responses, and to derermine whether cortisol responses to the laboratory stressor correlate with cortisol responses to naturally occurring stressors in daily life.

We found no differences between depressed and healthy subjects in cortisol responses to the experimental stressor. Cortisol responses to the laboratory stressor were larger in men than in women. In contrast, cortisol responses to negative events in daily life were smaller in depressed than in healthy subjects, with women exhibiting larger corrisol responses than men. We found a strong correlation berween laboratory and daily life baseline cortisol levels, but no association between cortisol responses in the laboratory and cortisol responses in daily life. Multiple measurements of stress responses across a variety of daily life situations may be more appropriate for studying individual differences in stress reacriviry than responses under standarized conditions.

\section{INTRODUCTION}

The hypothalamic-pituitary-adrenal (HPA) axis is an important neuroendocrine system that is involved in tesponses of the organism to stress. Abnormal responsiviry of the HPA axis to stress is thought to play a role in the pathophysiology of major depressive disorder (Holsboer, 2001). To date, normal or blunted cortisol responses to experimental stress in major depressive disorder (MDD) have been reported following surgical (Breier et al., 1988; Kudoh et al., 2000), cognitive (Croes et al., 1993; Gotrhardt et al., 1995; Trestman et al., 1991), and social stressors (Heim er al., 2000; Young et al., 2000).

If abnormal HPA axis responses to stress are indeed involved in the pathophysiology of MDD, they should manifest themselves in daily life siruarions. Therefore, the usefulness of laboratory assessments depends on the assumption that responses to stress in the laboratory are representative of those occurring in daily life. Three studies specifically addressed the relationship between cortisol responses to psychosocial stressors in laboratory and daily life sertings (Houtman \& Bakker, 1987; 
Lundberg et al., 1990; van Eck et al., 1996); none found a significant correlation between laboratory and field tesponses. To date, no study has examined the correlation between cortisol responses to an experimental stressor and to stressors in daily life in MDD.

The present study had several aims. Firstly, we examined cortisol responses to an experimental social stressor (speech task) in clinically depressed outpatients compared to healthy subjects. Secondly, because a heightened sensitivity to stress in women has been hypothesized to contribute to the greater prevalence of MDD in women (Young \& Korszun, 1999), we rested gender differences in the laboratory cortisol response. Finally, we examined whether corrisol responses to a laboratory stressor correlate with cortisol responses to marurally occurring stressors in daily life.

\section{METHODS}

\section{Subjects}

Forty-seven depressed subjects were recruited among patients seeking treatment at the community mental health center or the outpatient clinic of the regional psychiatric hospital in Maastricht, the Netherlands. The main inclusion criterium was a primary diagnosis of major depressive disorder, as assessed with the Structured Clinical Interview for DSM-IV (SCID-I; First et al., 1995) by a research psychiatrist (F.P.). Entry was restricted to patients $18-65$ years of age with a score of $\geq 18$ on the 17-item Hamilton Depression Rating Scale (HDRS; Hamilton, 1967). Exclusion criteria were substance abuse in the last six months, psychotic symptoms, bipolar disorder, pregnancy, weight loss exceding 15\% in the previous 6 months, endocrine and rheumatic disorders, medications (including antidepressanrs) known to affect the HPA axis, and insufficient Huency in Durch. At intake, five subjects had been taking antidepressants that were judged to be clinically ineffecrive; these drugs were tapered off, and subjecrs were then allowed ro participate in the study after a medication-free interval of at least one week (none used fluoxerine). Use of previously prescribed low-dose benzodiazepines was allowed (this applied to eight subjecrs). As reported elsewhere, use of benzodiazepines had no influence on cortisol levels in our sample (Peerers et al., 2002).

Thirty-nine healthy subjects, marched as a group to the patient sample for gender and age, were recruited from the community. Additional exclusion criteria were a lifetime history of any DSM-IV axis-I disorder or a history of inpatient treatment for an Axis I psychiatric disorder in a first-degree relative. The study was approved by a medical ethics committee, and writren informed consent was obtained from all subjects. 


\section{Assessment of stress reactivity in the laboratory}

Cortisol and emotional responses to an experimental stressor were measured in the laboratory during a speech task (Stress Inducing Speech Task; SIST). Subjects were asked to prepare (10 min.) and deliver $(5 \mathrm{~min}$.) a speech concerning their best and worst personal characteristics. They were told that their presentations would be videotaped for larer analysis by a ream of psychologists. The SIST has been shown to induce cortisol elevations within 15 minutes (Nicolson et al., 1997; wan Eck et al., 1996).

The SIST took place at $10.00 \mathrm{~h}$. Saliva samples were collecred with the Salivette device (Sarstedt) before subjecrs received instructions concerning the SIST (T0), immediately after their preparation (T10), after speech delivery (T15), and four times during a recovery period in which subjects read neutral magazines (T25, T40, T60, T90).

After receiving instructions concerning the SIST, rwo depressed subjects declined to participate. The SIST was prematurely aborted by the research assistant in four depressed subjects because of strong emotional reactions. Additionally, we excluded nine (five depressed and four healthy) subjects for whom cortisol data were missing, due ro insufficient saliva in the Salivette on any of the first 4 SIST measurements.

\section{Assessment of stress reactivity in daily life}

The Experience Sampling Methodology (ESM; Csikszentmihalyi \& Larson, 1987; deVries, 1992) was used to measure cortisol responses to daily events. Participants received auditory signals (beeps) from a wristwatch programmed to emit 10 beeps between $07.30 \mathrm{~h}$ and $22.30 \mathrm{~h}$ each day, at semi-random intervals of approximately 90 minures. After each beep, participants completed self-report forms concerning current mood states and possible confounding influences (e.g., food intake) on cortisol secretion. They were also asked to describe any negative event that may have taken place since the last ESM report. At the same time, subjects collected saliva with the Saliverte device, labelling each rube with the actual time of saliva collection. Participants completed ESM reports for six consecutive days. Procedures used in this part of the study are described in detail elsewhere (Peeters et al., 2002; Peeters et al., in press).

Compliance with the ESM procedure was good. The criteria set for inclusion in the analyses (more than 20 ESM reports and associated saliva samples completed within 25 minutes after the programmed time of the beep) were mer by all participants except one depressed participant. The final dara ser included 3861 valid responses with both ecological information and a cortisol level, or $76.6 \%$ of the maxi- 
mum possible observations. A total of 591 negarive daily ewents were reported. Four participants (two in each group) reported no negative events.

\section{Biochemical analyois}

Uncentrifuged saliva samples were stored at -20 degrees Celsius until analysis. Salivary free cortisol levels were determined in duplicate by direct radioimmunoassay, using 125 iodohistamine coupled to cortisol-3CMO. The lower detecrion limit of the assay was $0.33 \mathrm{nmol} / \mathrm{L}$, with mean inter-and intra-assay coefficients of variation of $8.3 \%$ and $4.3 \%$, respectively. All samples from an individual were analyzed in the same assay ro reduce sources of variability.

Extreme cortisol values ( $>44 \mathrm{nmol} / \mathrm{L}$ ) were excluded, which applied to 12 values from different individuals; all data (38 samples) were excluded from one depressed subject with $\mathbb{1}$ extreme cortisol values.

\section{Statistical analysis}

All cortisol values were log transformed, yielding an unskewed response variable. Group and gender differences were tested with t-rests or Chi-square tests. Laboratory response (L.Response) was defined following the description of Diedrich and Gehrke (Diedrich \& Gehrke, 1992). Firstly, daily life cortisol levels at the same points in time as the first four SIST measurements (T0 through T25) were calculated for all subjects separately. This was done by computing individual regression coefficients on the basis of mean cortisoll levels over 6 days at the second $( \pm 09.45 \mathrm{~h})$ and third $( \pm 11.15 \mathrm{~h})$ ESM beep. Next, these calculared daily life cortisol levels were substracted from the observed cortisol levels during the SIST for each subject. Finally, L. Response was expressed as the regression coefficient of the differences between the observed and predicted cortisol levels. The resulting laborarory responses are independent of absolute hormone levels and rake the normal decline of cortisol levels at this time of the morning into account. Non-response to the SIST was defined as L.Response $\leq 0$. Multivariate analysis of variance for repeated measures (MANOVA) was used to test for main and interaction effecrs of the factors group (depressed vs. healthy) and gender during the entire stay in the laboratory (T0 through T90). L. Basal was included as a covariate.

As the SIST always started at $10.00 \mathrm{~h}$, basal field cortisol levels (F. Basal) were defined as the mean level over 6 days at the second daily sampling point $( \pm 09.45 \mathrm{~h})$. F. Basal was missing for two depressed subjects.

Mulrilevel regression modelling (Bryk \& Raudenbustn, 1992), a variant of multiple regression appropriate for nested data, was used for the analysis of the field corrisol data; details have been presented elsewhere (Peeters et al., 2002). Individual cortisol 
response estimates to negative events in daily life were calculated using an empirical Bayes approach (Morris, 1983). These response estimates are weighted averages of an owerall regression estimate (based on the whole dataser) and a person-specific regression estimate. Individual response scores in daily life (F.Response) were estimated after diurnal patterns and confounding factors (e.g., food intake) with significant effects on cortisol levels were controlled for in the multilevel model. Non-response in daily life was defined as $F$. Response $\leq 0$. The association between cortisol responses in the laboratory and in daily life was tested with Spearman rank-order correlations.

\section{RESULTS}

\section{Subjects}

With respect ro the experimental stress task, the final data ser included 36 depressed and 35 healthy subjects. The depressed group was composed of 20 women and 16 men, the healthy group of 21 women and 14 men (Chi-square $=1.4, \mathrm{df}=1, \mathrm{p}=.71$ ). The mean age was 39.8 years $(s . d .10 .8)$ in the depressed and 44.9 years $(s . d .11 .9)$ in the healthy group $(\mathrm{t}=1.92, \mathrm{df}=69, \mathrm{p}=.06)$. In the depressed group, six out of 20 women used oral contraceptives; in the healthy group this was six out of 21 (Chi-square $=.01, \mathrm{df}=1, \mathrm{p}=.92$ ). Mean HDRS-score in the depressed group was $23.4(\mathrm{~s} . \mathrm{d} .3 .7)$.

As a result of the exclusion procedures, the comparison between cortisol reactivity in the laboratory and in daily life was restricted to 32 depressed and 34 heall thy subjects. These groups of depressed and healthy subjects did not differ in mean age ( $\mathrm{t}=$ $1.74, \mathrm{df}=64, \mathrm{p}=.09$ ), gender composition (Chi-square $=.21, \mathrm{df}=1, \mathrm{p}=.65$ ), or use of oral contraceptives (Chi-square $=.01, \mathrm{df}=1, \mathrm{p}=.91$ ).

\section{Contisol reactivity in the laboratory}

Salivary cortisol responses to the SIST in the depressed and healthy groups are shown in Figure $\mathbb{1}$. Mean cortisol levels in daily life for the two groups, taken around $09.45 \mathrm{~h}$ and $11.15 \mathrm{~h}$, are also displayed in the figure.

The repeated measures MANOVA showed a significant change in cortisol levels during the SIST $[F(5,61)=4.32 . p=.002]$, but no difference between depressed and healthy subjects $[\mathrm{F}(5,61)=.74, \mathrm{P}=.59]$. With respect to the rime course of the response, no difference between depressed and healthy subjects was detected lime by group; $\mathrm{F}(5,325)=.39, \mathrm{p}=.771$. 


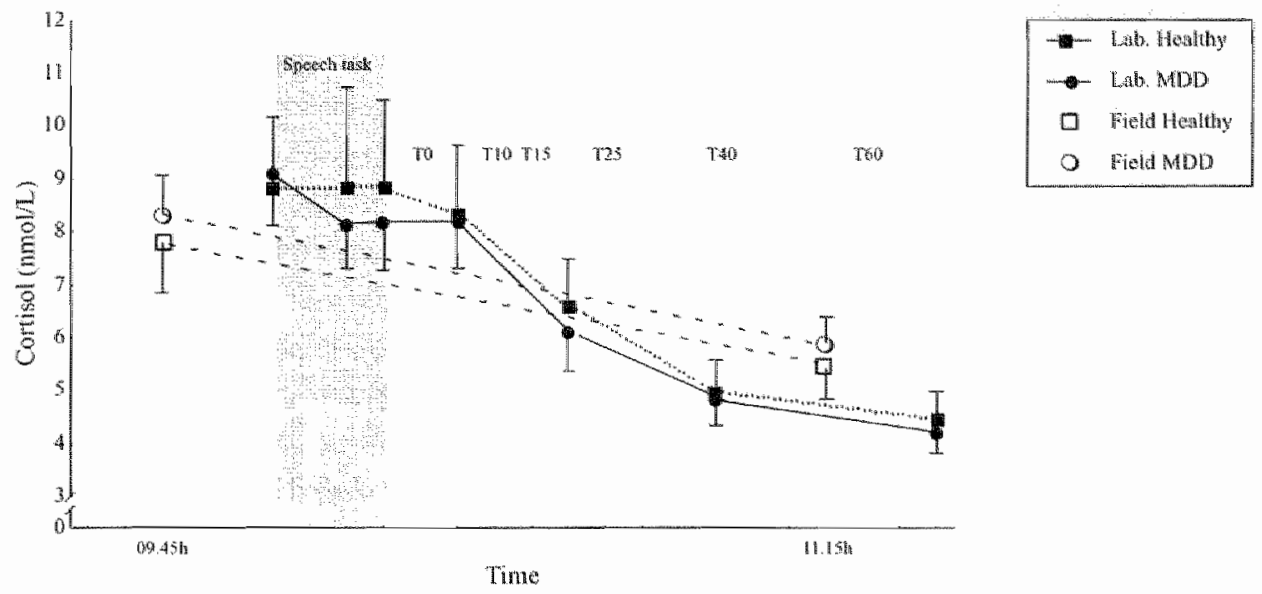

Figure 1. Mean (s.e.) corrisol levels during the SIST and daily life cortisol levels in 36 depressed (MDD) and 35 healthy subjects

Table 1 . Means $\left(s, d_{2}\right)$ of baseline and response variables in the laboratory and in dailly life for depressed (MDD) and healthy subjects.

\begin{tabular}{lll} 
& MDD & Healthy \\
\hline F.Basal (nmol/L) & $8.25(4.79)$ & $7.79(5.65)$ \\
L.Basal (nmol/L) & $8.65(5.04)$ & $8.91(7.34)$ \\
Cortisol peak response (nmol/L) & $4.12(1.39)$ & $3.66(1.59)$ \\
L.Response & $-.098(.74)$ & $-.007(.77)$ \\
F.Response** & $.038(.04)$ & $.060(.03)$ \\
\hline
\end{tabular}

Note. N's vary (from 36 to 17 in depressed and 35 to 19 in healthy subjects) due to the different exclusion procedures (see Methods). F. Basal is mean cortisol level in daily life ar \pm 09.45 h: L. Basal is cortisol level before SIST; L.Response is cortisol response un laboratory fexpressed as regression coefficient of the differences berwon observed and predicted cortisol lewels; see Merhods); F. Response is cortisol response in daily life (see Methods), ${ }^{* *} p<.01$

The main baseline and response variables in the laboratory and in daily lifeare displayed in Table 1. Baseline cortisol levels in the laboratory and in daily life were not significantly different between depressed and healthy subjects.

Depressed and healthy subjects did not differ on the L. Response measure $(\mathrm{t}=.51$. $\mathrm{df}=67, \mathrm{p}=.62$ ). Non-response to the SIST (L.Response $\leq 0$ ) occurred in 16 healthy and in 19 depressed subjects (Chi-square $=.35, \mathrm{df}=1, \mathrm{p}=.55$ ). Using a more stringent definition of 'response' (peak increment of $>2.76 \mathrm{nmol} / \mathrm{L}$; Kirschbaum \& Hellhammer, 1989), we found no difference in number of responders in the depressed $(\mathrm{n}=7)$ and healthy $(\mathrm{n}=5)$ groups (Chi-square $=.34, \mathrm{df}=1, \mathrm{p}=.56$ ). 
In the repeated measures analysis, men showed a larger response than women $[F(5,61)=2.34, p=.05]$, but no interaction effect between group (depressed vs. healthy) and gender was found $[\mathrm{F}(5,61)=.79, \mathrm{p}=.56]$. L. Response $(\mathrm{t}=2.57, \mathrm{df}=67$, $\mathrm{p}=.01$ ) were also higher in men than women. Women were more likely than men to show non-response (Chi-square $=5.29, \mathrm{df}=1, \mathrm{p}=.02$ ). Using the stringent response measure, more men $(n=9)$ than women $(n=3)$ were responders (Chi-square $=6.35$, $\mathrm{df}=1, \mathrm{p}=.01$ ).

\section{Comparison of cortisol reactivity in the laboratory and in daily life}

Cortisol levels at T0 (L.Basal) and F. Basal were highly correlated ( $\mathrm{r}=.63, \mathrm{p}<.001$ ), and did not differ significantly from each other in the combined sample $(\mathrm{t}=-.66, \mathrm{df}=$ $68, p=.51)$. L.Basal and F.Basal did not differ between depressed and healthy subjects (see Table 1). Over all subjects, the mean cortisol levels at T60 (approximally $11.00 \mathrm{~h})$ in the laboratory $(4.93 \mathrm{nmol} / \mathrm{L}$, s.d., 3.11) were significantly lower than levels taken in the field $(5.57$, s.d., 3.05) at approximately $11.15 \mathrm{~h}(\mathrm{t}=3.60, \mathrm{df}=68, \mathrm{p}$ $=.001)$. These laboratory and field cortisol levels showed a moderately strong correlation $(\mathrm{r}=.59, \mathrm{p}<.001)$.

Table 1 shows means and standard deviations of cortisol response estimares in daily life (F.Response) in the two groups. F. Response was smaller in the depressed group $(\mathrm{t}=2.91, \mathrm{df}=80, \mathrm{p}=.005)$. In contrast to the observed laboratory responses, F. Response was Jarger in women $(.056$, s.d. $=.035)$ than in men $(.038, \mathrm{~s} . \mathrm{d} .=.037 ; \mathrm{t}=$ $2.26, \mathrm{df}=80, \mathrm{p}<.01)$. Noteworthy is that in the MDD group, only three subjects showed non-response to negative events in daily life. In the healthy group, all subjects showed daily life cortisol responses. The association between non-response in the laboratory and the field was non-significant (Chi-square $=.38, \mathrm{df}=1, \mathrm{p}=.54$ ). It appears that the subjects in our sample were more likely to show cortisol responses to self-reported negative events in daily life than to a laboratory stressor.

We next examined the relationship berween cortisol responses to the SIST and individual estimates of cortisol reactivity to negative events in daily life. The correlation for the entire sample between F. Response and L. Response $(r=-.05, p=.68)$ was not significant. Even within the group of SIST-responders, no significant correlation was found berween F. Response and L. Response $(r=-.11, \mathrm{p}=.54)$. These correlarions remained non-significant when calculated for the groups of depressed and healthy subjects separately. 


\section{DISCUSSION}

The first aim of this study was to compare cortisol responses to an experimental speech task between depressed and healthy subjects. We found no differences in cortisol response between the groups, which is consistent with earler reports of responses to speech tasks (Heim et al, 2000; Younget al., 2000). With respect to the second aim, men showed larger cortisol responses than women in the laboratory, which is in line with orher studies (Kirschbaum et al., 1999; Kirschbaum et al., 1992; Nicolson et al., 1997). Our third aim was to compare cortisoli responses to the experimental stressor and naturally occurring stressors in daily life. Although the correlation between laboratory and field baseline cortisol levels was strong, we found no association becween cortisol responses to the experimental stressor and responses to stressors in daily life. In contrast with their responses in the laboratory, women showed larger cortisol responses in daily life than men.

The normal cortisol responses to a social stressor in MDD are in contrast with the blunted cortisol responses observed in depressed patients following cognitive stressors (Croeser al., 1993; Gorthardt et al., 1995; Trestman et al., 1991). One reason for this discrepancy may be that these cognitive stressor studies relied on inpatient-dominated samples, as opposed to the outpatient samples used in the speech task studies; inpatient samples tend to show more HPA axis abnormalities (Maes et al., 1994; Thase \& Howland, 1995). Additionally, tasks that contain both social-ewaluative and uncontrollable components appear to elicit larger HPA axis responses than experimental cognitive stressors in heal thy subjects (Dickerson \& Kemeny, 2002; Linden et al., 1998). Given the clinical features of MDD (e.g., difficulties in concentration and motivation, low self-esteem), it cannot be ruled out that cognitive and social experimental stressors are different types of challenges for depressed than for healihy subjects. Such a hypothesis should be tested directly in future studies.

We found a strong correlation between laboratory and daily life baseline cortisol levels, but no association between magnitude of cortisol responses in the laboratory and corrisol responses in daily life. Moreover, responses in the laboratory were larger in men than in women, but the opposite was found in field responses in the same individuals. This latter discrepancy may be explained by the effect of heterogenous variables in daily life like social support (Kirschbaum, Klauer er al., 1995), cognitive processes (e.g., ruminarion; Nolen-Hoeksema et al., 1999; Young \& Nolen-Hocksema, 2001), modulatory effects of gonadal steroids (Young \& Korszun, 1999), and behavioral responses (Taylor et al., 2000) that are thought to mediate HPA responses. Taken together, previous (Houtman \& Bakker, 1987; Lundberget al., 1990; van Eck et al., 1996) and present findings provide evidence that cortisol responses in experimental settings do not generalize ro daily life settings. This condusion is in accordance with results from cardiovascular studies, where baseline levels are found to be 
more stable than measures of reacrivity across settings (Gerin et al., 1998; Kamarck et al., 2000; Turner et al., 1994). One might expect that the validiry of laboratory stressors could be enhanced by improving their correspondence with the type of stressors encountered in daily life. However, such an approach has not yielded significant correlations between laboratory and field responses in the past (Houtman \& Bakker, 1987 ) and is restricted to the limited number of daily life stressors that can be simulated in the laboratory. Additionally, such a laboratory approach would ignore relevant event characteristics (e.g., content, severity, novelty, and duration) that are known to interacr with individual traits and previous experiences (Smyth et al., 1998; van Eck et al., 1996).

This study has some limirations. First, non-response to the SIST in this sample was relatively high and responses were fairly low compared to other studies that used the same task, but were done at a later time of the day (Nicolson et al., 1997) and only in men (van Eck et al., 1996). Cortisol responses to laboratory stressors administered in the morning appear to be lower than in the afternoon, which may explain the observed responses to the $10.00 \mathrm{~h}$ SIST (Dickerson \& Kemeny, 2002). Additionally, anticipation to and some pre-knowledge of the task may be held responsible because subjects were aware that a stressful task would be administered in the laboratory (a prerequisite for ethical approval of the study). Secondly, we obtained no information on phase of the menstrual cycle in female participants, which could have influenced cortisol responses to stress (Kirschbaum et al., 1999).

In general, responses of the HPA axis to stressors depend on the amount of distress and lack of control that is experienced by the individual (Biondi \& Picardi, 1999). Even under standarized conditions, the same stressor may be experienced differentlly by each subject, depending on the meaning the situation has for this particular individual. Daily process designs, such as ESM, focus on this subjective stress experience by an individual while interacting with the daily environment. They are highly appropriate for studying stress reactivity because they allow for aggregation of multiple measurements of stress responses across a variety of situations in the daily life of individuals. As daily stressors are often recurrent by nature, this may be another advantage over laboratory studies in which it appears necessary to repeat administration of the same experimental stressor to assess reliable individual differences in neuroendocrine responses (Gerra et al., 2001; Kirschbaum, Prussner et al., 1995; Negrao et al., 2000; Pruessner et al., 1997). Therefore, daily process designs may give more ecologically valid information about individual neuroendocrine responses. This is illustrated by the main finding of the present study: normal cortisol responses under standarized conditions did not reflect the blunted cortisol responses of depressed subjects in their daily lives. 


\section{Acknowledgements}

The authors would like to thank Dr. J. Sulon, University of Liège, Belgium, for performing the cortisol assays, and Lilly Finders, Truda Driessen, and Frieda Van Goethem for research assistance. This study was supported in part by unrestricted research grants from SmithKline Beecham Farma and Wyeth-Lederle. 


\section{REFERENCES}

Biondi, M. \& Picardi, A. (1999). Psychological stress and neuroendocrine function in humans: the last wwo decades of research. Pychother Pychosom, 68(3), 114-150.

Breier, A. Wolkowiz, O. M. Doran, A. R. Bellar, S., \& Pickar, D. (1988). Neurobiological effects of lumbar puncrure stress in psychiatric parients and healthy wolunteers. Psychiary Res. $25,187-194$.

Bryk, A. S., \& Raudenbush, 5. W. (1992). Hierarchical Linzar Madels: Applications and Data Analysis Methods. London: Sage Publicarions.

Croes, $S_{\text {., Merz, }}$., \& Netret, P. (1993). Corrisol reaction in success and failure condition in endogenous depressed parients and controls. Psychonewoendocrinalogy. 18(1), 23-35.

Csikszentmihalyi, M., \& Larson, R. (1987). Validity and reliability of the Experience-Sampling Mechod. JNew Men Dis, 175(9), 526-536.

deVries, M. (Ed.). (1992). The experience of psychopathology. Inzestigating watenal disorders in their atatual settings. Cambridge: Cambridge University Press.

Dickerson, S., \& Kemeny. M. (2002). Acute stressors and cortssal reachivity. Paper presented at the Annual conference of the American P'sychosomatic Society, Barcelona, Spain.

Diedrich, O, \& Gehrke, J. (1992). How to define an endocrine response. In C. Kirschbaum \& $\mathrm{G}$. F. Read \& D. H. Hellhammer (Eds), Asressment of homones and drugs in saliva in biobehavional research (pp. 59-64). Searte: Hogrefe \& Huber Publishers.

First, M. B., Spitzer, R. L., Gibbon, M., \& Williams, J. B. W. (1995). Smactared Clinical Interview for DSM-IVAxis / Disowders. New York: Biomerrics Research Department, New York State Psychiarric Institute.

Gerin, W., Christenfeld, N., Pieper, C., DeRafael, D. A., Su, O. Stroessner, S. J., Deich, J., \& Pickering, T. G. (1998). The generalizability of cardiowascular responses across sertings. / Pychosom Res, 44(2), $209-218$.

Gerta, G., Zaimovic, A., Mascetri, G. G., Gardini, S., Zambelli, U., Timpano, M., Raggi, M. A., \& Brambilla. F. (2001). Neuroendocrine responses to experimentally-induced psychological stress in healthy humans. Pychoneuroendocninology, 26(1), 91-107.

Gothardt, U., Schweiger, U., Fahrenberg, J., Lauer, C. J., Holsboer, F., \& Heuser, I. (1995). Cortisol, ACTH, and cardiovascular response to a cognitive challenge paradigm in aging and depression. Am J P/yyiol, 268(4 Pt 2), R865-873.

Hamilton, M. (1967). Development of at rating scale for primary depressive illness. Br / Soc Clin Psychol, $6(4), 278-296$

Heim, C., Newporr, D. J.. Her, S., Graham, Y. P., Wilcox, M., Bonsall, R., Miller, A. H., \& Nemeroff, C. B. (2000). Pituitary-adrenal and auronomic responses ro stress in women afrer sexual and physical athuse in childhood. JAMA, 284(5), 592-597.

Holsboer, F. (2001). Srress, hypercortisolistn and corricosteroid receptors in depression: implicatons for therapy. J Afor Divond, $62(1-2), 77-9)$.

Hourman, I. L., \& Bakker, F. C. (1987). Stress in student teachers during real and simulated standard. ized lectures. J Human Stwess, 13(4), 180-187.

Kamarck, T. W., Detski, T. T., \& Manuck, S. B. (2000). Enhancing the laboratory-to-life generalizability of cardiovascular reacrivicy using multiple occasions of measurement. Pychophyziolog, 37(4), 533-542.

Kirsohbaum, C. \& Hellhammer, D. H. (1989). Salivary corrisol in psychobiological research: an overview. Newtopsyobotioger, 22(3), 150-169.

Kirschbaum. C. Klaucr, T.. Filipp. S. H. \& Hellhammer, D. H. (1995). Sex-specific effects of social support on cortisol and subjective responses to acute psychological stress. Psworom Med, $57(1)$, $23-31$. 
Kirschbaum, C., Kudielka, B. M. Gaab, J., Schommer, N. C. \& Hellhammer, D. H. (1999). Impact of gender, menstrual cycle phase, and oral contraceprives on the activity of the hyporthatamus-piruitary-adrenal axis. Psychosom Med, 6l(2), $154-162$.

Kirschbaum, C., Prussner, J. C., Stone, A. A., Federenko, I., Gaab, J., Lintz, D. Schommer. N., \& Hellhammer, D. H. (1995). Persistent high cortisol responses to repeared psychological stress in a subpopularion of healthy men. Psychosom Med, 57(5), 468-474.

Kirschbaum, C., Wust, $S$., \& Hellhammer, D. (1992). Consistent sex differences in cortisol responses to psychological stress. Psysbowm Med, 54(6), 648-657.

Kudoh, A., Ishihara, H., \& Matsuki, A. (2000). Inhibirion of the cortisol response to surgical stress in chronically depressed pariencs. J Clin Anesth, 12(5), 383-387.

Linden, W., Rutledge, T., \& Con, A. (1998). A case for the usefulness of laboratory social stressors. Amm Behal Med, 20(4), 310-316.

Lundberg, U., Melin, B, Fredrikson, M., Tuomisto, M., \& Frankenhaeuser, M. (1990). Comparison of neuroendocrine measurements under laboratory and naturalistic condirions. F\%ownacol Bioctem Belsav, 37(4), 697-702.

Maes, M., Calabrese, J., \& Meltzer, H. Y. (1994). The relevance of the in-versus oupatient status for studies on HPA- axis in depression: spontancous hypercortisolism is a feature of major depressed inparients and nor of major depression per se. Progr Newropsychophamacol Brol Psydhutry. $18(3)$, $503-517$.

Morris, C. (1983). Parametric empirical Bayes inference: theory and applications. / Am Stat Ass, 78 , $47-65$.

Negrao, A. B., Deuster, P. A., Gold, P. W., Singh, A. \& Chrousos, G. P. (2000). Individual reactivity and physiology of the stress response. Bioned Pharmatowher, 54(3), 122-128.

Nicolson, N., Storms, C., Ponds, R., \& Sulon, J. (1997). Salivary cortisol levels and stress reacrivity in human aging. / Gerontol A. Biol Soi Med Sci, 52(2), M68-75.

Nolen-Hoeksema, S., Larson, J. \& Grayson, C. (1999). Explaining the gender difference in depressive symptoms. J Pers Sor Psychol, $77(5), 1061-1072$.

Peerers, F. P. M. L., Nicolson, N. A., \& Berkhof, J. (2002). Levels and wariability of daily life cortisol secretion in major depression. subwitted.

Peeters, F. P. M. L. Nicolson, N. A., Berkhof, J., Delespaull, P., \& DeVries, M. Effects of daily evenus on mood states in major depressive disorder. J Abnorm Psychol, in press.

Pruessner, J. C., Gab, J., Hellhammer, D. H., Lintz, D., Schommer, N., \& Kirschbaum, C. (1997). Increasing correlations berwen personality trairs and cortisol stress responses obrained by dara aggregation. Psychoneuroendocinology, 22(8), 615-625.

Smyth, J., Odkenfels, M. C., Porter, L., Kirschbaum, C., Hellhammer, D. H., \& Stone, A. A. (1998). Stressors and mood measured on a momencary basis are associated with salivary cortisol secterion. Psychoneuroendocrinology, 23(4), 353-370.

Taylor, S. E. Kein, L. C., Lewis, B. P., Gruenewald, "T. L., Gurung, R. A., \& Updegraf, J. A. (2000). Biobehavional responses to stress in females: rend-and-befriend, not fighror-flight. Pyothot Rev. $107(3), 411-429$.

Thase, M. E., \& Howland, R. H. (1995). Biological processes in depression: an updated revicw and incegration. In E. E. Beckham \& W. R. Leber(Eds), Aandhook of depression (pp. 213-279). New York: Guilford Press.

Tresman, R. L, Coccaro, E. F., Bernstein, D., Lawrence, T. Gabriel, S. M. Horvah, T. B., \& Sicver, L. J. (1991). Cortisol responses to mental arimmetic in acure and remitred depression. Bhol Psydhatry. $29(10), 1051-1054$.

Turner, J. R., Ward, M. M. Gellnan, M. D. Johnston, D. W. Lighr, K. C.. \& wan Dooren, L. I. P. (1994). The relationship beween laboratory and ambularory cardiovalscular activity: current ovidence and furure directions. Ann Behat Med. $16(1), 12-23$. 
wan Eck, M., Berkhof, H. Nicolson, N., \& Sulon, J. (1996). The effects of perceived stress, raits, mood states, and stressul daly ewents on salivary cortisol. Pyolosom Med, 58(5), 447-458.

warl Eck, M., Nicolson, N., Berkhof, H., \& Sulon, J. (1996). Individual differences in cortisol responses to a laboratory specth task and their relationship to responses to stressful daily events. Biol Pyychol, $43(1), 69-84$.

Young, $\mathrm{E}_{\mathrm{b}}$ \& Korszun, A. (1999). Women, stress, and depression: sex differences in hypothalamic-piruitary-adrenal axis regulation. In E. Leibenluft (Ed), Gender differences in mood and anxiety disorders (pp. 31-52). Washington, DC: American Psychiatric Press.

Young. E. A., Lopez, ). F., Murphy-Weinberg, V., Watson, S. J., \& Akil, H. (2000). Hormonal evidence for altered responsiveness to social stress in major depression. Nearopsychophamatalogy, 23(4). $411-418$.

Young, E. A, \& Nolen-Hoeksema, $\$$, (2001). Effect of ruminations on the saliva corrisol response to a social stressor. Pyydonetiroendocrinology, 26(3), 319-329. 


\section{CHAPTER 7}

\section{Dynamics of mood and cortisol in} depression: conclusions, general discussion, future directions, and final remarks 


\section{CONCLUSIONS}

The study described in this dissertation addressed the dynamics of mood and cortisol in the daily life of depressed outpatients in comparison to healthy participants with the use of the Experience Sampling Merhod. Both basal patterns of mood and cortisol as well as their teactivity to daily events were examined. Finally, reactivity of cortisol to an experimental stressor was assessed to determine wherher responses to experimental stressors provide a valid representation of the neuroendocrine processes that occur in individuals reacting to stressors in their daily lives. The main conclusions of the study can be summarized as follows.

- Mood in depressed outparients was characrerized by low levels of positive affect (PA) and high, fluctuating levels of negative affect (NA). Mood in healthy subjects was characterized by high $P A$, together with low and more stable levels of NA. Daily PA levels showed a circadian rhythm in all subjects, but an increase in PA levels throughout the day was only present in the depressed subjects (Chapter 2).

- Basal cortisol levels in depressed outpatients were not elevated, but could be characterized as more erratic, especially in patients with more severe and recurrent depressive episodes (Chapter 3).

- Responses of NA and PA to negative events in depressed subjects were blunted. In contrast, decreases in NA and increases in PA following positive events were larger in depressed than in healthy participants (Chapter 4).

- Cortisol responses to negative daily events were blunted in depressed subjects, despite the absence of elevated baseline cortisol levels. Positive daily events did not influence cortisol levels in either depressed or healthy individuals (Chapter 5).

- Cortisol responses to a speech task in the laboratory did not generalize to cortisol responses to stressors in daily life. This held for both healthy and depressed subjects (Chapter 6).

\section{GENERAL DISCUSSION}

\section{The dynamics of mood states in major depressiwe disorder}

Building on previous research (for reviews see; Cacioppo et al., 1999; Watson et al., 1999), the differentiation of mood states in terms of NA and PA dimensions, instead of the unidimensional approach used in previous studies, appeared useful in characterizing MDD (Chapters 2 and 4). Loss of interest in normally pleasant activities (one of the characteristic features of MDD) is most likely PA-related, whereas distressing feelings like anxiety, restlessness, and irritation are probably reflected in high and 
more variable NA. It appears that increases in PA are involved in the global improvement in mood during the day that can be seen in clinical pracrice.

Previous research has shown that the low PA in MDD may be related to decreased dopaminergic merabolism in brain structures such as the left prefrontal cortex and the anterior cingulate cortex (Depue et al., 1994; Tomarken \& Keener, 1998; Depue \& Collins, 1999; Kring \& Bachorowski, 1999; Drevets, 2001; Naranjo et al., 2001). The high levels of NA appear to be associated with heightened activation of the amygdala and the right prefrontal cortex in MDD (LeDoux, 2000; Drevets, 2001; Davidson et al., 2002; Drevets et al., 2002). Thus, further support for the distinction berween PA and NA comes from studies into the neurobiological regulation of mood.

The daily process design used in this study also allowed for the examination of mood responses following negative and positive events. The results (Chapter 4) refure, in part, the general opinion that depressed people are less responsive to environmental stimuli; although this appeared to be true for negarive events, responsiveness to positive events was enhanced. The greater mood responses following positive events in MDD may reflect a heightened sensitivity of the behavioral facilication system (BFS; see Chapter 2) to rewarding effects of environmental stimuli. This surprising result is in line with the recent finding that improvements in mood after psychopharmacological stimulation with dextroamphetamine are larger in depressed subjects than in healthy volunteers (Tremblay et al., 2002). Apparently, the BFS in MDD is highly responsive to borh environmental and chemical stimuli.

One may wonder why depressed subjects, given this heightened mood reacrivity to positive events, do not engage more often in activities that could lead to positive events. In an extensive review, Cacioppo et al (1999), present evidence for different modes of evaluative activarion of affective processes. They argue that in low activation states individuals are more motivared to PA-related approach than to NA-related avoidance. This phenomenon is known as "positivity offset" and is thought to stimulate the organism to learn "about novel or neutral-appearing environments and their potential reward value" (Cacioppo et al., 1999; p. 847). However, in states characterized by higher levels of negative affect, individuals exhibit a "negativity bias." In such circumstances, negative in formation or negative events receive more weight than positive information or positive events. This negativity bias may explain why depressed individuals, experiencing high NA and low PA, do not engage more in positive activities that could induce more normal affective stares.

\section{The dynamics of cortisol in major depressive disorder}

Based on the findings from this and others studies, an erratic parrem of cortisol secretion appears to be a more widespread and core feature of HPA dysregulation in MDD than hyperactivity per se. The current results (Chapter 3 and 5) indicate that this 
erratic activity is not solely driven by mood lability or responses to daily stress. The exact mechanism underlying this alteration in HPA function requires future clarification. Cortisol is the end producr of a very complex endocrine system involving many neural structures. Increased variability in cortisol secretion represents one form of HPA dysregulation, but it is not known how this is related to abnormalities at other levels of the axis (e.g., secretion of corticotropin-releasing hormone, vasopressin, adrenocorticotropin, and cortisol receptor sensitivity). The mechanism underlying increased variability in corrisol secretion must still be elucidated. As indicated in Chapter 3 , erratic cortisol release may be the result of a fundamental disturbance of circadian regulatory processes or more pulsatile episodes in cortisol secretion (Yehuda et al., 1996; Deuschle er al., 1997). Currently, it is thought that contemporary antidepressants and drugs that specifically targer HPA function, for example by inhibiting cortisol biosynthesis or antagonizing $\mathrm{CRH}$ receptors, normalize dysfunction of the HPA axis. Although it is generally assumed that hypercortisolemia is a prominent feature of HPA dysfunction in MDD, this appears not to apply to outpatient samples. As antidepressants are known to be effective in depressed outpatients, future studies will need to examine whether clinical remission following psychopharmacological treatment is associated with normalization of erratic cortisol secretion instead of normalization of hypercortisolemia.

As described in Chapter 5, corrisol responses to negative daily events were blunted in depressed subjects, despite the absence of elevated baseline cortisol levels. This finding contradicts the hypothesis that cortisol levels will rise in response to stressful conditions in MDD as a result of deficient feedback capacity (Checkley, 1992, 1996; O'Brien, 1997). Because mood appears to mediate cortisol responses to daily stressors (Chapter 5), it seems plausible that blunted cortisol responses to negative events in MDD reflect the blunted mood responses decribed in Chapter 4 . It is important to note, however, that the effects of negative events in the healthy subjects remained significant after inclusion of $\mathrm{NA}$ as a predictor in the multilevel model; this suggests that factors in addition to changes in self-reported affect are involved in cortisol responses. Positive events had no effect on corrisol levels in either group. Taken together, the results from Chapters 4 and 5 indicate that both mood and corrisol responses to daily events in MDD are abnormal.

\section{Cortisol responses in the laboratory and in daily life}

In Chapter 6, cortisol responses to a speech task in the laboratory were described. In contrast to the results for daily events, these responses appeared to be similar in depressed and healthy subjects. Corrisol responses to the speech task were larger in men than in women; in daily life, however, women showed larger cortisol responses 
to stressors than men. The correlation between cortisol responses in the laboratory and in daily life was low and non-significant.

The divergence of laboratory and field findings for cortisol reactivity may be due to some extent to methodological limitations, such as a relatively high non-response to the laboratory task and assessment of laboratory cortisol responses during the morning. However, the failure ro find any relarion between these two measures of cortisol reactivity does underscore some of the conceptual limitarions of experimental stress procedures. Laboratory experiments do not capture the heterogeneiry of stressful experiences in daily life and characteristics of events (like severity, novelry, and duration) that are known to influence cortisol responses. Stress experiments in the laboracory are useful in the sense that (1) they can serve as a model to build and test hypotheses, and (2) they allow for the measurement of additional parameters (e.g., AMRI). However, their ecological validity should not be assumed, but should be rested whenever possible.

\section{Dysregulation of mood and cortisol as an important characteristic of major depressive disorder}

A brain-behavior model that can entirely encompass and explain the enormous body of knowledge regarding major depressive disorder is still lacking. Although the transition into an episode of major depression can be understood as an adaptation to internal or environmental changes (Nesse, 2000), the many abnormalities in biological, behavioral, affective and cognitive domains indicate that an episode of MDD of significant severity should be understood as maladaptive. One of the major characteristics of this maladaptation may be dysregulation. Almost two decades ago, Siever and Davis (Siever \& Davis, 1985) postulated dysregulation of neurotransmitter systems to be the main characteristic of MDD, rather than sheer hyper-or hyponctivity of such systems. According to these authors, a dysregulated system is chatacterized by (1) impairment of homeostasis, (2) erracic output, (3) distupted periodiciries, (4) abnormal responsivity to environmental stimuli, (5) slower return to basal acriviry after pertubation, and (6) normalization following effective trearment. The dynamics of mood and cortisol in the daily life of depressed subjects seem ro sarisfy the criteria of a dysregulated system. The implications of this dissertation's findings in trems of a dysregulation hyporhesis are summarized below.

1. A dysregulated system is impaired in one or more regulatory or homeostatic control mechanisms. Siever and Davis $(1985 ;$ p. 1019$)$ argue that homeostasis ensures "that the system is appropriately responsive to incoming information" and " permits the system to adapt efficiently to shifts in internal organismic needs and external stimuli." The HPA axis is a classic example of a homeostatic system, with 
many feedback loops ensuring an equilibrium with a certain range around a set-point. As discussed in Chapter 3, hypercortisolemia is not a consistent finding in MDD; elevated, normal, and even decreased cortisol levels have been reported. It may well be that HPA function in MDD is best not examined in terms of too much or too little activity, but should be approached as a system with an unstable homeostaric equilibrium. The enormous research literature on alterations in feedback mechanisms in the HPA axis in MDD (e.g., dexamethasone suppression test) attests clearly to the impaiment of homeostaric control.

The homeostatic control of mood also appears to be impaired. The ser-points for NA and PA are clearly altered in cases of unipolar depression. However, every experienced clinician in the field of mood disorders will readily acknowledge the presence of 'better days," or even pronounced mood swings within episodes of MDD. Calls for better detection of bipolar type 2 disorders, which have higher prevalence rates than previously thought (Hirschfeld et al., 2000), and the introduction of the concept of bipolar spectrum disorders (Akiskal, 1996) point to the clinical significance of homeostatic control of mood in the affective disorders.

2. A dysregulated system shows signs of more erratic basal output. Such instability can also become evident with multiple measurements. Current results (Chapter 3) indicate that cortisol secretion in MDD is indeed more erratic. It can be hypothesized that aspects of vulnerability (e.g., familial loading, early adversity) combine with clinical characteristics (e.g., severity, recurrence) to produce a spectrum of HPA disturbances in MDD, perhaps progressing over time towards more severe forms. Subtle changes in HPA axis function, like those observed in the current outpatient sample, may be one of the first manifestations of dysregulation.

The langer variability in NA in depressed subjecrs may be a sign of erratic mood regulation, as it did not appear to be driven by external factors like stressful daily events. Whether the PA levels should be considered as more erratic is questionable. The (beep level) stability of PA levels in the depressed compared to the control group can hardly be called erratic. The increasing levels of PA during the day in depressed subjects, on the orher hand, suggest an alteration in the basal regulation of this mood state.

3. A dysregulated system is characterized by disturbances in normal periodicities. Numerous studies have shown abnormalities in the circadian thythm of the HPA axis in MDD, a finding paralleled by disturbances in circadian rhythms of sleep, body temperature, other hormones and neurorransmitters. Although analysis of circadian rhythm in cortisol secretion was not possible, and the sampling interval of roughly 90 minutes in the current study did not yield sufficient resolution for identifying pulsatile episodes, we found a significant difference between the shapes of the esti- 
mared diurnal cortisol curves between depressed and healthy subjects. This finding can be considered as indicarive of abnormal periodicicy.

Alterations in mood regulation are well known in MDD; both global improvement and deterioration of mood during the day is a common phenomenon in many depressed parients (Leibenluft et al., 1992; Gordijn et al., 1994). The finding of a change in the diurnal temporal partern in PA, bur nor in NA, in depressed subjects (Chapter 2) indicates that a disturbance in normal periodicity of mood regulation is most likely PA-related.

4. A dysregulated system is less selectively responsive to environmental stimuli. In Chapters 4 and 5 , responses of mood and corrisol to daily events were shown to differ from those in healthy subjects. Negative events were followed by blunted responses of mood states and no changes in cortisol levels. The larger mood responses to posirive events in depressed subjects are more difficult to reconcile with a dysregulation hypothesis, unless one broadens the concept of 'less selective responses' to both blunted and enhanced responses.

5. A dysregulated system shows slower return to basal activity following pertubation. As no clear cortisol responses to negative events were observed in depressed subjects, we found no evidence for slower declines in cortisol responses after negative events in MDD.

Based on cognitive and neurobiological theories, we expected that changes in NA following negative events would persist longer in depressed subjects; this was indeed the case. One can speculate that more evidence for delayed recovery of mood emerges if mood dynamics were studied over other time intervals than those in this study.

6. Effective treatments normalize the dysregulation. It is not known whether the disturbances of mood and cortisol regulation described in this dissertation normalize following clinical remission or recovery. As the depressed participants in this study were reassessed 18 months after study inclusion and intervening treatment, this question can be tested in the near future.

As far as the possible etiology of this dysregulation is concerned, many questions remain unanswered. It is very attractive and logical, but at the same time highly speculative, to consider the involvement of well-known distal and proximal risk factors for MDD in the development of dysregulation. Although beyond the scope of this dissertation, some general possibilities will be briefly outtined. Firstly, genetic influences may be involved, as cortisol secretion and mood regulation have been shown to be partially under generic control (Wust et al., 2000; Myin-Germeys et al., 2001). Secondly, early developmental factors could modify the funcrion of the HPA axis and 
mood regulation. There is growing evidence that HPA responses to stressors in adultthood are al trered by the experience of adversity in earlier life-stages (Heim et al., 2001; Meyer et al., 2001 ). It is not known whether such experiences influence mood regulation later in life; however, the strong association between early adwersiry and the development of a borderline personaliry disonder, typically characterized by affective instability (Koenigsberg et al., 2002), suggests that such a relationship may well exist. Thirdly, significant life events and chronic difficulties may play a role in the development of dysregulation of the HPA axis and mood. It should be noted, however, that a recent study indicates that stress-related HPA dysregulation does not necessarily lead to MDD (Strickland et al., 2002). This finding suggests that HPA dysregulation must interact with other factors; the development of an episode of MDD is best described within a more complex model of distal and proximal risk factors (Ormel et al., 2001). Finally, depression itself should be considered as a contributing factor to dysregulation. The so-called 'scar' and 'kindling' hypotheses predict that a prior history of MDD will lead ro enduring changes in biological, psychological, and interpersonal processes. In Chapter 3 , a positive association between previous episodes of MDD and erratic cortisol secretion was reported. It is possible that HPA axis dysregulation persists between episodes (Zobel et al., 2001) or is more quickly reactiwated by internal or external stressors in individuals with a prior history of MDD, thereby increasing their risk for relapse and recurrence.

\section{FUTURE DIRECTIONS}

The present study has provided a number of new insights into the dynamics of mood and cortisol in the daily life of depressed individuals. However, many questions remain unanswered. Fucure research is needed to address the following issues:

1. It is not clear whether the parterns observed in a current episode of MDD will normalize upon clinical recovery. Furure analysis of ESM and cortisol data collected 18 months after the initial study in a large subgroup of the original depressed participants will help answer this question. Furthermore, it will be possible to examine whether particular patterns in the daily dymamics of mood and cortisol during the index episode are predictive of subsequent clinical course during follow-up.

2. If the observed abnormalities indeed normalize following clinical improvement, it would be worthwile to use ESM to document the temporal patterns of change in the dynamics of mood and corrisol during the phase of acute treatment. Although one might ideally sample subjects continuously for at least 6-8 weeks, repeated sampling with the use of more practical timeframes (e.g., every other week for three days) may be sufficient. Such a detailed daily life study can address the following topics: 
- The order and pace of normalization of the dynamics of mood and corrisol during the process of remission. Such knowledge can potentially contribute to a better understanding of the nature of treatment resistance, which is generally still described only in terms of absence of changes in scores on rating scales. Evidence exists that NA and PA become less independent under conditions of high arousal; perhaps this is also true in an episode of MDD (Zautra et al., 1996; Zautra et al., 2002). It may be that an increase in $P A$ is only possible after a decrease in $N A$, but that true remission is conditional upon such an increase in PA. If this hypothesils is correct, treatment strategies designed to promore this sequence in mood changes could be developed.

- Some literarure indicates that different treatments are associared with different pathways to remission and may even be related to differences in cognirive (Thase et al., 2000), interpersonal (Weissman \& Markowitz, 1994), and biological funcrioning (Brodyet al., 2001; Martin et al., 2001) during remission. A derailed analysis of the temporal patterns in affective, endocrine, and behavioral changes in the process of remission following different treatments may increase knowledge about the mechanisms underlying their efficacy.

- In future studies, it may be possible to test whether the dynamics of mood and cortisol in MDD are related to distal and proximal risk factors. A model integrating known risk factors could be developed to test such potential relations.

\section{FINAL REMARKS}

In addition to other studies (deVries, 1992; Delespaul, 1995; Myin-Germeys, 2001; Barge-Schaapveld $\&$ Nicolson, 2002), the present study shows the importance of daily life studies in the field of psychopathology. The results described in Chaprers 4 , 5 , and 6 indicate that studying depressed people in their daily environment can yield different results than conventional questionnaire studies.

The results of the present study also contribute to a controversy in the research literarure on mood disorders. Much of the research in the field of mood disorders is carried out in distressed, but not clinically depressed samples (often referred to as 'analog' populations). The underlying assumption in such 'analog' studies is that similar psychological and/or biological processes operate along a continuum from distress or neuroticism through clinical depression. The limitations and advantages of this approach have been debated extensively (Coyne, 1994; Flett et al., 1997). The results on mood responses following events may serve as an example. Previous research reported larger NA responses to negative daily events in neurotic or distressed individuals (Suls et al., 1998; Swendsen, 1998; van Eck et al., 1998). A larger decrease in PA in response to negative events was found in individuals who reported greater perceived. 
stress (van Eck et al., 1998). One might therefore expect to find even larger mood responses to negative events in individuals with MDD, as they are known to score high on scales measuring neuroticism. Contrary to this expectation, the blunted mood responses in MDD (Chapter 4) suggest that findings from 'analog' populations cannot simply be extended to depression. The experience of mild depressive feelings or transient distress is likely to differ from that of symptoms such as severe anhedonia, farigue, cognitive dysfunctions, and suicidality that characterize MDD (Santor \& Coyne, 2001). Differences between distressed and clinically depressed populations thus appear to be nor only quantitative, but also qualitative. "The current results underscore the necessity of investigating stress reactivity in MDD in clinically depressed samples, despite the practical difficulties involved in such studies.

In concluding this dissertation, I have asked myself what I have learned, as a clinician, from rhis daily life study. The results were frequently surprising and sometimes counterintuitive. During my first years in clinical practice as a psychiatrist, I started to think of depression as a "disorder of isolation" because of the alienation that depressed people experience from their direct environment and from their normal selves. During the last two years, I discussed some of the results with patients who had participated in the study. Based on these discussions, the term "living on the edge" was added to my personall and qualitative view of depression. Depressed people are more or less constantly trying to maintain a balance: a balance between too much withdrawal from and too much interaction with their daily environment. My patients taught me that some of the results in this dissertation reflect a careful maintenance of this balance. For example, I was told that certain situations were perceived as positive (events) at the outset, but could easily turn into negative siruations when they became too complex or too strenous. Many person-environment interactions in daily life have lost their casualness for depressed people, forcing them into states of heightened vigilance. To translate the results back into a more clinical framework, depressed outpatients experience low levels of positive engagement with their environment and high levels of distressing emotions like anxiety, restlessness and irritation. The high and variable NA levels in depressed patients don't appear to be closely tied to environmental factors. This disconnection between subjective experience and environment may explain the general sense of doom and foreboding that is so often expressed by depressed people. It makes intuitive sense that small negarive events have a minor (mood) or no (corrisol) influence on people who are already experiencing higher levels of distress; small hassles are not likely to be of great influence or worth responding to. Even their bodies seem to tell us so, as can be deducted from the absence of cortisol responses. Strong and immediate responses to such small events are most beneficial for healthy people in order to return to their normal homeostasis with high levels of well-being. 
One can only speculate about the clinical consequences of erratic cortisol secretion in MDD. Cortisol is known to induce cognitive dysfunctions, mood decre-. ments, and disturbances of sleep and appetite (Holsboet, 2000). The erratic cortisol secretion perhaps further contributes to feelings of discomfort and to the vague somatic complaints that are experienced by so many depressed people (but that are largely ignored in today's psychiatry; Parker er al., 2001).

It was recently shown in healthy subjects that posirive emorions have a unique ability to speed recovery from negative emotions and that this ability only surfaces in the context of negative emotional arousal (Fredrickson et al., 2000; Fredrickson \& Joiner, 2002). The finding that positive events buffered the effects of negative events most clearly in depressed participants (Chapter 4) can be seen as indirect support for the experimental results of Frederikson et al. One can speculate (and hope) that this 'undoing effect' of positive experiences is particularly strong in depressed people, and is an affective representation of an intrinsic restorative capability. Fortunately, such capability can be witnessed in daily pracrice as many depressed people manage to cope with and/or recover from their depression.

In the introduction of this dissertation, I expressed my astonishment about the paucity of daily life studies in depression. Although daily process studies are very demanding for participants and researchers alike, the results of this study do show the value of studying depressed individuals in their daily environment. One can only hope that this study challenges other researchers to integrate experimental, laboratory-based approaches and epidemiological approaches with daily life studies in depression. Such integration can help to build a truly bio-psycho-social model of MDD, increase our understanding about how hypothetical pathophysiological processes manifest themselves in daily life, and help to bridge the gap between scientific research and clinical practice. 


\section{REFERENCES}

Akiskal, H. (1996). The prevalene clinical spectrum of bipolar disorders: beyond DSM-IV. J Clin Psychoptarwatal, $16(2($ Suppl 1$)), 45-14 \mathrm{~s}$.

Barge-Schapweld, D. Q. C.M., \& Nicolson, N. A. (2002). Effects of antidepressant treatment on the quality of daily life: an experience sampling study. J Chin Psyctiatry, 63(6), 477-485.

Brody, A. L, Saxena, S., Stoessel, P., Gillies, L. A. Fairbanks, L. A., Aborzian, S., Phelps, M. E., Huang, S. C, Wu, H. M., Ho, M. L., Ho, M. K. Au, S. C., Maidment, K., \& Baxter, L. R. Jr. (2001). Regional brain metabolic changes in patients with major depression treated with eirher paroxetine or interpersonal therapy: preliminary findings. Arch Gen Psychiatry, 58(7), 631-640.

Cacioppo, J., Gardner, W., \& Bernston, G. (1999). The affect system has parallel and integrative processing components: form follows funcriona. / Pers Soc Psychol $76(5), 839-855$.

Checkley, S. (1992). Neuroendocrine mechanisms and the precipitation of depression by life events. BrJ Psychiatry Siapd(15),7-17.

Checkley, S. (1996). The neutoendocrinology of depression. Int Rev Psychiatry, 52(8), 373-378.

Coyne, J. C. (1994). Self-reported distress: analog or Ersarz depression? Psychol Bull, 116(1), $29-45$.

Davidson, R. J., Pizzagalli, D., Nitschke, I. B., \& Putnam, K. (2002). Depression: perspectives from affective neuroscience. Annu Rev Psychol, 53, 545-574.

Delespaul, P. (1995). Assessing schizopisenia in daly life; the experience sampling method. Maastrichn: University Press Maastricht.

Depue, R. A. \& Collins, P. F. (1999). Neurobiology of the structure of personality: dopamine, facilitation of incentive motivation, and extraversion. Behav Brain Sci, 22(3), 491-517; discussion $518-469$.

Depue, R. A. Luciana, M., Arbisi, P., Collins, P., \& Leon, A. (1994). Dopamine and the structure of personality: relation of agonist-induced dopamine activity to positive emorionality. J Pers Soc Psychol, $67(3), 485-498$.

Deuschle, M., Schweiger, U., Weber, B., Gotthardt, U., Korner, A., Schmider, J., Standharde H., Lammers, C. H., \& Heuser, I. (1997). Diurnal activity and pulsarility of the hypothalamus-pituitary-adrenal system in male depressed patients and healthy controls. I Clin End Metabol, 82(1), $234-238$.

deVries, M. (Ed.). (1992). The expertence of psychopahology: Investigating mental disorder in thet natwal settings. Cambridge: Cambridge University Press.

Drevets, W. (2001). Neuroimaging and netropathological studies of depression: implicarions for the cognuive emotional fearures of mood disorders. Curr. Opin. Neurobiot, 11, 240-249.

Drevets, W. C., Price, ]. L., Bardget, M. E. Reich, T., Todd, R. D., \& Raichle, M. E. (2002). Glucose metabolism in the amygdalin in atepression: Relationship to diagnostic subrype and plasma corrisol

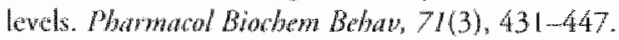

Flen, G. L., Vedenburg, K., \& Krames, L. (1997). The continuity of depression in dinical and nondinical samples. Pygchol Bull, 121(3), 395-4116.

Fredrickson, B. L., \& Joiner, T. (2002). Positive emotions trigger upward spirals toward emotional well-being. Psychol Sor, 13(2), 172-175.

firedrickson, B. L., Mancuso, R. A., Branigan, C., \&c Tugade, M. M. (2000). The Undoing Effect of Posirive Emortons. Motwation and emonion, 24(4), 237-258.

Gordijn, M. C., Beersma, D. G., Bouhuys, A. L., Reinink, E., \& Van den Hoofdakker, R. H. (1994). A longitudinal study of diurnal mood wariation in depression; characteristics and significance. $J$ Affet Disord, $3 r(4), 261-273$.

Heim, C., Newport, D. J., Bonsall, R., Miller, A. H., Be Nemeroff, C. B. (200I). Alrered pituitary-adrenal axis responses ro provocative challenge rests in adult survivors of childhood abuse. Am f Psyctiatioy, 158(4), 575-581. 
Hirschfeld, R. M., Williams, I. B., Spirzer, R. L., Callabrese, J. R., Flynn, L., Kedk, P. E, Jr, Lewis, L., McElroy, S. L., Post, R. M., Rapport, D. I. Russell, J. M., Sachs, G. S. \& Zajecka J. (2000). Development and validation of a screning instrument for bipolar specrum disorder: the Mood Disorder Questionnalre. Am J Psychiatry, 157(11). 1873-1875.

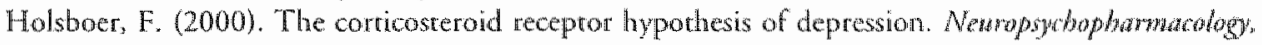
$23(5), 477-501$.

Koenigsberg, H. W., Harvey, P. D., Mitropowlou, V., Schmeidler, J., New, A. S., Goodman, M., Silverman, J. M., Serby, M., Schopick, F., \& Siever, L. J. (2002). Characterizing affective instability in borderline personality disorder. Am / Psydiany, 159(5), 784-788.

Kring, A., \& Bachorowski, ]. (1999). Enotions and psychoparhology. Cognition and emotion, 13(5), $575-599$.

LeDoux, J. E. (2000). Emotion circuits in the brain. Amm Rew Newosc, 23, 155-184.

Leibenluft, E., Noonan, B. M., \& Wehr, T. A. (1992). Dimrnal variation reliability of measurement and relationship to typical and atypical symptoms of depression. J Affeo Disord, 26(3), 199-204.

Martin, S. D., Martin, E., Rai, S. S., Richardson, M. A. \& Royall, R. (2001). Brain blood thow changes in depressed pariens reated with interpersonal psychotherapy or venlafaxine hydrochloride: preliminary findings. Arch Gen Psycliatry, 58(7), 641-648.

Meyer, S. E., Chrousos, G. P., \& Gold, P. W. (2001). Major depression and the siress system: a life span perspective. Dev Psychopatool, 13(3), 565-580.

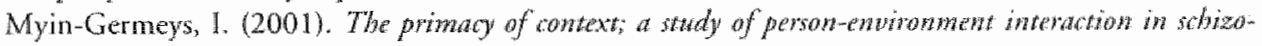
phrenia., Ph. D. Dissertation, Maastricht.

Myin-Germeys, 1., van Os, J., Schwarz, J. E., Stone, A. A., \& Delespatil P. A. (2001). Emotional reactivicy ro daily life stress in psychasis. Arch Gen Psychiatry, 58(12), 1.137-1144.

Naranjo, C. A., Tremblay, L. K., \& Busro, U. E. (2001). The role of the brain reward system in depression. Prog Newropsychophammacol Biol Pychatry, 25(4), 781-823.

Nesse, R. M. (2000). Is depression an adaprion? Arch Gen Psychiary, 57, 14-20.

O'Brien, J. T. (1997). The 'glucocorticoid cascade' hyporhesis in man, Br / Psychotry, 170, 199-20L.

Ormel, J., Oldehinkel, A. J., \& Brilman, E. I. (2001). The interplay and eriological continuity of neuroticism, difficultries, and life events in the eriology of major and subsyndromal, first and recurrent depressive episodes in later life. Aw / Psychiamy. 158(6), 885-891.

Parker, G., Gladstone, G., \& Chee, K. T. (2001). Depression in the planer's largest ethric group: the chinese. Am J Psychatry, $158(6), 857-864$.

Santor, D. A., 8x Coyne, J. C. (2001). Evaluating the continuty of sympromatology berween depressed and nondepressed individuals. J Almom Psychol, 11002$), 216-225$.

Siever, L. J., \& Davis, K. L. (1985). Onerview: toward a dysregulation hypothesis of depression. Amf Psphiaty, 1429$), 1017-1031$.

Strickland, P. L. Deakin, J. F., Percival, C., Dixon, J., Gater, R. A., \& Goldberg, D. P. (2002). Bio-social origins of depression in the communiry: Interactions between social adversicy, contisol and serotonin neurotransmission. Br/ Pychiatry, $180(2), 168-173$.

Suls, J. Green, P., \& Hillis, S. (1998). Emotional reactivity to everyday problems, affective incrial, and netroricism. Pers Soc Psychol Bull, 24(2), 127-136.

Swendsen, J. D. (1998). The helplessness-hopelessness theory and daily mood experitence an idiographic and cross-sircuational perspecive. J Pers Sor Psychol, 74(5), 1398-1408.

Thase, M. E., Friedman, E. S., Berman, S. R., Fasickka, A. L.. Lis, J. A. Flowland, R. H., \& Simons, A. D. (2000). Is cognurive behavior therapy just a 'nonspecific' intervention for depression? A retrospective comparison of consecutive cohorts treated with cognitive behavior therapy or supportive counseling and pill placebo. J Affect Disord, 57(1-3), 63-71.

Tomarken, A., \&eener, A. (1998). Frontal brain asymmetry and depression: a self-regulatory perspecrive. Cogmiton and emotion, $12(3), 387-420$. 
Trenblay, L. K., Naranjo, C. A. Cardenas, L. Hermann, N., 最 Busro, U. E. (2002). Probing brain reward system funcrion in major depresswe disorder: allered response to dexcroampheramine. Arh Gen Pyodiatin, 59(5), 409-416.

van Eck, M., Nicolson, N. A., \&c Berkhof, J. (1998). Effects of stressful dailly evernts on mood stares; relationship to global perceived stress. J Pers Soc Psychol 75(6), 1572-1585.

Waison, D., Wiese, D., Vaidya, J., \& Tellegen, A. (1999). The rwo general activation systems of affect: Strucrural findings, evolutionary considerations, and psychobiological ewidence / Pers Soc Psychol. $76(5), 820-838$.

Weissman, M.x \& Markowitz; J. (1994). Interpersonal Psychotherapy; current status. Arch Gen Psychiatry, 5I, 599-606.

Wust, S., Federenko, I., Hellhammer, D. H., \& Kirschbaum, C. (2000). Genetic facrors, perceived chronic stress, and the free cortisol response to awakening. Psychonewroendocrinology, 25(7). $707-720$.

Yehuda, R. Teicher, M. H. Trestman, R. L., Levengood, R. A., \& Siever, L. J. (1996). Cortisol regulation in postraumatic stress disorder and major depression: a chronobiological analysis. Biot Psychim atry, 40,79-88.

Zautra, A., Berkhof, J., \& Nicolson, N. (2002). Changes in affect interrelations as a funcrion of stressful evenrs. Cagnition and emotion, 16(2), 309-318.

Zautra, A., Potter, $\mathbb{P}$., \& Reich, J. (1996). The independence of affects is context-dependent an integrative model of the relationship berween positive and negative affecr. Ann Rev Gerontol Geriatr.

Zobel, A. W., Nickel, T., Sonntag, A., Uhr, M., Holsboer, F., \& Ising, M. (20011). Cortisol response in the combined dexamethasone/CRH test as predictor of relapse in patients with remitted depression. a prospective study. J Psychiatr Res, 35(2), 83-94. 


\section{SUMMARY}

Major depressive disorder (MDD) is one of the most prevalent psychiatric disorders. Most patients suffering from MDD are outpatients and try to deal with their psychiatric complaints in their natural environment. However, the vast majority of depression research is carried out in laboratories whereas daily life research is very scarce. The studies described in this thesis, were conducted with the aim of investigating the dynamics of mood and cortisol in depressed patients in their daily lives.

The Experience Sampling Methodology (ESM) was used to assess 47 clinically depressed outpatients and a comparison group of 39 healthy individuals in their daily environment. All participants received auditory signals (beeps) from a wristwatch programmed to emit 10 beeps between 7:30 a.m. and 10:30 p.m. each day, at semi-random intervals of approximately 90 minutes. After receiving a beep, participants completed self-report forms concerning current activities and mood states, and were asked to describe and appraise briefly any positive and/or negative event that may have taken place since the last ESM report. Participants completed ESM reports for 6 consecutive days, including a weekend. While completing the self-report forms, participants collected saliva samples for cortisol determination. Additionally, a laboratory stress test (a speech task) was included, to examine the association between stress responses in the laboratory and in daily life.

Chapter 1 describes the theoretical background of the study. It is argued that not much is known about patterns of mood states and corrisol secretion, and the relationship between daily events, mood, and determinants of neuroendocrine dysregulation in depressed patients in their natural environment. By addressing these topics in currently depressed and heallhy individuals, the present study was designed to fill some gaps in the theoretical models linking stress to MDD. The study addressed five main topics; (1) patterns of mood states, (2) cortisol secretory patterns, (3) reactivity of mood states to daily events, (4) cortisol responses to daily events, and (5) a comparison of cortisol responses to experimental stress wirh cortisol responses following daily life stress.

Basal patterns of mood in daily life are described in Chapter 2. Previous studies of mood changes have relied on a unidimensional concept of mood. However, research into the dimensionality of mood has provided evidence for the existence of two relatively independent mood states; negative affect (NA) and positive affect (PA). The aim of this chapter was to determine whether daily levels and inter-and 
intraindividual variability of NA and PA in depressed outpatients differed from healthy individuals. NA levels were higher and more variable, whereas PA levels were lower in the depressed subjects in comparison to heal thy subjects. NA levels showed a (slight) decline throughout the day in both groups. The pattern of diurnal variation in $P A$ in depressed subjects included an increasing function with an inverted U-shape. Daily PA levels in healthy subjects included an inverted U-shape only.

In Chapter 3, basal corrisol levels in daily life in depressed and healthy participants are examined. Although more severe symptoms were associated with small elevations in cortisol levels, there was no clear evidence for hypercortisolism in MDD outpatients. MDD was characterized by a more erratic pattern of basal cortisol secretion, especially in patients with more severe or recurrent episodes. A chaotic pattern of corrisol secretion may be a more central feature of HPA axis dysregulation than elevated levels, especially in MDD outpatient populations.

Chapter 4 describes the changes in NA and PA following minor negative and positive events in MDD compared to healthy participants. Contrary to expectation, MDD participants did not report more frequent negative events, although they did report fewer positive events and appraised both types of events as more stressful. Multilevel regression showed that both NA and PA responses to negative events were blunted in the MDD group, whereas responses to positive events were enhanced. NA responses to negative events persisted longer in $\mathrm{MDD}$. Depressed participants with a positive family history or longer current episode showed relatively greater NA responses to negative events.

The corrisol responses following negative and positive daily events are described in Chapter 5. In contrast to healthy participants, depressed participants showed no increase in cortisol following negative events. Responses were even more blunted in depressed participants with a family history of mood disorders. Although the effects of negative events on cortisol responses appeared to be mediated by changes in mood, negative affect tended to be less closely associated with cortisol levels in depressed participants. Depressed women showed larger cortisol responses to negative events than depressed men. Positive events had no effect on cortisol levels in either group. These results suggest that responses of the HPA axis to negative daily events and mood changes are blunted in MDD.

The aims of Chapter 6 are to examine cortisol responses to an experimental stressor (speech task) in clinically depressed outpatients compared to healthy subjects, to investigate gender differences in both types of stress responses, and to determine whether cortisol responses to the laboratory stressor correlate with cortisol responses to naturally occurring stressors in daily life. There were no differences between depressed and healthy subjects in cortisol responses to the experimental stressor. Cortisol responses to the laboratory stressor were larger in men than in women. In contrast, cortisol responses to negative events in daily life were smaller in 
depressed than in healthy subjects, with women exhibiting larger cortisol responses than men. The correlation between laboratory and daily life baseline cortisol levels was strong, but there was no association between cortisol responses in the laboratory and cortisol responses in daily life. Multiple measurements of srress responses across a variery of daily life situations may be more appropriate for studying individual differences in stress reactivity than responses under standarized conditions.

Chapter 7 summarizes and discusses the main research findings, and attempts to integrate the results into a general framework. More specifically, the results are discussed in terms of the dysregulation hyporhesis of MDD. Finally, directions for future studies are outlined. 



\section{SAMENVATTING}

De depressieve stoomis is een van de meest voorkomende psychiatrische aandoeningen. Veruit her groorste gedeelte van de mensen die aan een depressie lijden, zijn niet opgenomen en leiden zo goed en kwaad als her gaat hun dagelijkse leven. Opvallend genoeg is er echrer nog maar heel weinig onderzoek verricht bij depressieve mensen tijdens hun dagelijkse bezigheden in hun eigen dagelijkse omgeving. Het onderzoek dat in dit proefschrift wordt beschreven, is met name gericht geweest op het beloop van de sremming en de dagelijkse productie van cortisol (een belangrijk stresshormoon in her menselijk lichaam) bij depressieve mensen in hun gewone dagelijkse leven. Her onderzoek is uitgevoerd met de Experience Sampling Methode (ESM). Proefpersonen kregen een horloge dar gedurende 6 dagen 10 maal per dag een alarmsignaal gaf waarna de proefpersonen in een klein boekje steeds vragen over stemming, bezigheden en kleine gebeurtenissen moesten beantwoorden. Ook namen ze tijdens her beantwoorden van de vragen bij zichzelf een speekselmonster af (met een watje) waarin later de hoeveelheid cortisol werd bepaald.

In hoofdstuk I zijn de theoretische achtergronden van het onderzoek beschreven. Het afgelopen decennium wordt er in onderzoek naar stemming in toenemende mate gebruik gemaakt van een onderscheid in negatief affect (NA) en positief affect (PA). NA is een verzamelnaam voor gevoelens van onwelbevinden zoals angst, nervositeit en boosheid. PA is een reflectie van de mate van verbondenheid met de omgeving; het wordr gemeten met begrippen als enthousiasme en alertheid. In vergelijking met gezonde mensen, ervaren depressieve mensen een NA hoog niveau (veel angst en nervositeit) en een laag PA niveau (weinig enthousiasme en alertheid). Veranderingen in onze dagelijkse stemming zijn een normaal verscluijnsel. Deze veranderingen zijn onderhevig aan schommelingen in het basale verloop van stemming gedurende de dag en worden eveneens beinvloed door gebeurtenissen die zich tijdens de dag voordoen. Hoe de niveau's van NA en PA over de dag varieren bij depressieve mensen in vergelijking mer gezonde mensen is niet bekend.

Bij depressie is niet alleen de stemming verstoord, maar zijn er ook tal van afwijkingen in lichamelijke processen. Een van deze lichamelijke processen is de hypothalamus-hypofyse-bijnier as (HPA-as). De HPA-as is een belangrijk onderdeel van de reactie van het menselijk lichaam op (psychologische) stress; van stress (bijwoorbeeld ingrijpende levensgebeurtenissen) is bekend dar her bij hiervoor 
kwetsbare mensen kan leiden tot een depressie. Tevens zijn er in eerder onderzoek in laboratoria bij depressieve mensen afwijkingen in het functioneren van de HPA-as gevonden. Een van de meest gerapporteerde afwijkingen is een verhoogde afgifte van cortisol (hypercortisolemie). In samenhang met deze hypercortisolemie, wordt verondersteld dat de reactie van depressieve mensen op stress (bijvoorbeeld vervelende kleine gebeurtenissen in her dagelijks leven) afwijkend is; dit zou zich dan kunnen uiten in een afwijkende productie van cortisol na dergelijke gebeurtenissen. Over de cortisol productie in her dagelijks leven van depressieve mensen is echrer weinig bekend.

Het onderzoek dat in dit proefschrift staat beschreven, betreft vijf onderdelen; (1) basale stemmingspatronen, (2) basale cortisolproductie, (3) reactiviteit van stemming op dagelijkse gebeurtenissen, (4) cortisol reacties op dagelijkse gebeurtenissen en (5) een vergelijking tussen cortisol reacties op een stresserende taak in her laboratorium en cortisol reacties op stress in her dagelijks leven.

In hoofdstuk 2 is het beloop van NA en PA in het dagelijks leven van depressieve mensen onderzocht. Depressieve mensen hadden een hoger en meer varierend NA niveau, terwijl hun PA niveau lager was in vergelijking met gezonde mensen. Beide groepen vertoonden een kleine daling van NA gedurende de dag. PA vertoonde in beide groepen een duidelijk dagpatroon met lagere waarden aan het begin en het einde van de dag. Alleen bij depressieve mensen bleek er tevens sprake van een srijgende lijn in PA waarden. De duidelijke verschillende patronen in NA en PA zowel binnen de groepen als tussen de twee groepen maken duidelijk dat onderzoek naar stemming in de dagelijkse omgeving een zinvolle aanvulling kan zijn op bestaande onderzoeksmethoden.

Het onderzoek naar de dagelijkse afgifte van het stresshormoon cortisol bij gezonde en depressieve mensen is beschreven in hoofdstuk 3. In tegenstelling tot onderzoek bij opgenomen patiënten, blijkt er bij pariënten in hun dagelijks leven geen sprake van een verhoogde cortisolafgifte. De cortisol afgifte bleek bij depressieve pariënten echter grilliger dan bij de gezonde proefpersonen. Deze grilligheid was binnen de patiëntengroep nog groter bij diegenen die meer ernstig depressief waren en bij degenen die reeds eerder een depressie hadden doorgemaakt. Verdere analyses maakten duidelijk dar de grillige cortisolproductie bij de depressieve mensen niet werd veroorzaakt door veranderingen in de stemming of het gevolg waren van reacties op negatieve dagelijkse gebeurtenissen; ze lijken dus niet direct aan stemming of stress gerelateerd, maar wijzen wellicht op een autonome ontregeling van de HPA-as bij depressie.

De veranderingen in NA en PA na kleine negatieve- en positieve gebeurtenissen in her dagelijks leven bij de beide groepen zijn het onderwerp van hoofdstuk 4 . Het was allereerst opvallend dat er door de depressieve mensen niet meer negatieve gebeurtenissen dan door de gezonde mensen werden gerapporteerd. Het aantal 
gerapporteerde positieve gebeurtenissen was bij de depressieve mensen echter lager. Zowel de NA als PA veranderingen na negatieve gebeurtenissen waren bij depressieve mensen kleiner dan bij de gezonde deelnemers; de stemming verandert dus minder bij de depressieve mensen na negatieve gebeurtenissen. De verhoging van NA na negatieve gebeurtenissen bleef bij depressieve mensen wel wat langer bestaan. $\mathrm{Na}$ kleine positieve gebeurtenissen waren de veranderingen in NA en PA bij depressieve mensen groter; hun stemming verbeterde relatief meer in vergelijking tot gezonde mensen.

In hoofdstuk 5 worden de cortisolreacries na her optreden van dagelijkse gebeurtenissen bij depressieve en gezonde mensen vergeteken. In tegenstelling tor de gezonde mensen, traden er bij de depressieve mensen geen verhogingen van het corrisol gehalte op na negatieve gebeurtenissen. De stijging van het cortisolgehalte bleek deels samen te hangen met de NA verhoging na de negatieve gebeurtenissen. Binnen de groep depressieve mensen, bleken de cortisol reacties op negarieve gebeurtenissen bij vrouwen groter dan bij mannen. Positieve dagelijkse gebeurrenissen gingen bij geen wan de groepen gepard mer veranderingen in her cortisolgehalte.

In hoofdstuk 6, zijn de cortisolreacties tussen de depressieve en gezonde mensen tijdens een stressvolle taak in een Jaboratorium met elkaar vergeleken. Dit onderzoek bood tevens een gelegenheid om de mate van overeenstemming re onderzoeken tussen cortisolreacties in het laboratorium en in her dagelijks leven. De cortisolreacties in het laboratorium waren in beide groepen gelijk. De basale cortisol niveau's in het laboratorium en in het dagelijks leven vertoonden een grote mate van overeenstemming, maar er werd geen overeenstemming gevonden tussen de cortisolreacties op stress in het laboratorium en in het dagelijks leven. Dit betekent dat onderzoek naar cortisolreacties na stress in het laboratorium waarschijnlijk weinig kennis opleveren over dergelijke reacties in het dagelijks leven.

In hoofdstuk 7 zijn de belangrijkste conclusies van het onderzoek nog een keer samengevat en wat uirgebreider besproken. De bevindingen wan her onderzoek passen deels bij een al wat oudere theorie, die stelt dat de regulering wan diverse systemen bij depressie verstoord is. Een dergelijke dysregulatie kan worden opgevar als een verstoring van de aanpassing van het organisme aan interne (bijwoorbeeld een ziekte) en exrerne (bijvoorbeeld stressvolle levensomstandigheden) veranderingen. Verder onderzoek zal duidelijk moeten maken in hoeverre de afwijkingen in stemming en cortisol zoals beschreven in dit proefschrift, verdwijnen nadat de depressie is opgeklaard. Daarnaast zal verder onderzoek verricht moeten worden naar oorzakelijke mechanismen van deze afwijkingen in stemming en cortisol bij depressie. 



\section{DANKWOORD}

Proefschriften zijn vaak het resultaat van de inspanningen van velen en dit proefschrift is hierop geen uitzondering. I $\mathrm{k}$ ben dan ook dank verschuldigd aan heel veel mensen.

Allereerst bedank ilk de mensen die me een inkijk in hun dagelijks leven en wat speeksel hebben willen geven, in het bijzonder diegenen die dat hebben gedaan in een moeilijke periode van hun leven. Vaak gaven pariënten toestemming met de toevoeging dat ze hoopten dat de kennis over depressie er wat groter van zou worden; ik hoop dat ik hun vertrouwen niet heb beschaamd.

Mijn promotor, Marten deVries, dank ik voor de kans die hij me geboden heeft om me te ontwikkelen van klinicus tor klinische wetenschapper/werenschappelijke klinicus. Al halverwege de jaren ' 80 zouden we in Boston "iets" samen doen; het is er uiteindelijk in Maastricht van gekomen. Terwijl ik me de afgelopen jaren concentreerde op de details en de cijfertjes, heb je me gelukkig steeds herinnerd aan de grote lijn, me uitgedaagd 'lateraal' te blijven denken en de klinicus in me aangesproken. Wat mij berreft gaan de discussies door.

Ik had me geen betere co-promotor kunnen wensen dan Nancy Nicolson. Met grote bewondering en respect kijk ik terug op je begeleiding. Ik mocht bouwen op jouw idee voor dir onderzoek en kon alrijd ("Nancy, even een vragge") een beroep doen op je scherpzinnigheid, kennis en ervaring. Tevens wil ik je danken voor de lessen in wetenschappelijk schrijven. I schik me in de gedachte dat ik echter nooit jouw niveau van duidelijk en nauwkeurig formuleren zal bereiken. Ik hoop dat we verder gaan werken aan alles wat nog in de kast ligt.

Het proefschrift was nooit afgekomen zonder Hans Berkhof, die her merendeel van de statistische analyses heeft verricht. Onze samenwerking is een schoolvoorbeeld van multidisciplinair onderzoek; in eindeloos veel telefoontjes en e-mails hebben we een 'taal' ontwikkeld war we allebei mee uit de voeten konden en die me over de grenzen van mijn vakgebied heen hielp. Heel veel dank voor het beschikbaar stellen van je scherpe brein, je creativiteit in het bedenken van statistische oplossingen voor mijn argeloze vragen, voor je eindeloze geduld, voor de vele uren vrije tijd die je hebt opgeofferd en het plezier dar we hebben gehad.

Lilly Finders heeft als onderzoeks-assistente bijna alle gegevens verzameld. Dank voor je enthousiasme, flexibiliteit, de sigaretten en de koffie. Het werd erg stil op onze kamer na je vertrek naar Amsterdam. Truda Driessen heeft de daraverzameling 
vlekkeloos voltooid. Frieda van Goethem was de stille kracht die de enorme hoevelheid data in de computer heeft weten te krijgen. Jose Sulon in Luik heefr de cortisol bepalingen in de speeksel monsters gedaan en onthaalde me steeds gastvrij als ik weer een lading buisjes kwam afleveren. Rob Havermans heeft geholpen mer het formeren van onze gezamelijke groep gezonde proefpersonen. Ik thad in Philippe Delespaul een fantastische kamergenoor; een 'godfarher' van ESM, compurerexpert, Klinicus en pratpaal verenigd in één persoon. Mijn andere collega's bij de sectie Sociale Psychiarrie en Psychiatrische Epidemiologie ben ik dank verschuldigd voor het plezier, de discussies, hand- en spandiensten en een stimulerend onderzoeksklimaat.

Mijn collega's bij de RIAGG Maastricht en op de polikliniek van Vijverdal waren bereid hun patiënten te benaderen voor deelname aan her onderzoek. Zonder hun inzet, in her bijzonder van Frans Lensing en Ken Smith, was ik nu nog bezig geweest met het werven van proefpersonen. Verder dank ik al mijn klinische collega's voor de ruimte die ik in een latere fase kreeg om me op het proefschrift te concentreren. Met name Paul Wijts, Hannie van Genderen, Tonnie van Gisbergen, Anja Karst en Frans Lensing hielden me uir de wind.

Eric Griez en de medewerkers van het Academisch Angstcentrum boden me de gelegenheid om een gedeelte van het budget voor het onderzoek bij elkaar te sprokkelen.

Ik ben zeer vereerd met Joke Janmaat en Giovanni Poddighe als mijn paranimfen. Beiden staan symbool voor langdurige vriendschap en de menselijke mat in het werken met mensen in nood. Fijn dar jullie altijd achter me hebben gestaan en dat nu opnieuw willen doen.

Velen hebben me de afgelopen jaren gesteund met hun vriendschap ("is dat boekje nou nog niet af") en muziek. Paul van Eijsden overleed vlak voor de voltooiing van het proefschrift. Ik zal als eerbetoon en blijk van respect zijn levensmotto graag als stelling verdedigen. Verder dank ik in her bijzonder Marion, Helen, Dik, Helène, Gerard, Jolien, Anton, Kitty, Hans, Henk, Jan, Monique en Rob. De dame en heren van Combo Picon gaven me de gelegenheid een en ander van me af te spelen en nieuwe inspiratie op te doen. Al Defino ("a blues everydlay keeps the doctor away") was een fantastische leermeester en hielp me dusdanig over gitaristische grenzen heen dat ik de rest van mijn leven niet meer uirgestudeerd raak.

Mijn ouders hebben me altijd gestimuleerd om "door te leren'; ik ben misschien wat langer doorgegaan dan jullie hadden voorzien. Jullie hebben her doorzerringswermogen voorgeleefd dat ik hard nodig heb gehad om deze onderneming tot een goed einde re brengen.

Marjolein, de liefde van mijn leven, gaf me onvoorwaardelijke gelegenheid om aan het proefschrift te werken en deelde de hoogte- en dieptepunten. We hebben intense jaren achrer de rug, ik hoop dat we er nog heel veel voor de boeg hebben. 


\section{CURRICULUM VITAE}

Frenk Peeters werd geboren op 20 april 1959 in Breda. In 1978 behaalde hij het diploma Gymnasium- $\beta$ waarna hij Geneeskunde in Antwerpen en Maastricht studeerde. Na het artsexamen (1985) werkte hij als assistent-geneeskundige in her Provinciaal Ziekenhuis te Santpoort. Tussen 1987 en 1991 specialiseerde hij zich in de psychiatrie in Maasrricht (opleiders: Prof.dr. Richartz en Prof. dr. Romme). Vanaf 1991 werkt hij als psychiater bij de RIAGG Maastricht waar hij zich mer name heeft bezig gehouden met de kortdurende behandeling van patiënten met stemmings- en angststoornissen. Van 1996 tot 2002 was hij tevens universitair docent bij de Vakgroep Psychiatie en Neuropsychologie aan de Faculteir der Geneeskunde bij de Universiteit Maastricht. Sinds 2001 is hij programmaleider van het zorgprogramma stemmingsstoornissen op de afdeling volwassenenzorg-kort bij de RIAGG Maastricht. Vanaf oktober 2002 is hij als psychiater werkzaam in het academisch ziekenhuis Maastricht binnen her andachtsgebied stemmingsstoornissen; deze functie combineert hij met het voornoemde programmaleiderschap bij de RIAGG Maastricht. 



\title{
PUBLICATIES
}

\author{
ARTIKELEN
}

Werken op Leros: een goede afloop var een Griekse tragedie? F.P.M.L. Peeters, G.A.J. Vincken. Maandblad Geestelijke Volksgezondheid (1990), 2,169-175.

Comment on the inpatient treatment of mood disorders. F.P.M.L. Peeters, M.W. de Vries. Psychological Reports (1995), 77, 1041-1042.

Dental caries with longterm use of antidepressants. M.W. deV ries, F.P.M.L. Peeters. The Lancet (1995), 346, 16 december, 1640 (lerter).

Affectiviteit en zeltbeoordeling van depressie en angst. F.P.M.L. Peeters, R.W.H.M. Ponds, M.T.G. Vermeeren. Tijdschrift voor Psychiatrie (1996), 38, 3, 240-250.

Remming van de speekselsecretie door antidepressiva; risico's voor de mondgezondheid. F.P.M.L. Peeters, M.W. deVries, A. Vissink. Nederlands "Tijdschrift voor Geneeskunde (1996), 140,10,533-536.

Affectiviteit en zelfbeoordeling van depressie en angst. F.P.M.L. Peeters, R.W.H.M. Ponds, M.T.G. Vermeeren. Psychoscoop (1996), 4/5, 7; 82-89.

'W.A.J. van der Sanden. Depressie overwinnen'. F.P.M.L. Peeters. Tijdschrift voor Clientgerichte Psychotherapie (1996), 4, 34, 65-67(bockbespreking).

Melatonin as a therapeutic agent in the treatment of sleep disturbance in depression. M.W. deVries, F.P.M.L. Peeters. The Journal of Nervous and Mental Disease (1997), 183, 3, 201-202.

Huisarts en depressieve patiënt: een problematisch duo? F.P.M.L. Peeters. Tijdschriff voor Psychiarrie (1997), 39, 3, 309-320. 
De huisarts alls poortwachter voor de RIAGG? Een onderzoek naar aanmeldingen bij de RIAGG Maastricht. F.P.M.L. Peeters, H. Bayer, H.C. Milius, T. Verschuren, S.Kempinski, F.v.d. Horst. Maandblad Geestelijke volksgezondheid (1997), 12, $1219-1230$.

Risks for oral heal th with the use of antidepressants. F.P.M.L. Peeters, M.W. deVries, A. Vissink. General Hospital Psychiatry (1998), 20, 150-154.

Melatonin as a therapeuric agent in the treatment of sleep disturbance in depression. M.W. deVries, F.P.M.L. Peeters. Review Series Psychiarty (1998), 5, 12-14.

"No-show" for inirial screening at a community mental health centre; rate, reasons and further help-seeking. F.P.M.L. Peeters, H. Bayer. Social Psychiatry and Psychiatric Epidemiology (1999), 34, 6, 323-327

Affectieve dimensies bij depressie en angst. M.T.G. Vermeeren, F.P.M.L. Peeters Tijdschrift voor Psychiatrie (1999), 41, 2, 109-113

Een protocol voor het gebruik van antidepressiva? Bezint eer ge begint! W. Kelders, F. Peeters. Nederlands Tijdschrift woor Geneeskunde (1999), 143, 13, 695 (referaat).

Heftige ontrekkingsverschijnselen mer koorts bij staken van paroxerine. F.P.M.L. Peeters, J. Zandbergen. Nederlands Tijdschrift woor Geneeskunde (1999), 143, $1429-1431$

Affectieve dimensies bij depressie en angst. F.P.M.L. Peeters, M.T.G. Vermeeren (reactie op commentaar). Tijdschrift voor Psychiatrie (1999), 41, 5, 306-308.

"Management of mental health problems in primary care." B.G. Tiemens. F.P.M.L. Peerers. Maandblad Geestelijke volksgezondheid (1999), 54, 10, 1101-1104 (boekbespreking).

Hefrige ontrrekkingsverschijnselen met koorts bij staken van paroxetine. F.P.M.L. Peeters, I. Zandbergen (reacrie op commentaar). Nederlands Tijdschrift voor Geneeskunde (1999), 143, 1795-1796

Over mogelijkheden van een cliëntgerichte behandeling van depressieve stoornissen in de volgende eeuw. F.P.M.L. Peeters. Tijdschrift voor Client-gerichte Psychocherapie (1999), 37, 4, 279-295. 
Electrolyte and orher blood serum abnormalities in normal weight bulima nerwosa; findings in a community mental health center. F.P.M.L. Peeters, A. Meijboon. International Journal of Eating Disorders (2000), 27, 3, 358-362.

Dwangmatig handelen: niet alrijd een obsessieve compulsieve stoornis. F.P.M.L. Peeters, G.Poddighe. Tijdschrift voor Psychiatrie (2000), 5, 353-357.

Een 'depressiedag' voor patiënten en hulpverleners. Een verslag van een experiment op de afdeling Sociale Psychiatrie van het AWT Osdorp van her Riagg Zuid/N-West te Amsterdam. M.C. de Leeuw, F.P.M.L. Peeters \& D. Tenback. Maandblad Geestelijke volksgezondheid (2000), 55, 5, 445-450

Chronische depressie (2) J. Spijker, met antwoord van M. de Leeuw, F. Peeters \& D. Tenback. Maandblad Geestelijke volksgezondheid (2000), 55, 7/8, 629-631.

Correlates of autobiografical memory specificity: the role of depression, anxiety and childhood trauma. I.Wessel, M. Meeren, F. Peeters, A. Arntz, H. Merckelbach. Behaviour Research and Therapy (2001), 39, 409-421.

Autobiographical memory specificity and the course of major depressive disorder. Peeters, F., I. Wessel, H. Merckelbach and M. Boon-Vermeeren. Comprehensive Psychiatry (2002), 43, 5, 344-350.

Emotional reactivity to daily life stress in psychosis and affective disorder: An Experience Sampling Study. Myin-Germeys, I., F. Peeters, R. Havermans, N. Nicolson, P. Delespaul, M. deVries and J. v. Os (Acta Psychiatrica Scandinavica, in press).

Effects of daily events on mood states in major depressive disorder. Peeters, F. P. M. L., N. A. Nicolson, J. Berkhof, P. Delespaul and M. DeVries (Journal of Abrormal Psychology, in press).

Cortisol responses to daily events in major depressive disorder. Peeters, F. P. M. L., N. A. Nicolson and J. Berkhof (under revision, Psychosomatic Medicine).

How psychotic are individuals with non-psychotic disorders? Hanssen, M., F. Peeters, L. Krabbendam, S Radstake, J wan Os. (Social Psychiatry and Psychiatric Epidemiology, in press). 
Cortisol responses to a speech task in major depression and their relationship to cortisol responses ro negative events in daily life. Peeters, F. P. M. L., N. A. Nicolson and J. Berkhof (submitted).

Levels and variability of daily life cortisol secretion in major depression. Peeters, F. P. M. L., N. A. Nicolson and J. Berkhof (submitted).

Daily patterns of mood states in major depressive disorder. Peeters, F., J. Berkhof, Ph. Delespaul, N. A. Nicolson. (submitted).

Differential Affect Structure in Depressive and Anxiety Disorders. Williams, J., F. Peeters and A. Zautra (submitred).

\section{BOEKBIJDRAGEN}

Interpersoonlijke psychorherapie. F.P.M.L. Peeters. In: Behandelingsstrategieën bij bulimia nervosa. A. Jansen, A. Meijboom (red.). Bohn, Stafleu en Van Loghum. Houren, 1998, 46-57

Psychofarmaca. M.Verbraak, F.P.M.L. Peeters In: Behandelingsstrategieën bij bulimia nervosa. A. Jansen, A. Mejiboom (red.). Bohn, Stafleu en Van Loghum. Houten, 1998, 36-45

Stemmingsstoornissen. F.P.M.L. Peerers. In: Klinische Psychologie, diagnostiek en therapie. G. Smeers, S. Bögels, $\mathbb{H}$, van der Molen, A. Arntz (red). Wolters-Noordhoff, Groningen, 1999, 291-324.

RAPPORT

Handleiding bij de Nederlandse vertaling van de Positive and. Negative Affect Schedule (PANAS). F.P.M.L. Peeters, R.W.H.M. Ponds, M.T.G. Boon-Vermeeren (1999). 